\author{
Aus dem Fachbereich Medizin \\ der Johann Wolfgang Goethe-Universität \\ Frankfurt am Main
}

betreut am

Institut für Transfusionsmedizin und Immunhämatologie

DRK-Blutspendedienst Baden-Württemberg-Hessen

Direktor: Prof. Dr. Erhard Seifried

\title{
Die Rolle des a4-Integrins in der \\ Pathophysiologie des Autoimmundiabetes am Modell der spontan diabetischen NOD Maus
}

\author{
Dissertation \\ zur Erlangung des Doktorgrades der Medizin \\ des Fachbereichs Medizin \\ der Johann Wolfgang Goethe-Universität \\ Frankfurt am Main
}

vorgelegt von

Salim Oulghazi

aus Frankfurt am Main

Frankfurt am Main, 2021 
Dekan:

Referent:

Korreferent/in:

2. Korreferent/in:

Tag der mündlichen Prüfung:
Prof. Dr. Stefan Zeuzem

Prof. Dr. Halvard Bönig

Prof. Dr. Thomas Oellerich

Prof. Dr. Ingrid Fleming

12.10.2021 
Meinen Eltern, Naima Tazzoute und Hammou Oulghazi 


\section{Inhaltsverzeichnis}

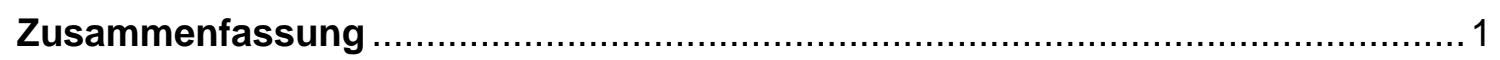

Summary

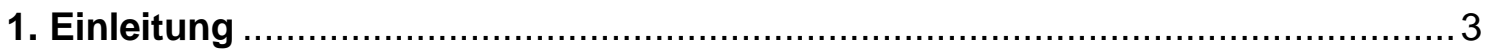

1.1. Humaner Typ 1 Diabetes - Epidemiologie, Genetik, Autoimmunität,

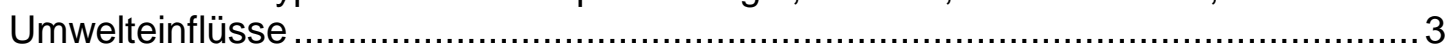

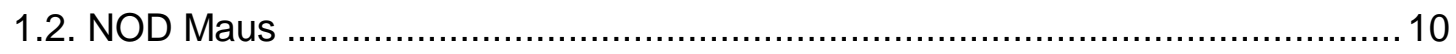

1.3. Das a4-Integrin - Molekularbiologie, Immunologie, pharmakologische und

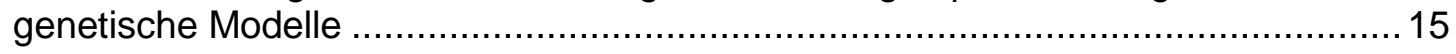

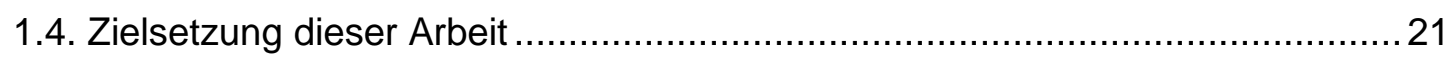

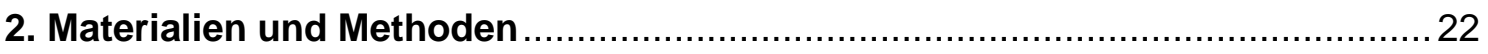

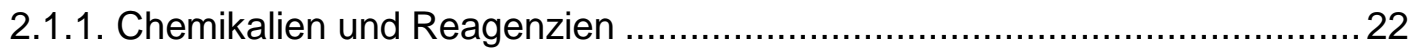

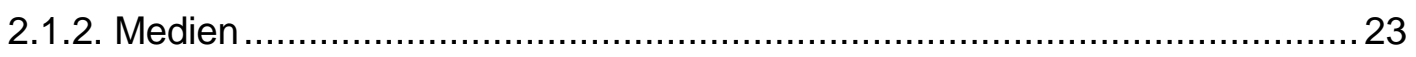

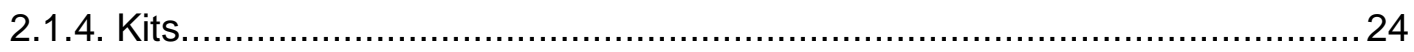

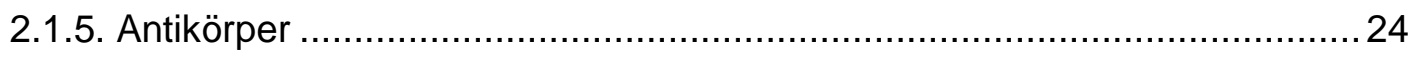

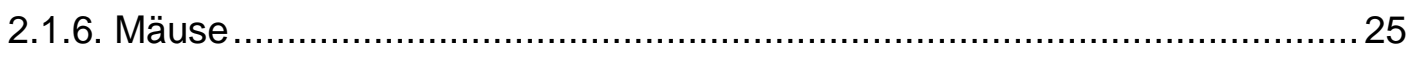

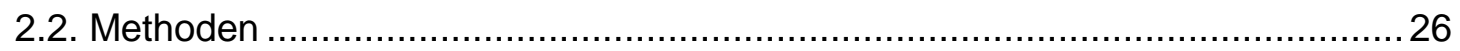

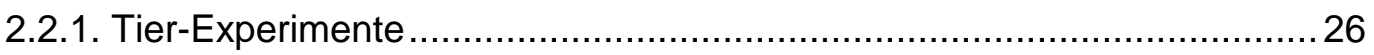

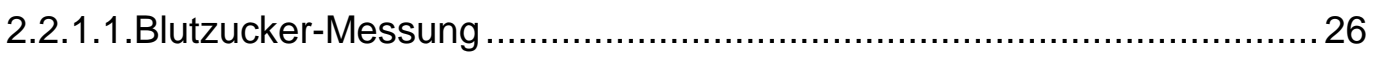

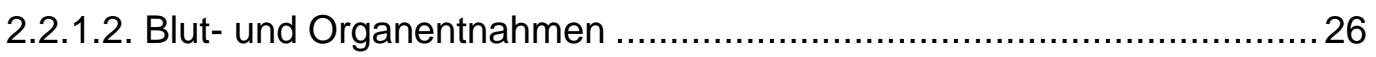

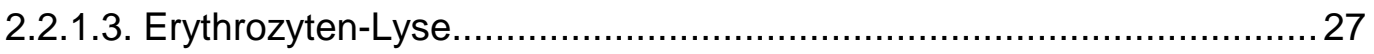

2.2.1.4. Präparation von Splenozyten und Knochenmark .............................27

2.2.1.5. Automatische Hämazytometrie .................................................... 27

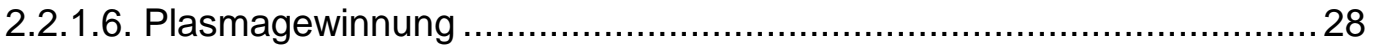

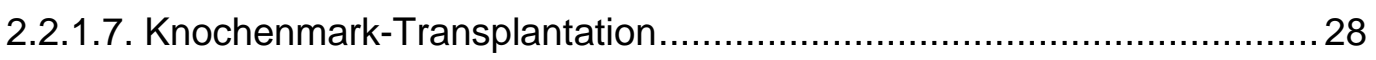

2.2.1.8. Adoptiver T-Zell Transfer ........................................................... 28

2.2.1.9. Ex vivo Imaging nach adoptivem Transfer von transduzierten CD3+

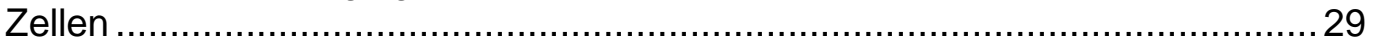

2.2.1.10. Präparation von Pankreas-infiltrierenden Lymphozyten ..................... 30

2.2.1.11. Prüfung der humoralen Immunkompetenz von NOD und NOD.a4-/Mäusen .................................................................................... 31

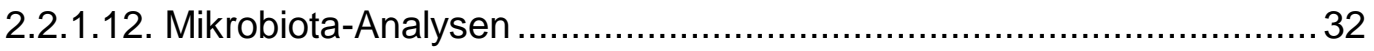

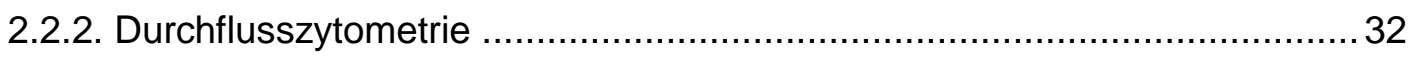

2.2.2.1. Oberflächenanalyse ................................................................. 33

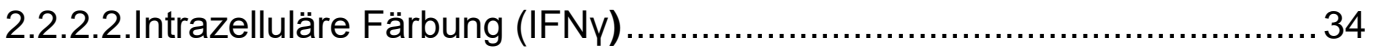

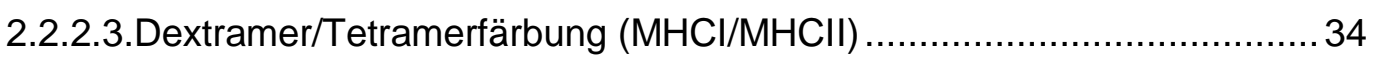

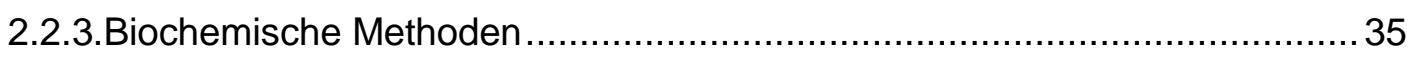

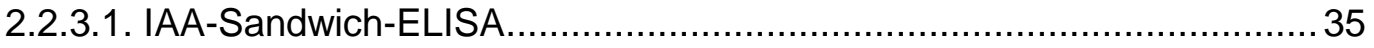

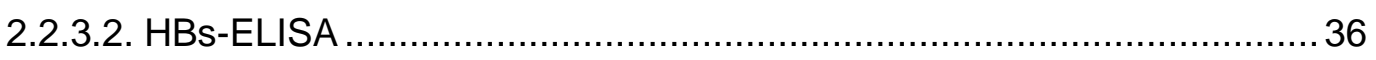

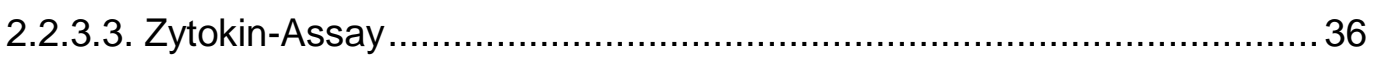

2.2.3.4. Immunomagnetische Zellanreicherung ........................................... 36 


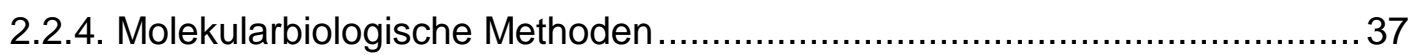

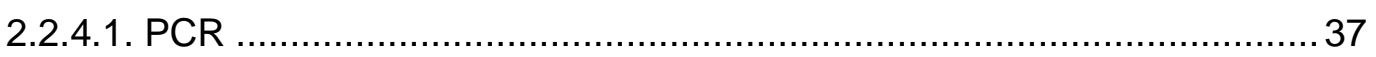

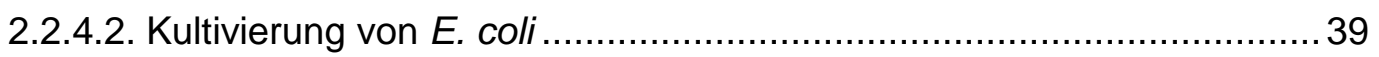

2.2.4.3. Transformation von E. coli .............................................................. 40

2.2.4.4. Testrestriktion ....................................................................... 41

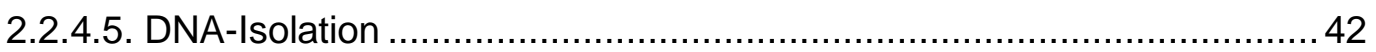

2.2.4.6. Kultivierung von HEK293T Zellen ...................................................... 42

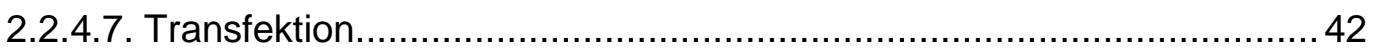

2.2.4.8. Aufkonzentrierung der Viruspartikel............................................ 43

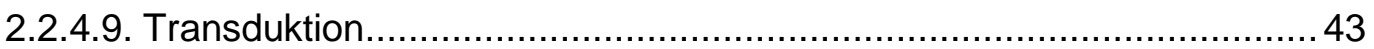

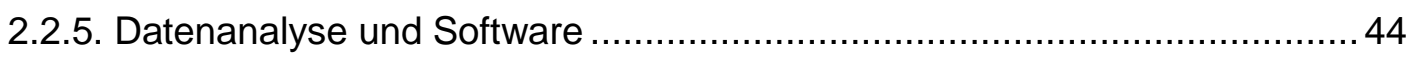

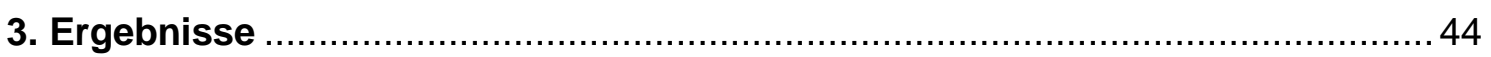

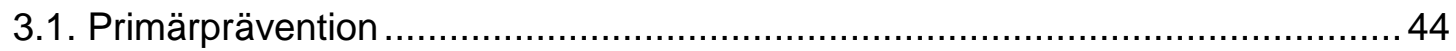

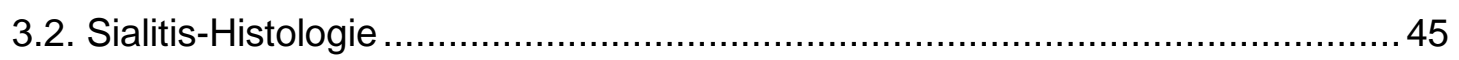

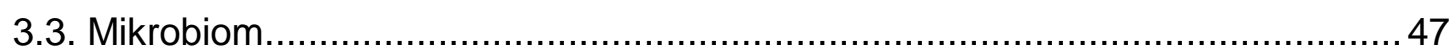

3.4. Analyse des zellulären Immunsystems der NOD.a4-/- Maus ............................ 49

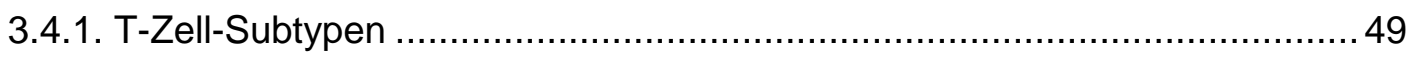

3.4.2. Inselzell-reaktive zytotoxische T-Zellen ............................................... 54

3.4.3. Inselzell-reaktive T-Helfer-Zellen........................................................ 56

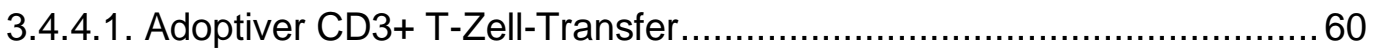

3.4.4.2. Ex vivo Luminographie nach adoptivem CD3+ T-Zell-Transfer .............62

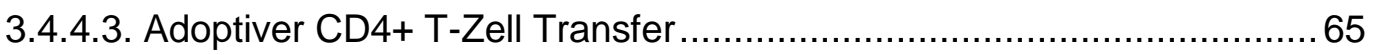

3.5. Analysen der humoralen Achse des Immunsystems der NOD.a4-/- Maus........67

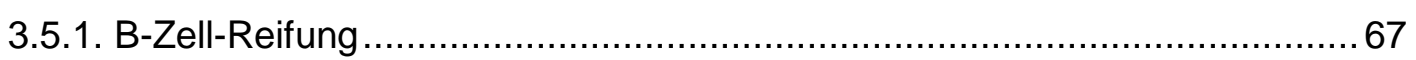

3.5.2. Impfantwort: Primär- und Sekundärimmunisierung................................ 70

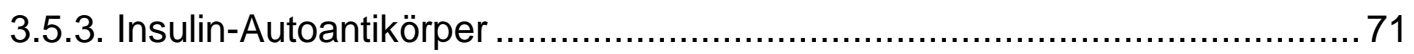

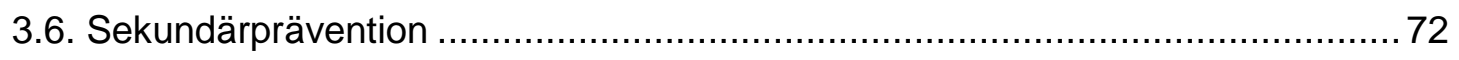

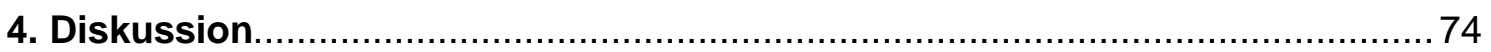

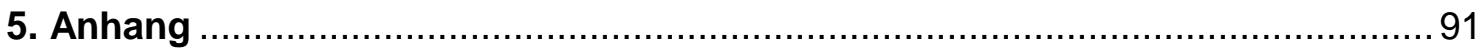

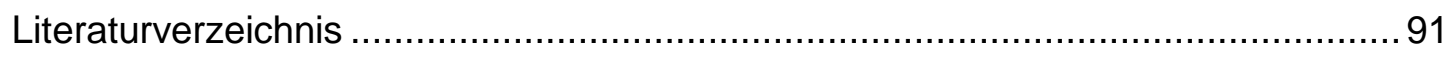

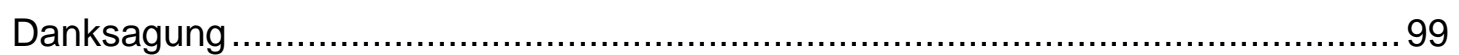

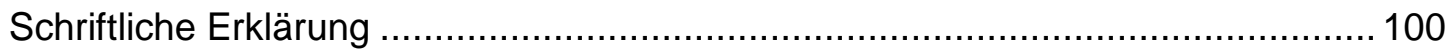




\section{Tabellenverzeichnis}

Tabelle 1. Liste der in dieser Arbeit verwendeten Geräte ............................................22

Tabelle 2. Liste der in dieser Arbeit verwendeten Chemikalien und Reagenzien..........22

Tabelle 3. Liste der in dieser Arbeit verwendeten Medien ...........................................23

Tabelle 4. Liste der in dieser Arbeit verwendeten Kits............................................ 24

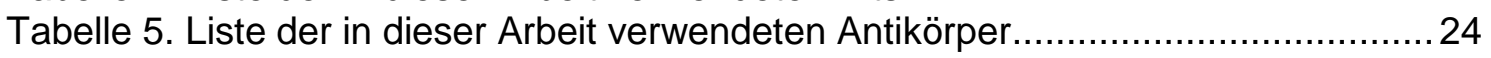

Tabelle 6. Reaktionsansatz und PCR-Programm zur Genotypisierung ....................... 38

Tabelle 7. Eingesetzte Oligonukleotidpaare in der Genotypisierungs-PCR ...................38

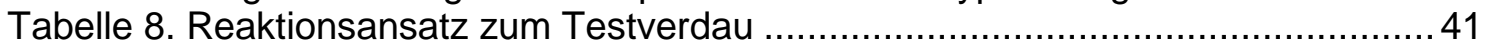

Tabelle 9. Ansatz der OPTI-MEM-Lösungen zur Transfektion ................................. 43 


\section{Abbildungsverzeichnis}

Abbildung 1 Pathogenese des Typ 1 Diabetes nach Atkinson und Eisenbarth, 2001...6 Abbildung 2 Einflüsse von nicht-HLA-assoziierten Loci in der Pathogenese des Typ 1 Diabetes. Nach Concannon et al., 2009.

Abbildung 3 Intrazelluläre a4-Integrin-vermittelte Signalwege und deren Regulation durch ILK (integrin-linked-kinase) nach Shishido et al., 2014.

Abbildung 4 Schematische Darstellung des in dieser Arbeit verwendeten

Transplantationsregimes.

Abbildung 5 Schema des in dieser Arbeit verwendeten adoptiven T-Zell-Transfers ...29

Abbildung 6 Schematische Darstellung des in dieser Arbeit verwendeten

Transduktionsregimes.

Abbildung 7 Schematische Darstellung der Hepatitis-B Immunisierungsstudie ............31

Abbildung 8 Repräsentatives Beispiel für die a4-Expression auf PBMCs der

wildtypischen NOD Maus.

Abbildung 9 Konstruktion der loxP-flankierten a4-Allele und Genotypisierungsstrategie.

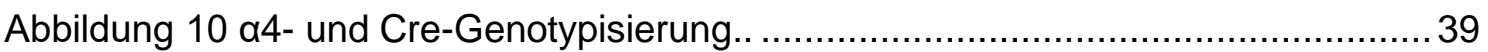

Abbildung 11 Plasmid-Karte des pSEW-lucs2-Vektors mit Darstellung der

Schnittstellen für Restriktionsenzyme.

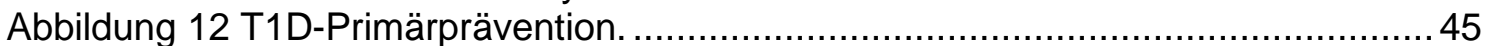

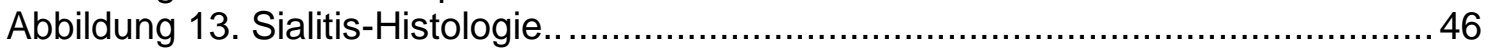

Abbildung 14. Sialitis-Primärprävention. Infiltrationsscore ................................... 47

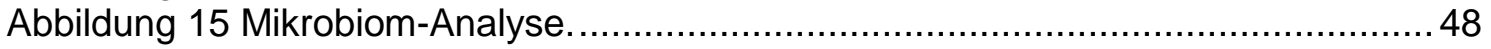

Abbildung 16. Gating-Strategie für T-Zell-Subtypenanalyse .................................50

Abbildung 17. Frequenz von CD3+ T-Zellen unter den Leukozyten...........................51

Abbildung 18. Frequenz der NK-Zellen (CD335+) unter den Leukozyten.....................51

Abbildung 19 Relativer Anteil der T-Zell-Subtypen................................................. 52

Abbildung 20 Detektion inselzellreaktiver zytotoxischer T-Zellen............................55

Abbildung 21. Detektion Inselzell-reaktiver T-Helfer-Zellen ......................................57

Abbildung 22 Induzierte IFNy-Sekretion von T-Helfer-Zellen...................................58

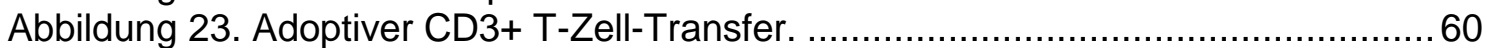

Abbildung 24 a4-Expression von Peripherblut- und Pankreas-infiltrierenden

Lymphozyten von NOD.a4-/- Mäusen nach adoptivem CD3+ T-Zell-Transfer

diabetischer Spender.

Abbildung 25. FACS-Analysen von Splenozyten vor und nach lentiviraler Transduktion

mit dem pSEW-lucs2 Vektor und nach FACS-basierter Zellsortierung. ........................62

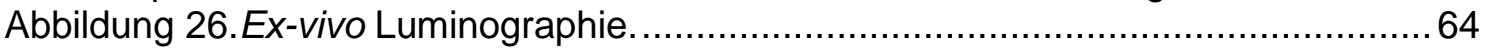

Abbildung 27. Quantitative Analyse der Radiance nach in vivo Transfer Luciferase-

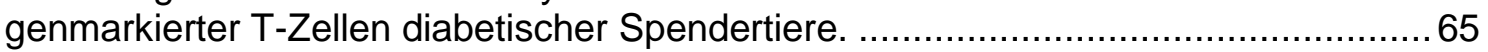

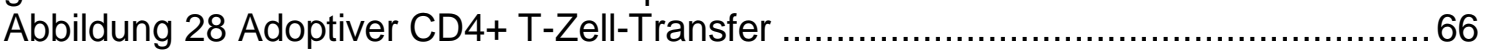

Abbildung 29. Gating-Strategie der B-Zell-Entwicklungsstadien...............................68

Abbildung 30 Relativer Anteil unreifer B-Zellen an B220+ Zellen ................................ 69

Abbildung 31. B-Zell-Reifung. Frequenz der verschiedenen Entwicklungsstufen an

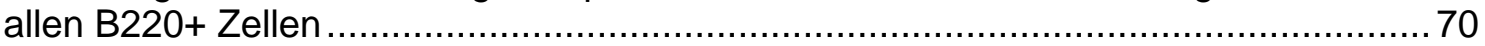

Abbildung 32 Humorale Immunantwort gegenüber einem für Induktion einer B-Zell-

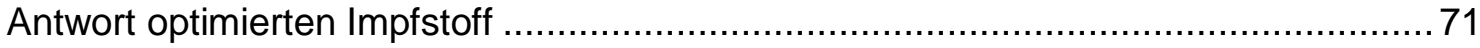

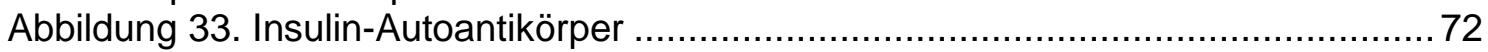

Abbildung 34 Sekundärprävention durch Knochenmark-Transplantation. .................. 74 


\section{Abkürzungsverzeichnis}

\begin{tabular}{|l|l|}
\hline Abkürzung & Bedeutung \\
\hline 7-AAD & 7-Aminoactinomycin \\
\hline ANA & Antinuclear antibody \\
\hline BLI & Biolumineszenz-Imaging \\
\hline BSA & Bovine Serum Albumin \\
\hline CMV & Cytomegalievirus \\
\hline DMEM & Dulbeccos Modified Eagles Medium \\
\hline DNA & Desoxyriboneukleinsäure \\
\hline EAE & Experimentelle Autoimmun-Enzephalitis \\
\hline EDTA & Ethylendiamintetraacetat \\
\hline FMO & Fluorescence minus one \\
\hline GAD65/ & Glutamat-Decarboxylase 65 / Glutamat-Decarboxylase Antikörper \\
\hline GADA & \\
\hline GFP & Green fluorescent protein \\
\hline GPCR & G-Protein coupled receptor \\
\hline Gy & Grey \\
\hline HBSS & Hanks balanced salt solution \\
\hline HLA & Humanes Leukozyten-Antigen \\
\hline IA2A & Islet Tyrosine Phosphatase 2 Antibody \\
\hline IAA & Insulin Autoantibody \\
\hline ICA & Anti-Islet Cell Antibody \\
\hline IDDM & Insulin dependent diabetes mellitus \\
\hline IGRP & Islet-specific glucose-6-phosphatase catalytic subunit-related protein \\
\hline KO & Knockout \\
\hline LB & Lysogeny broth \\
\hline MHC & Major Histocompatibility Complex \\
\hline NOD & Non-obese diabetic \\
\hline NOD.scid & Non-obese diabetic/severe combined immunodeficiency \\
\hline PBMC & Peripheral blood mononuclear cells \\
\hline PBS & Phosphat-gepufferte Salzlösung \\
\hline PCR & Polymerase Kettenreaktion \\
\hline PMA & 4-Methoxyamphetamin \\
\hline RBC & Red blood cells \\
\hline RPMI & Roswell Park Memorial Institution \\
\hline RT & Raumtemperatur \\
\hline T1D & Typ 1 Diabetes \\
\hline TCR & T cell receptor \\
\hline VLA-4 & Very late antigen-4 \\
\hline WT & Wildtyp \\
\hline ZnT8A & Zinc Transporter 8 Antibody \\
\hline & \\
\hline
\end{tabular}




\section{Zusammenfassung}

Die NOD.a4-/- Maus ist eine auf hämatopoetische Zellen beschränkt a4inkompetente Maus auf dem NOD Hintergrund. Die Maus ist vollständig gegen Diabetes gefeit, entwickelt keine Insulitis und keine Sialitis. Analysen der $\alpha-$ und B-Diversität des Mikrobioms zeigen eine vergleichbare Zusammensetzung in NOD.a4-/- und NOD Kontrollmaus, während erkrankte Mäuse ein auffällig eingeschränktes Mikrobiom und atypische Spezies aufweisen. Inselzellantigenspezifische CD8+ T-Zellen und anti-Insulin-Autoantikörper sind quantitativ stark vermindert im Vergleich zu NOD Kontrollen, jedoch sicher nachweisbar. Das 5Linien-Differenzialblutbild ist absolut und relativ unauffällig. Die NOD.a4-/- Maus entwickelt nach adoptivem Transfer von CD3+ Zellen diabetischer NODSpender mit kurzer Latenz und 100\%iger Penetranz Diabetes, ein isolierter Transfer diabetogener CD4+ Zellen ist hierzu nicht hinreichend. a4-kompetente CD8+ Zellen sind also unerlässlich für den adoptiven Transfer von Diabetes in die NOD.a4-/- Maus. Rekonstitution prädiabetischer wildtypischer NOD Empfänger mit NOD.a4-/- Hämatopoese schützt diese zuverlässig vor dem Progress der Insulitis zum Diabetes. Diese Arbeit unterstreicht und sichert die bisherigen a4-Antikörper Studien in der NOD Maus und korrigiert die Annahme, a4-Blockade schütze nicht vor dem Voranschreiten der Sialitis. NOD.a4-/Lymphozyten werden regelrecht gegen Autoantigene sensibilisiert, in Ermangelung effektiver Infiltration der Zielorgane bleibt jedoch die Expansion antigenspezifischer T-zellen und das Boosten von humoralen Autoimmunantworten aus. a4-inkompetente Leukozyten migrieren auch nach Beginn einer Insulitis oder damit einhergehender Hochregulierung verschiedenster endothelialer Oberflächenproteine nicht in die entzündeten Langerhans-Inseln. Die sichere Prävention der Erkrankung durch Rekonstitution mit a4-/- Hämatopoese identifiziert die a4-Blockade als mögliche Therapie des Typ 1 Diabetes während der Phase des Prädiabetes. 


\section{Summary}

The incidence of autoimmune (Type 1) diabetes (T1D) is increasing, meanwhile the age of onset decreasing. Treatment is with insulin replacement although islet preservation would be preferable. The spontaneously diabetic NOD mouse is a faithful model of human T1D and thus suitable for development of such therapies. Given the pivotal role of $a 4$ integrin (CD49d) in other autoimmune diseases, we generated NOD mice with a4-deficient hematopoiesis (NOD.a4-/-) to assess their risk of diabetes development, and to study mechanistic questions such as adaptive immunity of NOD.a4-/- mice against islet antigens and adoptive transfer of isolated diabetic $\mathrm{T}$-cell populations into a4-deficient NOD mice. Moreover, NOD.a4-/- mice offered the unique opportunity to compare the microbiota of co-housed unperturbed pre-diabetic and diabetic NOD and diabetes-resistant NOD.a4-/- animals. NOD.a4-/- mice had isletspecific T-cells and antibodies, albeit quantitatively less than their a4+ counterparts. Nevertheless, NOD.a4-/- mice were completely and life-long protected from diabetes and insulitis. Transfer of $\alpha 4+/ C D 3+$ but not $\alpha 4+/ C D 4+$ splenocytes from diabetic to NOD.a4-/- mice induced diabetes with short latency. Despite a modest contribution of adoptively transferred $\alpha 4+/ C D 3+$ cells to peripheral blood, pancreas-infiltrating T-cells were exclusively graft derived, i.e. $\alpha 4+$. Microbiota of diabetes-resistant NOD.a4-/- and pre-diabetic NOD.a4+ mice were identical. The co-housed diabetic NOD.a4+ mice showed the characteristic diabetic dysbiosis, implying causality of diabetes for dysbiosis. Transplantation with isogeneic a4-/- bone marrow prevented progression of prediabetic NOD.a4+ to T1D. Incidentally, NOD.a4-/- mice were protected from autoimmune sialitis. The data propose $a 4$ integrin as a target for diabetes prevention. 


\section{Einleitung}

\subsection{Humaner Typ 1 Diabetes - Epidemiologie, Genetik, Autoimmunität, Umwelteinflüsse}

Typ 1 Diabetes (T1D) ist eine Autoimmunerkrankung, die durch den Verlust von insulinproduzierenden B-Zellen infolge autoreaktiver zytotoxischer T-Zellen gekennzeichnet ist. Die Erkrankung beginnt meist im Kindes- oder jüngeren Erwachsenenalter und geht anfangs zumeist mit einer Trias von Symptomen einher: Polydipsie, Polyphagie und Polyurie. Diese durch eine Hyperglykämie ausgelösten Symptome des Hypoinsulinismus werden derzeit durch eine lebenslange Insulinsubstitution, meist mit rekombinantem Insulin, behandelt. Die Dosen müssen hierbei stets auf den aktuellen Blutzuckerwert, die geplante Mahlzeit und Bewegungsumfang abgestimmt werden und bergen regelhaft die Gefahr einer Hypoglykämie und der damit verbundenen Komplikationen, einer akuten, krisenhaften Hyperglykämie bis zum Coma diabeticum, als auch der langfristigen vaskulären Schäden eines im Mittel chronisch erhöhten Blutglukosespiegels bei (chronischer) Untersubstitution.

Als eine der häufigsten chronischen Erkrankungen im Kindesalter zeigt T1D eine zweigipflige Inzidenzkurve, die im Alter zwischen fünf bis sieben Jahren den ersten und während der Pubertät ihren zweiten Gipfel erreicht. ${ }^{1}$ Während die meisten Autoimmunerkrankungen Frauen häufiger betreffen, ist dies beim Typ 1 Diabetes nicht der Fall. Ätiologisch möglicherweise informativ, zeigt sich eine saisonale Häufung bezüglich des Erkrankungsbeginns. So erkranken mehr Menschen in den Herbst- und Wintermonaten an Typ 1 Diabetes als im Frühling und Sommer. ${ }^{2}$ Neue Studien, die die Entwicklung der T1D-assoziierten Autoimmunität noch vor Erkrankungsbeginn untersuchen sollten, konnten interessanterweise zeigen, dass die angesprochenen Jahreszeiten mit einer Synchronisierung der Antikörper-Titer einhergehen. ${ }^{3}$ Möglicherweise bedeutet das, dass im Frühjahr prävalente Antigene, etwa saisonale Viren oder Pflanzenteile, die mit Inselzellantigenen kreuzreagieren, diese Antikörper boostern und vielleicht sogar kausal an der Entstehung des Diabetes beteiligt sind. Erste multizentrische Zahlen zur Verteilung der Prävalenzen in Europa, den USA und weltweit lieferten die Arbeitsgruppen EURODIAB, SEARCH for 
Diabetes in Youth ${ }^{4}$ und DIAMOND 5 . Außerdem konnte hierdurch auch gezeigt werden, welche Rolle die Ethnien bezüglich des Erkrankungsrisikos haben. Hier ist deutlich zu sehen, dass unter den weniger als zehn Jahre Alten die "nonHispanic whites" die höchste Prävalenzrate von 24,8/100000 pro Jahr haben, gefolgt von „African-Americans“ bei etwa 16/100000 pro Jahr. Von Interesse ist zudem der unabhängig von Ethnien oder Geschlecht auftretende Anstieg der Prävalenzen von 21,1\% im Zeitraum von 2001-2009. Diese Anstiege pro Jahr belaufen sich in Schweden und Norwegen auf etwa 3,3\% und in Finnland auf etwa 2,4\%. Bei einer Fortsetzung eines solchen Anstiegs würden die Inzidenzen sich im kommenden Jahrzehnt nahezu verdoppeln und eine weitere erhebliche Belastung der Gesundheitssysteme bedeuten.

Global betrachtet lassen sich auch interessante Kenntnisse für die offensichtliche Rolle von umweltbedingten Einflüssen beim Typ 1 Diabetes zeigen. So zeigt sich bei den ländereigenen Angaben zu Inzidenzen und Prävalenzen des T1D eine 350-fache Varianz. ${ }^{6,7}$ Wie auch bei der Multiplen Sklerose, einer Autoimmunerkrankung des zentralen Nervensystems, lässt sich im Falle von T1D ein Nord-Süd-Gefälle beobachten, mit einem deutlich erhöhten Risiko nördlich des Äquators. ${ }^{5}$ Länder, die die niedrigsten T1DErkrankungsraten haben sind China, Indien und Venezuela mit etwa 0,1 Fällen pro 100000 Individuen. Dem gegenüber stehen Länder wie Schweden, Norwegen, Portugal, Großbritannien oder Kanada mit einer Prävalenzrate die jeweils höher als 20/100000 ist. ${ }^{8}$ Führend sind jedoch Finnland und Sardinien mit mehr als 60 beziehungsweise 40 Fällen pro 100000 Individuen. Interessanterweise sind die direkten Nachbarn dieser Länder deutlich weniger betroffen. Dies ist vor allem am Beispiel von Finnland und Estland zu verdeutlichen. Diese zwei Länder liegen nur etwa 80 Kilometer voneinander entfernt und sind ethnisch nah verwandt, unterscheiden sich jedoch hinsichtlich ihrer Prävalenz um etwa das Dreifache. Diese Beobachtungen können zum jetzigen Zeitpunkt nicht wirklich erklärt werden, deuten aber gleichermaßen auf einen exogenen Trigger hin, der diese Erkrankung innerhalb strenger geographischer Grenzen antreibt. ${ }^{8}$

In den letzten drei Jahrzehnten wurde unser Wissen rund um die Pathogenese des T1D dramatisch verbessert, sodass selbst älteste Dogmen nun wieder in der Diskussion stehen. Die Entwicklung von Methoden zur Untersuchung von 
Genen, Autoantikörpern oder auch metabolischen Markern, wie beispielsweise dem C-Peptid, führten zur Etablierung erster Modelle der Erkrankung. Besonders hervorzuheben ist das Modell nach G. S. Eisenbarth aus dem Jahre 1986 (s. Abbildung 1). Dieses beschreibt den Typ 1 Diabetes als eine Erkrankung von Individuen mit einer genetischen Prädisposition und einer determinierten Anzahl an funktionsfähigen insulinproduzierenden B-Zellen, die ausgelöst durch einen exogenen Trigger (Viren, Bakterien, Diät, Vitamin D) die Produktion von Autoantikörpern und autoreaktiven T-Zellen anregen und über diese schließlich zur Zerstörung der B-Zellen und Verlust der sekretorischen Fähigkeit dieser Zellen führt. ${ }^{9}$ Gemäß diesem Modell muss ein Verlust von 80 $90 \%$ der B-Zellen vorliegen, um eine Hyperglykämie auszulösen. Zusätzlich ist zu betonen, dass nach Autosensibilisierung und Beginn der Insulitis zum Teil mehrere Jahre vergehen können, bevor ein manifester Diabetes auftritt. Auch wenn dieses Modell mit Sicherheit als Orientierung und Erklärungsansatz hilfreich war und ist, gibt es einige neuere Erkenntnisse, die das Modell infrage stellen. Erstens wurde beobachtet, dass Patienten trotz früher T1D Diagnose Jahrzehnte später noch immer residuale insulinproduzierende B-Zellen aufweisen, sprich die B-Zellen werden nie in ihrer Anzahl gänzlich zerstört, was die Frage aufwirt, welche regulatorische Mechanismen dies verhindern. ${ }^{10}$ Außerdem ist bei einigen T1D Patienten zu Beginn der Erkrankung (bei Erstmanifestation mit klinisch apparenter Hyperglykämie) festzustellen, dass noch etwa $40-50 \%$ der B-Zellen vorhanden sind. ${ }^{11}$ Dies könnte eine Erklärung sein, warum trotz Fortschreitens der Erkrankung noch Jahre später eine funktionelle Insulinsekretion vorhanden ist. Abschließend sei noch zu erwähnen, dass bei genauerer Untersuchung der Produktion verschiedener Autoantikörper, der quantitativen Verteilung zwischen Effektor-T-Zellen und regulatorischen T-Zellen, als auch funktionell über die Messung von B-Zellspezifischen Proliferationsraten der Zeitraum zwischen Autoimmunität und symptomatischem Diabetes nicht streng-progredient, sondern zu- und abnehmend im Sinne eines remittierenden oder "relapsing“ Typ 1 Diabetes, verläuft. ${ }^{12}$ Eine fortschreitende intensive Auseinandersetzung mit der „prädiabetischen Phase" bleibt entscheidend, um weitere Studien zur (Sekundär-)Prävention dieser Erkrankung voranzubringen. 

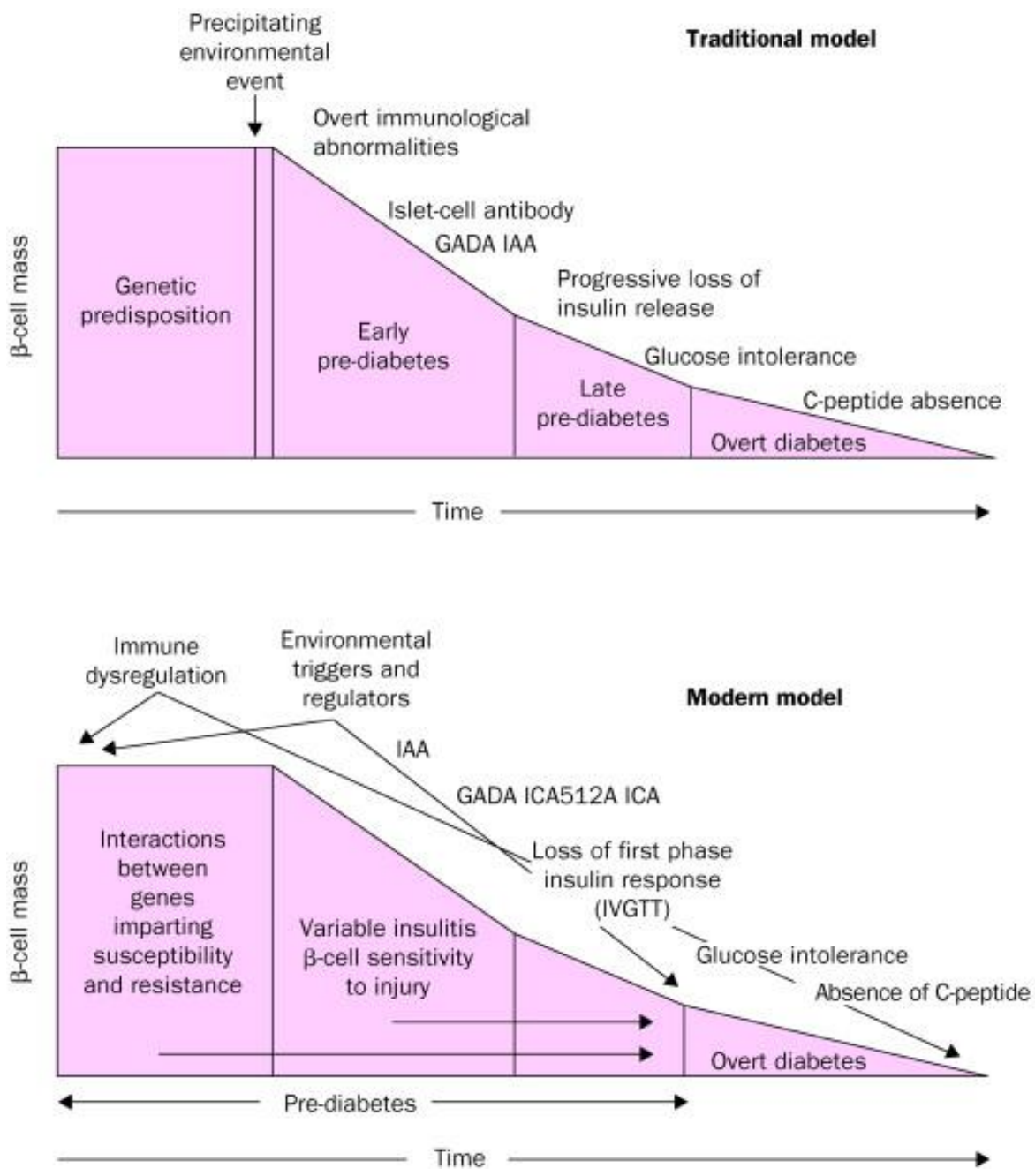

Abbildung 1 Pathogenese des Typ 1 Diabetes nach Atkinson und Eisenbarth, 2001.

Der Typ 1 Diabetes ist eine Erkrankung, die oftmals familiär gehäuft auftritt, jedoch keinesfalls einem strengen Mendel'schen Vererbungsmuster folgt und somit eine komplexe multifaktorielle Erkrankung darstellt. So konnten schon 1972 erste Studien zeigen, dass erstgradig Blutsverwandte ein 15-fach erhöhtes Erkrankungsrisiko haben. ${ }^{13}$ Dem entgegenzusetzen ist jedoch das Phänomen, dass etwa $85 \%$ der Neuerkrankten keine positive Familienanamnese ausweisen. Außerdem konnte gezeigt werden, dass es von Relevanz ist, welcher der beiden Elternteile die genetische Prädisposition mitbringt. So liegt die Prävalenz bei Kindern von betroffenen Vätern bei 7\%, während es bei Kindern von betroffenen Müttern nur $2 \%$ sind. ${ }^{13}$ Diese epidemiologischen Beobachtungen verdeutlichen, dass es ein genetisches Risiko gibt und dass bei genauerer Beobachtung auch das Vererbungsmuster eine gewisse Rolle spielt. Bis dato sind etwa 50 Genloci beschrieben, die mit einer erhöhten Inzidenz einhergehen. ${ }^{14,15,16}$ Trotz dessen ist kein Gen an sich 
ausreichend oder notwendig, um an Diabetes Typ 1 zu erkranken. Die bei weitem höchste Suszeptibilität ist bestimmten Polymorphismen im HLA (humanes Leukozyten Antigen) - System zuzuschreiben, wobei bestimmte Merkmale der Klasse II den höchsten Einfluss haben. ${ }^{13}$ Da HLA Klasse II Gene für Proteine der Antigenpräsentation kodieren, weist dies auf einen mutmaßlich kritischen Punkt der Pathogenese hin. Die Mehrheit der T1D Patienten tragen HLA-DR3 oder - DR4 Klasse II Antigene, wobei etwa 30\% DR3/DR4heterozygot sind. Vor allem HLA-DR3 ist außerdem mit anderen Erkrankungen, wie beispielsweise dem Polyendokrinen Autoimmunsyndrom assoziiert. Bei diesem Erkrankungsbild kann es zu multiplen endokrinen Ausfällen wie etwa einer Hashimoto-Thyreoiditis, einem Morbus Addison als auch T1D kommen. Ein weiteres Suszeptibilitäts-Gen kodiert für CTLA-4. Genau wie CD25 und PTPN22 ist dies ein Molekül, das mit Schlüsselfunktionen innerhalb der Immunantwort in Verbindung gebracht wird und diese reguliert. Zentral ist, dass die Mehrheit an bekannten Suszeptibilitäts-Loci für Moleküle kodieren, die mit der Immunantwort und deren Regulation zu tun haben. ${ }^{15}$

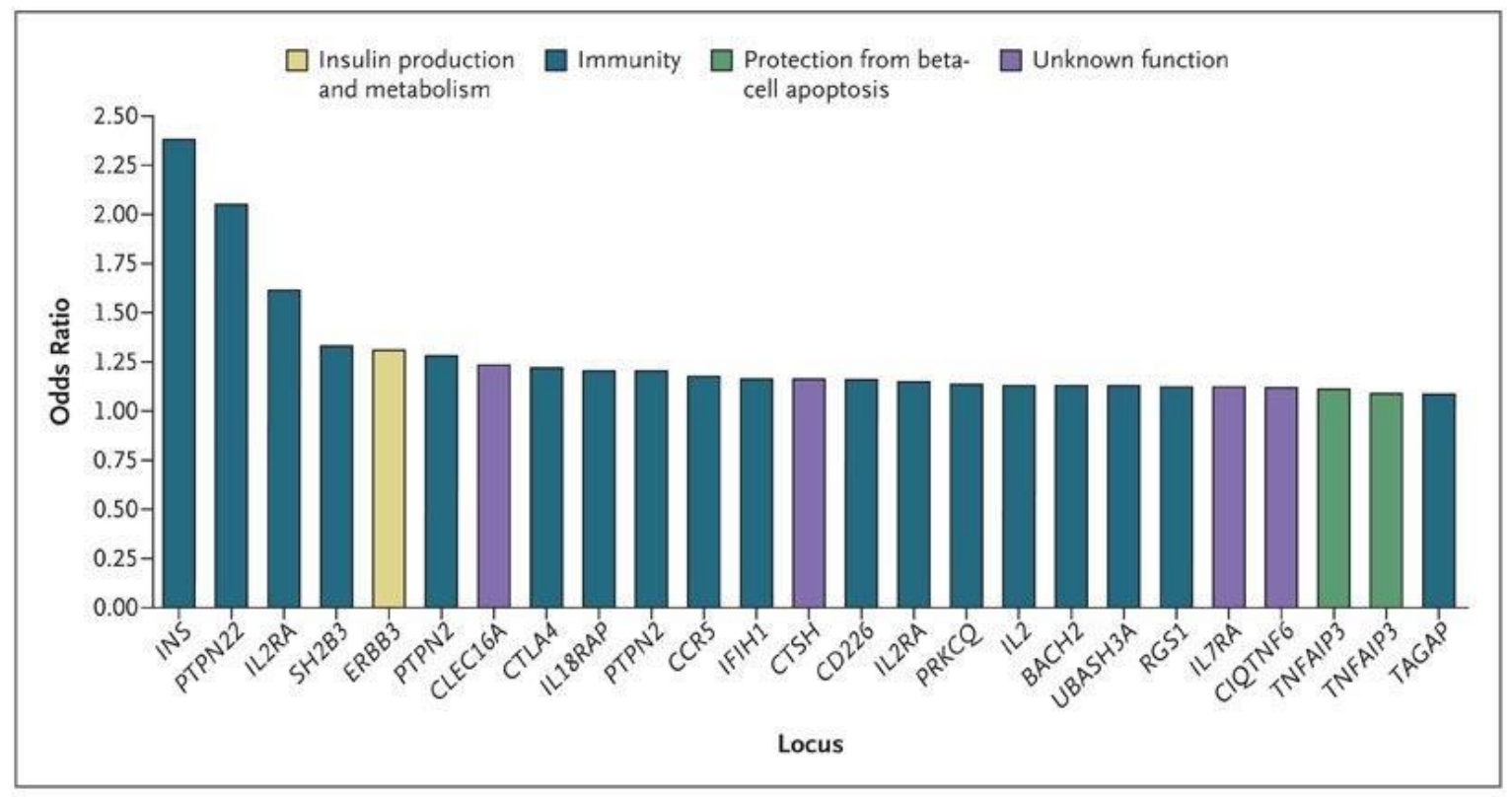

Abbildung 2 Einflüsse von nicht-HLA-assoziierten Loci in der Pathogenese des Typ 1 Diabetes. Nach Concannon et al., 2009. ${ }^{15}$

Autoimmunität in Falle des T1D liegt in der Bildung von Autoantikörpern und autoreaktiven T-Zellen begründet. Die humane Insulitis ist eine Läsion, über die man bis heute noch sehr wenig weiß. Dies liegt vor allem darin begründet, dass Pankreas-Biopsien aufgrund der intraperitonealen Lage zu gefährlich und 
Pankreas-Resektionen post mortem sehr selten sind. Mit dieser Limitation bleibt die Messung von Autoantikörpern die einzige und beste Methode zur Risikobewertung von Menschen mit positiver Familienanamnese und als Diagnostikum des T1D. Wenngleich sie lange nur als "smoke of the fire“ ohne direkte krankheitsrelevante Wirkung betrachtet wurden, sprechen ihr jüngere Studien doch eine nicht unerhebliche funktionelle Rolle, vor allem bei der Präsentation körpereigener Antigene an autoreaktive T-Zellen, zu. So zeigen sowohl die Therapie im NOD-Mausmodell als auch bei Menschen mit B-Zelldepletierenden Antikörpern eine signifikante Verspätung des Erkrankungseintritts. ${ }^{17}$ Die Kinetik der Nachweisbarkeit der Autoantikörper ist inzwischen bestens untersucht. So ist etwa bei $70-80 \%$ der Patienten bei Erkrankungsbeginn mindestens ein Autoantikörper nachweisbar, ${ }^{18}$ während es bei Verwandten ersten Grades 3-4\% sind und in der Durchschnittsbevölkerung etwa 0,5\%. ${ }^{19}$ Jedoch spielen hier Alter, Geschlecht, BMI, Ethnie, geographische Umstände als auch die Sensitivität des Autoantikörper-Assays eine Rolle. Bei genauerer Untersuchung zeigt sich zudem ein quantitativer Zusammenhang zwischen der Höhe des Titers als auch der absoluten Anzahl der gemessenen Autoantikörpertargets und der Progression der Erkrankung. Beispielweise tragen Individuen, die für zwei Autoantikörper positiv sind, ein 50-60\%iges Risiko innerhalb der nächsten 5 Jahre zu erkranken, während es bei Individuen mit drei Autoantikörpern knapp 70\% und bei vier knapp 80\% sind..$^{20}$ Die Liste an Autoantikörpern, die mit dem Typ 1 Diabetes assoziiert sind, ist lang. So gibt es derzeit mehr als 20, von denen ICA, GADA, IAA, IA2A als auch ZnT8A den größten Zusammenhang mit der Prävalenz zeigen und auch am genauesten untersucht sind. ${ }^{18,20,21}$

Ganz im Gegensatz zu den Fortschritten in der Etablierung von AutoantikörperMessungen und den prädiktiven Aussagen, die diese erlauben, hat man bei der Erforschung der Umwelteinflüsse auf den Typ 1 Diabetes noch viele ungeklärte Fragen. Hierbei gibt es einige Theorien, die den Einfluss bestimmter Faktoren versuchen zu erklären und sich teilweise widersprechen. Die „accelerator hypothesis" beschreibt die zunehmende Kinds-Fettleibigkeit in den nördlich gelegenen Regionen als Stressor für die $\beta$-Zellen, welche sich an einen erhöhten Insulinbedarf anpassen müssen und somit anfälliger für Zellschäden werden und damit einhergehend die zunehmende Prozessierung und 
Präsentierung von Autoantigenen fördern. ${ }^{22}$ Die oft erwähnte Hygiene-Theorie sieht die verminderte Immunstimulation durch Vermeidung des Organismus von Fremderregern als ursächlich, ${ }^{23}$ während die "fertile field hypothesis" in der Auseinandersetzung des Immunsystems mit Fremderregern die Entwicklung eines aktivierten Zustands beschreibt, der die Ausbildung von autoreaktiven TZellen begünstigt. ${ }^{24}$ Durch den Einfluss der Darmflora auf andere Erkrankungen entstand zudem die "old friends hypothesis“, die durch veränderte Darmbesiedlung, Ernährungsgewohnheiten und einer veränderten Darmwandpermeabilität einen direkten Regulator des Immunsystems beschreibt. ${ }^{25}$ Abschließend sei noch die „threshold hypothesis“ erwähnt. Diese bietet ein mathematisches Modell, welches aufgrund genetischer Vorbelastung und exogener Gegebenheiten davon ausgeht ein messbares Risiko für die Prävalenz errechnen zu können. ${ }^{26}$ Ein kausaler Zusammenhang zwischen viraler oder bakterieller Infektion und Typ 1 Diabetes wird ebenfalls diskutiert. Die besten Beispiele einer Assoziation sind für Rubella und Enteroviren beschrieben, auch wenn diese nicht zweifelsfrei belegt sind. ${ }^{27,28}$ Was die Enteroviren angeht, konnte man bei Typ 1 Diabetes Patienten erhöhte Antikörper-Titer und virale RNA innerhalb des Pankreas als auch im Blut nachweisen. Genau wie bei infektiösen Einflüssen wird auch ein Zusammenhang zwischen Ernährung und der Prävalenz berichtet. Hierbei wurde ein Zusammenhang bei verkürzter Stilldauer und verfrühter Gabe von Kuhmilch (vor dem 4. Lebensmonat) beobachtet. ${ }^{29}$ Dafür sprechen unter anderem die zahlreichen Fremdproteine wie BSA (Bovine Serum Albumin), Casein als auch bovine insulin, denen mehrere Untersuchungen eine Rolle in der Pathogenese zusprechen. So wurde beispielweise eine Kreuzreaktivität zwischen Insulin und bovine $\alpha$-caseine berichtet. ${ }^{30}$ Allerdings spricht die längere Stilldauer in Entwicklungsländern bei gleichzeitigem Anstieg der Typ 1 Diabetes Inzidenz gegen diese Beobachtung. Bezüglich des Einflusses der Ernährung auf die Inzidenz sei noch Vitamin D zu erwähnen. Eine gute Erklärung für das Nord-Süd-Gefälle wäre der verminderte Vitamin D-Spiegel in der Bevölkerung nördlich des Äquators. ${ }^{5}$ Hierfür sprechen unter anderem die verminderten Plasmaspiegel der Patienten zu Erkrankungsbeginn, ${ }^{31}$ oder auch der Zusammenhang zwischen erhöhter Inzidenz und Polymorphismen innerhalb eines Gens, das eine Rolle in der Vitamin D-Metabolisierung spielt. ${ }^{32}$ Erste 
klinische Studien bestätigen diese Hypothese und zeigen einen verbesserten Glucosestoffwechsel als auch eine Zunahme von regulatorischen T-Zellen bei bereits erkrankten Patienten unter einer Vitamin D-Substitution. ${ }^{33}$ Weitere Untersuchungen sind jedoch nötig, vor allem um zu klären, ob und über welche Mechanismen ein erhöhter Vitamin D-Spiegel protektiv wirken könnte. Der Vollständigkeit halber müssen an dieser Stelle noch die perinatalen Risikofaktoren erwähnt werden. Diese sind vor allem eine Blutgruppeninkompatibilität (ABO, Rh), Präeklampsie, Neonatale Infektion, Geburt durch Kaiserschnitt, Geburtsgewicht und -lage, als auch mütterliches Alter. ${ }^{34}$ Wie oder ob diese den Typ 1 Diabetes wirklich kausal begünstigen, ist bis zu diesem Zeitpunkt Umstand reiner Spekulation.

\subsection{NOD Maus}

Die Entstehung der NOD Maus geht auf eine Inzucht der Cataract Shionogi Rasse (CTS) in Japan zurück. In der ersten Publikation von Makino et al. aus dem Jahr 1980 beschreibt dieser eine Inzucht-Maus, dessen weibliche Vertreter zu etwa $70-80 \%$ diabetisch werden, einhergehend mit Glukosurie und Polyurie und wenig später Kachexie. Männliche Mäuse haben jedoch nur eine Diabetesinzidenz von etwa 20\%. Dieser Geschlechtsdimorphismus ist zu einem großen Teil hormonellen Einflüssen unterworfen. So erreicht eine Gonadektomie bei männlichen Mäusen eine Erhöhung der Inzidenz auf etwa $80 \%$, während Weibchen nach analoger Intervention eine verminderte Inzidenz von etwa $30 \%$ aufweisen. ${ }^{35 ; 36}$

Der wissenschaftliche Erfolg dieser Maus kam in den Folgejahren in mannigfaltiger Form, einschließlich der Identifizierung von Suszeptibilitäts-Loci und Umwelteinflüssen auf die Entstehung und Pathogenese des murinen und auch humanen T1D. Außerdem lieferte uns die NOD Maus auch Einblicke in die Funktionsweise und Einflusssphären des angeborenen Immunsystems als auch den Beitrag von B-Zellen in eine hauptsächlich durch T-Zellen vermittelte Erkrankung. ${ }^{37}$ Als Tiermodell für den humanen T1D teilt die NOD Maus viele pathophysiologische Eigenschaften. Dadurch sind vielerlei Immuninterventionsstrategien entwickelt worden, von denen sich jedoch nur ein kleiner Teil klinisch übertragen ließ. ${ }^{38}$ Erste wegweisende Beschreibungen zur Pathogenese des 
T1D im Mausmodell stammen von Tarui et al. aus dem Jahr 1986. ${ }^{39}$ Diabetes in der NOD Maus wird hier als Insulitis aufgrund von zuvor aufgetretener Leukozyteninfiltration der Langerhans-Inseln beschrieben. Den ersten histologischen Nachweis infiltrierender Leukozyten findet man rund um die pankreatischen Gefäße und sekretorischen Duktuli. Diese Läsion wird als pervasives leukozytisches Infiltrat beschrieben. Hiernach sammeln sich diese Leukozyten an einem oder mehreren Polen vereinzelter Langerhans-Inseln und beginnen das Bild einer Peri-Insulitis darzustellen, welche sich kurze Zeit später zu einer vollständigen Peri-Insulitis entwickelt. Zwischen der 5. und 7. Lebenswoche zeigen alle Weibchen eine weitgehend vollständige Insulitis mit Leukozyten, die bereits das Zentrum der Langerhans-Inseln infiltrieren. Dieses Stadium tritt bei Männchen erst einige Wochen später auf. In der histologischen Untersuchung unserer wildtypischen NOD-Kohorte ist die Manifestation der Insulitis im Mittel im Vergleich zu diesen Werten leicht verzögert und deutlich weniger synchronisiert. So lag bei acht Wochen alten nicht-diabetischen NOD Weibchen und bei an Diabetes erkrankten NOD Weibchen der mittlere InsulitisScore bei 1,36 beziehungsweise 3,66 (Grading 0 bis 4, Dissertation Sarah K. Wegner). An die Phase der T-Zell-Infiltration schließt sich eine Phase der Inselzellproliferation an. So zeigen die Langerhans-Inseln dieser prädiabetischen Mäuse einen größeren Umfang im Vergleich zu der sehr nah verwandten NON/Lt Rasse. Auf funktioneller Ebene zeigt sich ein Rückgang des Insulinspiegels im Alter von 12 Wochen, wobei auch hier die Männchen einige Wochen später nachziehen. Bezeichnend für den selektiven $\beta$-ZellNiedergang zeigen NOD Mäuse hohe Glukagonspiegel. Nach Erkrankungsbeginn werden NOD Mäuse schnell hyperglykämisch und ketonämisch, aber nicht ketoazidotisch. ${ }^{40}$ In unserer Kohorte werden erste Weibchen im Alter von 14 Wochen diabetisch und die Inzidenz nimmt in etwa linear zu, bis im Alter von 36 Wochen knapp 90\% aller NOD Weibchen erkrankt sind (s. Abb. 12).

Neben der Kinetik der Inselzellläsion ist es weiterhin lohnenswert, die Immunpathogenese der NOD Mäuse zu betrachten. ${ }^{40}$ Die ersten Leukozyten im Inselzellinfiltrat sind T- und B-Lymphozyten als auch Makrophagen, wobei die T-Lymphozyten dominieren. Die Diabetogenese ist an sich T-Zell-abhängig und zu einem überwiegenden Teil T-Zell-vermittelt. Zur Initiation der Inselzellläsion 
sind sowohl CD4+ als auch CD8+ T-Zellen notwendig, wobei aufgereinigte CD4+ Zellen von diabetischen Spendern im Gegensatz zu CD8+ Zellen von selbigen Spendern einen Diabetes in unbestrahlte NOD.scid Empfänger transferieren können sollen. ${ }^{41}$ NOD.scid Mäuse haben aufgrund einer Mutation des PRKDC-Gens (DNA-abhängige Proteinkinase, katalytische Untereinheit) einen kombinierten DNA-Reparaturdefekt und Defekt des Rearrangements zur Ausbildung Antigen-spezifischer Rezeptoren. Dies macht sie unfähig, funktionelle T- und B-Lymphozyten auszubilden, weshalb sie inhärent vor Autoimmundiabetes geschützt sind. ${ }^{42}$ Christianson et al. berichten, ein adoptiver Transfer von CD4+ Zellen diabetischer Spender löse bei (aufgrund des Fehlens eines adaptiven Immunsystems nicht sensibilisierbaren) kombiniert immundefizienten, MHC isogenen NOD.scid Mäusen einen Diabetes aus. Prädiabetische CD4+ T-Zellen hingegen, also sensibilisierte T-Zellen, deren Träger aber noch keinen Diabetes entwickelt hatte, seien nicht in der Lage, Diabetes zu transferieren. Eine konkrete Erklärung für diese partiell widersprüchlichen Beobachtungen wird nicht angeboten. Interessanterweise seien sensibilisierte CD8+ Zellen allein nicht dazu befähigt, in NOD.scid Mäusen einen T1D auszulösen. Makrophagen innerhalb des Infiltrats sind offenbar für die Rekrutierung weiterer T-Lymphozyten verantwortlich und aktivieren diese. Eine zweite größere Welle an Leukozyten erreichen die Langerhans-Inseln zwischen der 10. und 12. Lebenswoche. Zu diesem Zeitpunkt ist eine relevante Anzahl an CD4+ Zellen nachzuweisen. Im Laufe der Sensibilisierung und des EpitopeSpreadings reagiert das NOD-Immunsystem auf immer mehr $\beta$-Zell-Antigene, wie beispielsweise Insulin, GADA, IGRP als auch endogene retrovirale Genprodukte. ${ }^{40}$

Neben den T-Lymphozyten zeigen auch die Antigen-präsentierenden Zellen (APCs) der NOD-Mäuse pathologische Züge. APCs spielen eine zentrale Rolle des Immunsystems. So haben sie einen großen Einfluss auf die Entwicklung des T-Zell-Repertoires durch intrathymische Präsentation von Selbst-Antigenen und ebenso durch die Präsentation prozessierter Peptide durch ihre MHCIIMoleküle (Major histocompatibility complex II) an antigenspezifische T-Zellen. In der NOD Maus sieht man eben diese Funktionen der APCs gestört. So sind sie offenbar nicht in der Lage, T-Suppressor-Zellen in der Peripherie zu aktivieren, genauso wie es innen nicht gelingt, die Entwicklung $\beta$-Zell-spezifischer T-Zellen 
im Thymus zu unterdrücken. NOD Mäuse zeigen mit zunehmendem Alter Infiltrate in verschiedensten Organen. Außerdem ist zu erwähnen, dass NKZellen in diesem Stamm vorhanden, aber nicht funktionsfähig sind. Dies sind gleichzeitig die größten Unterschiede zwischen der NOD-Maus und der BioBreeding (BB) rat, welche ein alternatives Modell für die Erforschung des T1D darstellt, sich jedoch im Vergleich zur NOD Maus durch eine Lymphopenie auszeichnet. ${ }^{40}$

Als multifaktorielle Erkrankung spielt die genetische Prädisposition auch bei der NOD-Maus eine vorrangige Rolle mit zahlreichen bisher identifizierten Genloci. Das bei weitem wichtigste Gen im Rahmen der Diabetogenese ist das Major histocompatibility complex. Klasse I und II-Moleküle werden sowohl für die Positiv- als auch Negativselektion von autoreaktiven T-Zellen benötigt und stellen hierbei in der „binding groove“ für die T-Lymphozyten präsentierte Antigene bereit. Beispielweise ist das $\mathrm{MHCl}-\mathrm{Ag} 7$ Allel essentiell für die Pathogenese des Diabetes der NOD Maus, während andere Allele wie $\mathrm{MHCl}$ Ek protektiv wirken. ${ }^{40}$ Das Äquivalent dieser Moleküle im Menschen ist die Human Leukocyte antigen-Region, welche ebenfalls bestimmte Polymorphismen aufweisen kann, von denen manche für Autoimmungeschehen prädisponieren, während andere protektiv wirken. Die genaue Einschätzung der verschiedenen Allele hat sich zum Screening von Individuen für klinische Präventionsstudien als sehr hilfreich erwiesen. Des Weiteren erkranken etwa 20\% der Menschen mit einer Spontanmutation im autoimmune regulator gene (AIRE), welches direkt die intrathymische Insulin-Expression der Epithelzellen in der Medulla kontrolliert, an T1D. ${ }^{43}$ Dies unterstreicht die Hypothese eines Defekts der Negativselektion von insulinreaktiven T-Zellen im Thymus. Dafür spricht außerdem der Nachweis von insulinspezifischen CD4+ Zellen aus den Pankreata von 8 Wochen alten NOD-Weibchen. Weitere Untersuchungen zeigen einen zunehmenden Verlust an Immuntoleranz gegenüber multiplen Epitopen und deuten somit darauf, dass es wahrscheinlich nicht ausreichend ist, gegen ein Inselzellantigen sensibilisiert zu sein, sondern mehrere zur Befeuerung der Insulitis von Nöten sind. Interessanterweise verhindert die Toleranz gegenüber Proinsulin die Ausbildung IGRP-spezifischer T-Zellen in der NOD Maus, wenngleich das Fehlen IGRP-spezifischer Zellen nicht ausreicht, das Fortschreiten des Diabetes zu verhindern. ${ }^{44}$ Zusätzlich gibt es 
noch dutzende Allele, die jedes mit einer erhöhten Diabetesinzidenz einhergehen. Die meisten sind direkt oder indirekt mit der T-Zell-vermittelten Inselzellzerstörung verbunden, konnten jedoch nicht im Einzelnen genutzt werden, um gezielte Therapiestrategien zu entwickeln. Es scheint sich also um eine Reihe von „Immundefekten“ zu handeln, die im Zusammenspiel die Immunregulation behindern. Betroffen sind u.a. Genloci wie IL-2, IL-2ra (CD25), CTLA-4, PTPN22 und Pdca1 (PD-1). ${ }^{15}$

Des Weiteren ist die Erkrankungsrate des NOD Stammes auch exogenen Einflüssen unterworfen. Hier zeigte sich schon sehr früh, dass gewisse mikrobielle Stimuli die Diabetesinzidenz verringern, beispielsweise Injektionen von Mykobakterien oder anderer Erreger. Jüngere Studien konnten zudem aufzeigen, dass die Zusammensetzung der Darmflora von NOD Mäusen einen protektiven Einfluss auf die Entwicklung eines Diabetes haben kann. Hierbei ist vor allem das MyD88-Gen in Erscheinung getreten. Als Regulator einer Reihe von Rezeptoren des angeborenen Immunsystems, welche mikrobielle Stimuli erkennen, wirkt sich ein Knockout des MyD88-Gens durch eine veränderte Darmflora protektiv aus. Zusätzlich gibt es viele weitere Faktoren, die sich auf die Inzidenz des NOD-Stamms auswirken. ${ }^{45}$ Beispielsweise verringert Vitamin D im NOD-Modell nachweislich die Diabetesinzidenz und ist deshalb auch bereits Gegenstand klinischer Studien. ${ }^{33}$ Abschließend sei erwähnt, dass sich Hinweise häufen, die diversen viralen Erregern eine Rolle in der Pathogenese des T1D zusprechen. Diese scheinen durch molekulare Mimikry oder direkten Einfluss auf die Selbst-Toleranz des angeborenen Immunsystems durch dessen Aktivierung einen Trigger darzustellen. ${ }^{46}$

Seit der Veröffentlichung der NOD-Maus $1980^{35}$ bis hin zum Jahr 2004 wurden mehr als 463 potenziell immunmodulierende Substanzen in über 321 Publikationen im NOD Modell untersucht. ${ }^{38}$ Diese Reagenzien können in Adhäsionsmoleküle, Zellsuspensionen und Antigene bis hin zu Immunmodulatoren, Zytokinen, Hormonen und pathogenen Erregern unterteilt werden. Interessanterweise haben viele dieser Reagenzien keinen und einige sogar einen ungünstigen Effekt auf die Inzidenz. Bei genauer Analyse stellt man zudem fest, dass die Therapieeffizienz abhängig von der Krankheitsphase bzw. dem Lebensalter unterschiedlich ist. Anti-CD40 gehört zu Ersteren. ${ }^{47}$ Eine Behandlung von 3 Wochen alten NOD Weibchen ist präventiv, während 9-10 
Wochen alte NOD Weibchen nur zu einem Anteil von der Therapie profitieren. Dies spricht entweder für die Rolle des CD40-CD40L-Pathway zu Erkrankungsbeginn oder der Rolle von Dosis und Dauer der Behandlung, da in diesem Beispiel die Dosis bei der älteren NOD-Kohorte nicht angepasst wurde und die Therapiedauer sogar kürzer war. Zu Letzteren gehört TNF- $\alpha$ (Tumornekrosefaktor- $\alpha$ ), welches bei unmittelbar postnataler Gabe die Inzidenz erhöht jedoch bei Gabe jenseits der 4 . Woche protektiv wirkt. ${ }^{48}$ Von den 463 Therapeutika wurden nur 23 in diabetischen NOD Mäusen getestet und nur 16 dieser 23 hatten einen kurativen Effekt. In Anbetracht der Tatsache, dass heute noch bei weitem die meisten T1D-Studienteilnehmer zu Beginn der Studie bereits diabetisch sind, ist der Bedarf an protektiven Therapeutika für diesen Zeitpunkt immens.

\subsection{Das a4-Integrin - Molekularbiologie, Immunologie, pharmakologische und genetische Modelle}

Das very-late-antigen-4 (VLA-4) ist ein Integrin, das sich aus den beiden Einheiten $\alpha 4$ und $\beta 1$ zusammensetzt. VLA-4 wird auf der Oberfläche der meisten mononukleären Lymphozyten, Monozyten, eosinophilen und basophilen Granulozyten, als auch auf nichthämatopoetischen Tumorzellen exprimiert. Integrine sind Transmembranrezeptoren, welche grundlegend aus zwei Untereinheiten bestehen und in vielerlei Kombinationen nichtkovalente Bindungen zu Heterodimeren eingehen. Diese Untereinheiten werden in zwei Familien ( $\alpha$ und $\beta$ ) unterteilt, welche wiederum 15 und 8 verschiedene Untereinheiten besitzen. ${ }^{49}$ Der Name "Integrin“ geht auf ihre Rolle in der Integrierung der extrazellulären Matrix mit dem Zytoskelett der Zellen zurück.

Der Hauptligand von VLA-4 ist das vascular cell adhesion molecule-1 (VCAM1), welches auf Endothelzellen exprimiert wird. Ein weiterer Ligand ist das CS1Motiv von extrazellulären Matrixproteinen wie Fibronectin (Fn), die abgesehen vom Bindegewebe auch im Plasma nachgewiesen werden können. Um jedoch eine aktive Bindung zu Fn einzugehen, ist eine höhere Aktivität von VLA-4 von Nöten. Die Expression des Hauptliganden VCAM-1 auf Endothelzellen kann von pro-inflammatorischen Zytokinen und Chemokinen hochreguliert werden und erleichtert somit dem Immunsystem den Zugang zu Inflammationsherden. ${ }^{50}$ 
a4 ist alternativ in der Lage, mit der Untereinheit $\beta 7$ ein Heterodimer zu bilden. Das Heterodimer $\alpha 4 \beta 7$ interagiert unter anderem mit denselben Liganden wie a4ß1 (VCAM-1, Fn), wobei diese Interaktionen im Vergleich schwächer ausgeprägt sind. Der Hauptligand von $\alpha 4 \beta 7$ ist das mucosal-addressin cell adhesion molecule-1 (MAdCAM-1) und befindet sich vor allem im Gastrointestinaltrakt. Zellen mit homogener $\alpha 4 \beta 7$ Expression sind NK-Zellen, eosinophile Granulozyten als auch B- und T-Zellen von Neugeborenen. B- und T-Zellen im adulten Organismus zeigen eine eher heterogene $\alpha 4 \beta 7$-Expression. MAdCAM-1 wird auf jeglichen Mukosa-assoziierten lymphatischen Geweben exprimiert und erlaubt den dort ankommenden Leukozyten das Homing. In diesem Rahmen wird MAdCAM-1 eine essentielle Rolle in der Aufrechterhaltung der Integrität der Darmmukosa einschließlich der Immunfunktion zugesprochen. ${ }^{49}$

Zur Immun-Surveillance gehört eine adäquate Rekrutierung von Lymphozyten zum Inflammationsherd. Im physiologischen Zustand verlassen nur vereinzelte Lymphozyten das Peripherblut, um Bindegewebe oder Organe zu infiltrieren. Wenn allerdings eine Inflammation entsteht, geht dies mit der Freisetzung von Inflammationsmediatoren wie Zytokinen und Chemokinen aus aktivierten TZellen oder residierenden Monozyten einher. Diese Signale verleiten das benachbarte Endothel dazu die Dichte an VCAM-1 auf der Oberfläche zu erhöhen und erleichtern somit den zirkulierenden Leukozyten die Adhäsion und Migration ins Gewebe. Wie genau dies passiert, ist im Detail noch nicht ganz verstanden. Den Prozess kann man biomechanisch in sequenzielle Phasen unterteilen. Das physiologische "tether and rolling“ der Leukozyten auf der Endotheloberfläche wird innerhalb von Millisekunden durch stimulierende Signale der oberflächengebunden Chemokine des Endothels an die Leukozyten beendet. Diese Chemokine führen zu einem Remodelling des Zytoskeletts und einer verstärkten VLA-4/VCAM-1-Bindung, die letztendlich zur Adhäsion führt. Hierbei spielen sowohl "high affinity states“, die durch den Einfluss der Chemokine auf die Konformation des Integrins entstehen, als auch die Ausstattung an GPCRs eine wichtigere Rolle als der Zelltyp der Leukozyten. Die „affinity changes“ finden innerhalb von Sekunden statt und sind reversibel. Anschließend können die Leukozyten in einem Diapedesis genannten Vorgang durch das Endothel und anschließend ins Interstitium migrieren. Interessant ist 
zudem, dass das a4-Integrin an allen vier Phasen direkt und indirekt beteiligt ist, indem es zusätzlich eine $\beta 2$-abhängige Adhäsion und Diapedesis fördert. Im Bindegewebe angekommen, können Leukozyten Fibronectin binden und zur Proliferation oder Zytokinproduktion führen. ${ }^{51}$

Wie bereits erwähnt, spricht man von niedrigen und hohen Affinitätszuständen. Initial geht man bei jeder VLA-4/VCAM-1 Bindung von einem "low affinity state“ des VLA-4 aus. Erst die Aktivierung der Leukozyten durch Chemokine führt zu einer Konformationsänderung und zum „high affinity state“. Neben dieser Art der Aktivierung sind ebenfalls Induktionen durch Antigene, anti-CD3-Antikörper, Phorbolester, $\mathrm{Mn}^{2+}$ und $\beta 1$-spezifische-Antikörper beschrieben. Neben der Bindung des Oberflächenrezeptors spielt auch die zytoplasmatische Domäne eine Rolle in der Regulierung der Zelladhäsion. Hier konnte gezeigt werden, dass Paxillin, ein 68kDa-Protein des Zytoplasmas, die zytoplasmatische Domäne der a4-Untereinheit binden und regulieren kann und somit direkt Einfluss auf die Migrationsfähigkeit von Leukozyten hat. Neben diesem „Insideout" Signal ist die zytoplasmatische Domäne in der Lage, den Zelltod als auch das Zytoskelett zu beeinflussen und die Genexpression zu verändern. ${ }^{52}$ 


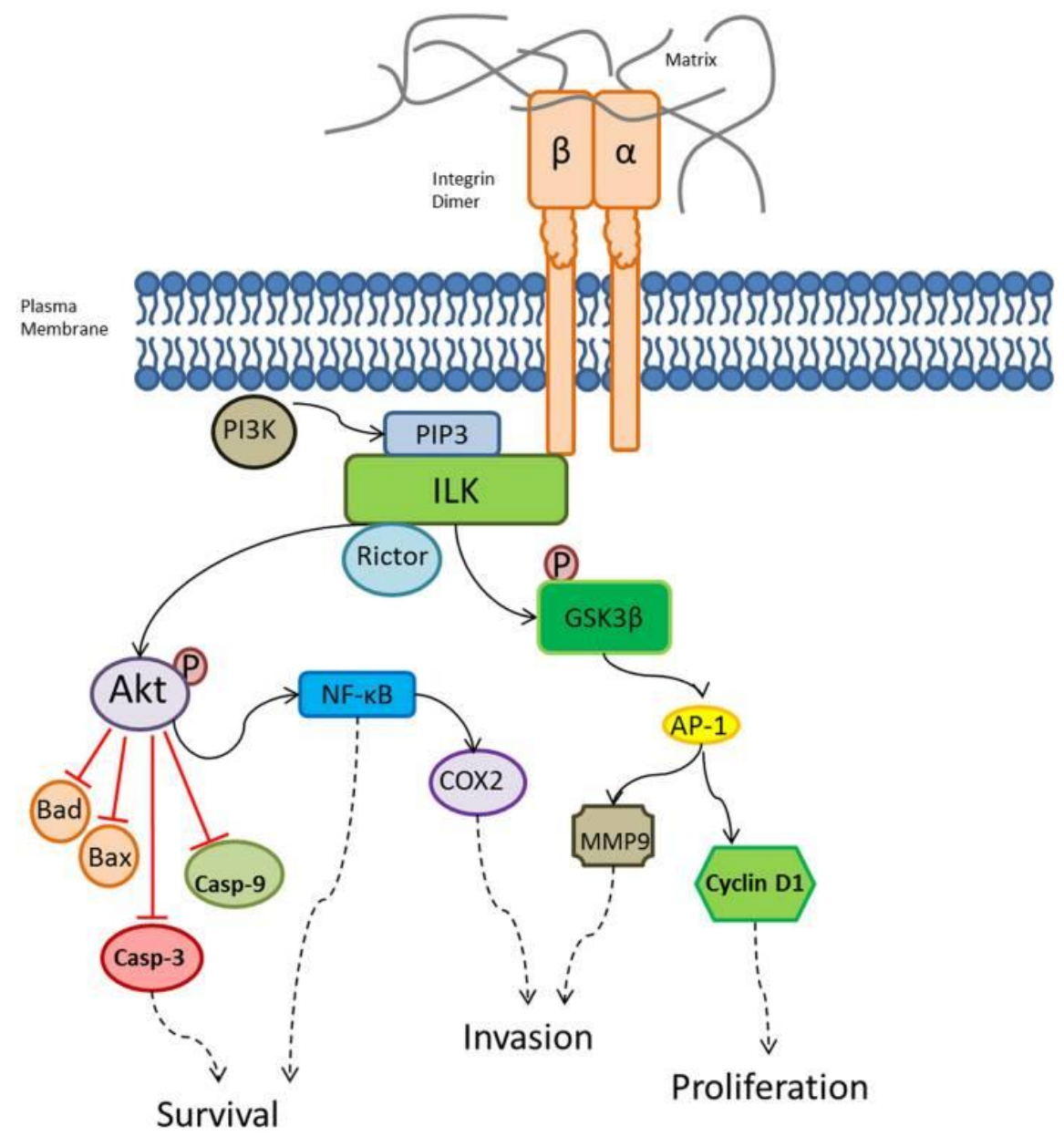

Abbildung 3 Intrazelluläre a4-Integrin-vermittelte Signalwege und deren Regulation durch ILK (integrin-linked-kinase) nach Shishido et al., 2014.

Um die Rolle des a4-Integrins in der Hämatopoese zu untersuchen, wurde von Scott et al. 2003 eine konditionelle Knockoutmaus generiert. ${ }^{53}$ Konstitutive Deletion von a4-Integrin ist früh embryonal letal. Dies ist dem Umstand geschuldet, dass a4 auf zahlreichen nichtlymphatischen Geweben im sich entwickelnden Embryo exprimiert wird. Im konditionellen Knockout konnte im Peripherblut eine dauerhafte achtfach erhöhte Anzahl hämatopoetischer Vorläuferzellen gezeigt werden, welche sich in abgeschwächter Form auch in der Milz darstellte. Außerdem konnten beachtliche Homing- und EngraftmentDefekte beobachtet werden, die in den zuvor generierten a4-null Chimären nicht untersucht werden konnten. Empfänger von a4-/Blutstammzelltransplantaten zeigen zudem eine gestörte Repopulation von TZellen im Thymus und eine verminderte Rekonstitution der lymphatischen Gewebe des Darms. Des Weiteren konnten verminderte IgM- und IgE-Spiegel und eine erhöhte IFNY-Antwort auf Ovalbumin beobachtet werden. Letzteres 
führten die Autoren auf eine gestörte Interaktion zwischen B- und T-Zellen zurück. ${ }^{54 ; 55}$

Außerdem wurde ein genetischer Knockout genutzt, um die Rolle von a4 in der Pathogenese des allergischen Asthmas zu untersuchen. Diese Studie konnte aufzeigen, dass in der a4-/- Maus eine bronchio-alveoläre Stimulierung mit potenziellen Allergenen nicht ausreichend ist, um ein Asthma auszulösen. 56;57 Zudem konnte festgestellt werden, dass durch Ovalbumin-Behandlung sensibilisierte a4-kompetente CD4+ Zellen in der Lage sind allergisches Asthma in die a4-/- Maus adoptiv zu transferieren. Es genügt offenbar, a4 im hämatopoetischen Kompartiment zu exprimieren, da die a4-/- Empfänger im vaskulären Kompartiment a4-defizient sind. Andererseits konnte der adoptive Transfer von a4-inkompetenten CD4+ Zellen eines zuvor mit Ovalbumin behandelten a4-/- Spenders kein Asthma in wildtypischen Empfängern auslösen. Interessanterweise verhindert der a4-Mangel zudem die VCAM-1 Hochregulation in betroffenen Gefäßen. Hinsichtlich der immunologischen Antwort auf Ovalbumin wurde eine verminderte Sensibilisierung der T-Zellen gemessen, genau wie eine verminderte IgE-Produktion in vivo. Andererseits konnte eine VCAM-1 Defizienz nicht vor allergischem Asthma schützen und somit zugleich auf die Interaktion von a4 mit anderen Liganden hinweisen. Unklar bleibt ob eine Sensibilisierung der a4-inkompetenten T-Zellen stattgefunden hat, ein etwaiger Selektionsdefekt in Thymus oder Lymphknoten vorliegt oder ob eine Sensibilisierung stattgefunden hat, die T-Zellen aufgrund der a4-Defizienz jedoch nicht in der Lage waren, in das Lungenparenchym zu migrieren und dort wirken zu können. ${ }^{56 ; 57}$ Außerdem wurde die a4-Blockade noch im EAE und Colitis-Modell erfolgreich untersucht und ist heute fester Bestandteil der Therapie von an Multipler Sklerose und Morbus Crohn erkrankten Patienten. ${ }^{58 ; 59}$

Bisherige Interventionen bezüglich des a4-Integrins in der NOD Maus waren stets Antikörper-vermittelt. Die beiden informativsten Studien dazu stammen aus dem Jahr 1994 und kamen zu ähnlichen Ergebnissen. Baron et al. injizierten Splenozyten von diabetischen Spendern in bestrahlte NOD-Weibchen und behandelten diese vor dem Transfer in vitro mit Antikörpern gegen a4, VCAM-1 und ICAM-1. PS1/2, ein anti-funktioneller Antikörper gegen a4, verminderte die Inzidenz von 95\% auf 30\% und verzögerte dosisabhängig den 
Erkrankungsbeginn um bis zu 17 Tage im Vergleich zur Kontrollgruppe. VCAM1 Blockade zeigte eine schwächere Wirkung und ICAM-1, im Kontrast zu bisherigen Erfolgen im EAE-Modell, keinen Effekt. Jedoch unterschied sich keine der Kohorten bezüglich der T-Zell-Antwort auf Inselzelllysate in vitro. Darüber hinaus war die mit PS1/2 behandelte Gruppe die einzige, die eine signifikant verminderte Insulitis zeigte. ${ }^{60}$ Yang et al. behandelten fünf Wochen alte NOD-Weibchen über sieben Wochen mit einem Antikörper gegen a4 oder L-Selectin in zwei verschiedenen Dosen. Die anti-a4-Therapie führte zum vollständigen Schutz vor Insulitis und die anti-L-Selectin-Therapie zu einer verminderten Insulitis. Für beide Antikörper war eine Dosisabhängigkeit zu beobachten. Auch im adoptiven Transfermodell waren beide Antikörper protektiv, für anti-CD62L partiell, für anti-a4 sogar vollständig, wobei das Follow-Up nur 35 Tage betrug und die Kohorte nur fünf Weibchen pro Gruppe umfasste. Auch in diesem Falle gab es keine Unterschiede bezüglich der Proliferationsantworten auf Inselzellantigene in vitro.61;62 Diese Ergebnisse sprechen gegen eine Suppression der Immunantworten durch die genannten Interventionen. Kommjosyula et al. veröffentlichten 2001 eine Studie, in der sie

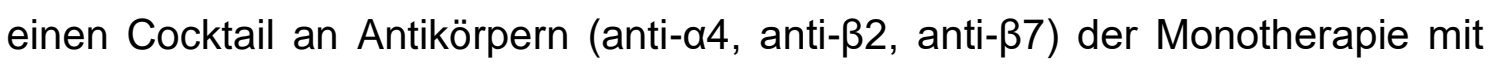
anti-a4 gegenüberstellten. Durch den Cocktail an Antikörpern konnte die Erkrankung nach adoptiven Transfer von Splenozyten verhindert werden, während die anti-a4 Therapie die Inzidenz von 86\% auf $63 \% 52$ Tage nach Transfer reduzierte. Zudem konnte die Therapie mit multiplen Antikörpern die Inzidenz des spontan auftretenden Diabetes von $71 \%$ auf $17 \%$ verringern, während die anti-a4-Therapie die Inzidenz auf 33\% reduzierte. Eine Protektion gelang ohnehin nur dann, wenn die Therapie in einem Alter von sieben Tagen begonnen worden war. Therapieversuche ab einem Alter von 40 oder sogar 70 Tagen waren bei weitem weniger erfolgreich. Des Weiteren konnten Kommajosyula et al. beobachten, dass das Leukozyteninfiltrat um die Langerhans-Inseln nach der Therapie eine veränderte Expression an IFN- $\mathrm{y}$, IL4 und iNOS zeigten. ${ }^{63}$ Abschließend sei zu erwähnen, dass Uniyal et al. 1999 untersuchten, welche Effekte die Injektionen von anti-a4 und anti-a5 auf die Insulitis von zehn Wochen alten Weibchen als auch diabetischen Mäusen haben. Während die Effekte in diesem Alter relativ gering waren und nur eine geringe Reduktion der Insulitis gezeigt werden konnte, beschreiben sie neben 
einem additiven Effekt durch anti-a5-Therapie eine zügige Zunahme der Insulitis nach Therapieende mit beiden Antikörpern und beschreiben somit die temporäre Wirkung dieser Antikörper-Therapien. ${ }^{64}$

\subsection{Zielsetzung dieser Arbeit}

Bisherige Daten aus unserem Labor hatten an einer Kohorte von zehn a4-/NOD Weibchen eine vollständige Protektion gegen Insulitis und Entstehung eines T1D gezeigt, während die wildtypischen Wurfgeschwister der Frankfurter NOD Kolonie mit einer annähernd linear ansteigenden Prävalenz zwischen den Wochen 14 und 36 bis auf etwa 90\% an T1D erkrankten. Durch den konditionellen Knockout des a4-Integrins auf dem Hintergrund der NOD Maus gelingt es, diese vor einer T1D Erkrankung zu schützen. Dieser Knockout ermöglicht es, die vollständige a4-Blockade, ohne die durch die AntikörperTherapie entstehenden Nebenwirkungen, in diesem Modell zu untersuchen. Frühere Studien deuten darauf hin, dass die protektive Wirkung der a4Blockade auf einem Migrationsdefekt beruht. Der Ausschluss von anderen Wirkungen, wie zum Beispiel eine beeinträchtigte Lymphknotenzirkulation oder beeinträchtigte Interaktionen zwischen Leukozyten-Subgruppen können durch die Antikörper-Therapien nicht beantwortet werden. Die Beantwortung dieser und weiterer Fragen in der Pathogenese und Prävention des T1D in der NOD Maus erfordern eine möglichst vollständige Blockade von $\alpha 4$, welche wir durch die unter dem Tie2-Promoter exprimierte Cre-Rekombinase-vermittelte Deletion des Itga-4-Gens erreichen.

In der vorliegenden Arbeit möchten wir den beschriebenen Effekt der Diabetes Protektion durch den a4 Knockout in einer zweiten Kohorte bestätigen. Zweitens möchten wir, neben der Untersuchung genereller Immunreaktionen, Inselzellantigen-spezifische T-Zellen im CD4+ und CD8+ Kompartiment als auch Autoantikörper-Titer zur Überprüfung einer etwaigen humoralen Immunantwort gegen Inselzellantigene bestimmen. Drittens soll die Übertragbarkeit des Diabetes durch adoptiven Transfer bestimmter T-Zellen als auch die Wirksamkeit einer Sekundärprophylaxe durch hämatopoetische Stammzelltransplantation von a4-kompetenten Empfängern mit a4inkompetenten Spenderknochenmarks-zellen überprüft werden. Schließlich 
zeigt die NOD-Maus auch das Krankheitsbild einer Sialitis. Hier möchten wir untersuchen, ob und wie sich diese in der NOD.a4-/-Maus darstellt.

\section{Materialien und Methoden}

\subsection{Materialien}

Tabelle 1. Liste der in dieser Arbeit verwendeten Geräte

\begin{tabular}{|c|c|}
\hline Geräte & Hersteller \\
\hline ACCU-CHECK Aviva & Roche Diabetes Care, Mannheim \\
\hline ACCU-CHECK Aviva Teststreifen & Roche Diabetes Care, Mannheim \\
\hline ARCHITECT i1000SR & Abbot, Abbot Park, IL, USA \\
\hline $\begin{array}{l}\text { AutoMACS pro immunomagnetischer } \\
\text { Zellsortierer }\end{array}$ & Miltenyi Biotec, Bergisch Gladbach \\
\hline EH4 basic Wasserbad & IKA, Staufen \\
\hline FACSAria II Durchflusszytometer & BD Biosciences, Heidelberg \\
\hline FACSFortessa LSR II Durchflusszytometer & BD Biosciences, Heidelberg \\
\hline Fluoreszenzmikroskop CKX41 & Olympus, Tokyo-Shinjuku, Japan \\
\hline Gefrierschrank MDF-53V $\left(-80^{\circ} \mathrm{C}\right)$ & Sanyo, Osaka, Japan \\
\hline Gefrierschrank ÖkoArctis $\left(-20^{\circ} \mathrm{C}\right)$ & AEG, Frankfurt am Main \\
\hline Gel Doc XR+ Transilluminator & BioRad, Dreieich \\
\hline $\begin{array}{l}\text { Gelelektrophoresekammer Power Pac } \\
\text { Basic }\end{array}$ & BioRad, Dreieich \\
\hline Holton Safe 20101.2 Sterilwerkbank & Thermo Scientific, Karlsruhe \\
\hline IVIS Lumina II Lichtmikroskop & Caliper Life Science, PerkinEImer, USA \\
\hline Multi-Cell 3/LV Hemavet Hämazytometer & Drew Scientific, Miami Lakes, USA \\
\hline Nanodrop Spektralphotometer & ChemoMetec, Allerod, Dänemark \\
\hline pH/ORP-Meter HI2211 & Hanna Instruments, Vöhringen \\
\hline Rotina 420(R) Zentrifuge & Hettich, Tuttlingen \\
\hline Thermocycler ,My Cycler'/,Gradient Cycler' & Applied Biosystems, Foster, USA \\
\hline $\begin{array}{l}\text { ThermoForma Sterile-Cycle CO2- } \\
\text { Inkubator }\end{array}$ & $\begin{array}{l}\text { Thermo Fisher Scientific, Waltham, MA, } \\
\text { USA }\end{array}$ \\
\hline Thermomixer $\mathrm{R}$ & Eppendorf AG, Hamburg \\
\hline Victor X4 Plattenlesegerät & Perkin Elmer, Waltham, USA \\
\hline
\end{tabular}

\subsubsection{Chemikalien und Reagenzien}

Tabelle 2. Liste der in dieser Arbeit verwendeten Chemikalien und Reagenzien

\begin{tabular}{|l|l|}
\hline Name & Hersteller \\
\hline 10x FD Green Buffer & $\begin{array}{l}\text { ThermoFisher Scientific, Inc., Rockford, IL, } \\
\text { USA }\end{array}$ \\
\hline 7-Aminoactinomycin D (7-AAD) Viability Dye & BD, Heidelberg \\
\hline Agarose & Merck (Sigma-Aldrich), Darmstadt \\
\hline Ampicillin & Merck (Sigma-Aldrich), Darmstadt \\
\hline
\end{tabular}




\begin{tabular}{|c|c|}
\hline Bovine Serum Albumin (BSA) & Merck (Sigma-Aldrich), Darmstadt \\
\hline Cytofix/Cytoperm ${ }^{\mathrm{TM}}$ & BD, Heidelberg \\
\hline $\mathrm{D}(+)$-Saccharose & Carl Roth GmbH + Co. KG, Karlsruhe \\
\hline $\begin{array}{l}\text { Dynabeads }{ }^{\mathrm{TM}} \text { Mouse T-Activator CD3/CD28 } \\
\text { für T-Zell Expansion und Aktivierung }\end{array}$ & Gibco, Life Technologies, Darmstadt \\
\hline eBioscience $^{\text {TM }}$ 1X RBC Lysis Buffer & Thermo Scientific, Inc., Rockford, IL, USA \\
\hline Ethidiumbromidlösung (1\%) & Carl Roth GmbH + Co. KG, Karlsruhe \\
\hline Ethylendiamintetraessigsäure (EDTA) & Merck (Sigma-Aldrich), Darmstadt \\
\hline FastDigest BamHI & $\begin{array}{l}\text { ThermoFisher Scientific, Inc., Rockford, IL, } \\
\text { USA }\end{array}$ \\
\hline FastDigest Notl & $\begin{array}{l}\text { ThermoFisher Scientific, Inc., Rockford, IL, } \\
\text { USA }\end{array}$ \\
\hline Fetal Calf (bovine) Serum (FBS) & PAA Laboratories, Pasching \\
\hline Fixation/Permeabilization Diluent & $\begin{array}{l}\text { ThermoFisher Scientific, Inc., Rockford, IL, } \\
\text { USA }\end{array}$ \\
\hline Fixation/Permeabilization Konzentrat & $\begin{array}{l}\text { ThermoFisher Scientific, Inc., Rockford, IL, } \\
\text { USA }\end{array}$ \\
\hline Formaldehyd $10 \%$ & Carl Roth $\mathrm{GmbH}+$ Co. KG, Karlsruhe \\
\hline GeneRuler 1 kb Plus DNA Ladder & $\begin{array}{l}\text { ThermoFisher Scientific, Inc., Rockford, IL, } \\
\text { USA }\end{array}$ \\
\hline Glutamat (100x) & Gibco, Life Technologies, Darmstadt \\
\hline GolgiPlug - Protein Transport Inhibitor & BD, Heidelberg \\
\hline HBVAXPRO (10 ug/mcg) & Sanofi-Pasteur, Swiftwater, PA, USA \\
\hline HEPES & Carl Roth GmbH + Co. KG, Karlsruhe \\
\hline $\begin{array}{l}\text { IGRP Catalytic Subunit - related Protein (206 - } \\
214 ; \text { VYLKTNVFL) }\end{array}$ & AnaSpec Inc., Fremont, CA, USA \\
\hline Ionomycin aus Streptomyces conglobatus & Merck, (Sigma-Aldrich), Darmstadt \\
\hline Kollagenase IV aus Clostridium histolyticum & Merck (Sigma-Aldrich), Darmstadt \\
\hline Paramethoxyamphetamin (PMA) & Merck (Sigma-Aldrich), Darmstadt \\
\hline Penicillin/Streptomycin & Merck (Sigma-Aldrich), Darmstadt \\
\hline Perm/Wash ${ }^{\mathrm{TM}}$ Buffer & BD, Heidelberg \\
\hline Permeabilization Buffer 10X & $\begin{array}{l}\text { ThermoFisher Scientific, Inc., Rockford, IL, } \\
\text { USA }\end{array}$ \\
\hline Polyethylenimin (PEI) & Merck, (Sigma-Aldrich), Darmstadt \\
\hline Protaminsulfat & Merck (Sigma-Aldrich), Darmstadt \\
\hline Proteinase K & AppliChem GmbH, Darmstadt \\
\hline Recombinant Murine IL-2 & PEPROTECH, Rocky Hill, NJ, USA \\
\hline REDExtract-N-Amp PCR Reaction Mix & Merck (Sigma-Aldrich), Darmstadt \\
\hline Streptozotocin & Cayman Chemical, Ann Arbor, MI, USA \\
\hline Tri-Natriumcitrat-Dihydrat & Carl Roth GmbH + Co. KG, Karlsruhe \\
\hline Trypsin & Merck (Sigma-Aldrich), Darmstadt \\
\hline VivoGlo luciferin & Promega, Madison, WI, USA \\
\hline
\end{tabular}

\subsubsection{Medien}

Tabelle 3. Liste der in dieser Arbeit verwendeten Medien

\begin{tabular}{|l|l|l|}
\hline Medien & Zusätze & Hersteller \\
\hline $\begin{array}{l}\text { RPMI } 1640(1 \mathrm{x},+\mathrm{L}- \\
\text { Glutamate })\end{array}$ & $\begin{array}{l}\text { Gibco, Life Technologies, } \\
\text { Darmstadt }\end{array}$ \\
\hline RPMI++ & $\begin{array}{l}\text { Penicillin/Streptomycin } \\
(1 \%)\end{array}$ & \\
\hline
\end{tabular}




\begin{tabular}{|l|l|l|}
\hline & FCS (10\%) & \\
\hline $\begin{array}{l}\text { PBS (1x), without } \mathrm{Ca}^{2+}, \\
\mathrm{Mg}^{2+}\end{array}$ & BSA (0,5\%) & $\begin{array}{l}\text { Gibco, Life } \\
\text { Technologies, Darmstadt }\end{array}$ \\
\hline PBS/BSA & $\begin{array}{l}\text { PBS } \\
\text { BSA }(0,5 \%) \\
\text { EDTA (2mM) }\end{array}$ & \\
\hline MACS Puffer & & $\begin{array}{l}\text { Gibco, Life } \\
\text { Technologies, Darmstadt }\end{array}$ \\
\hline $\begin{array}{l}\text { DMEM, high glucose, } \\
\text { GlutaMax }\end{array}$ & $\begin{array}{l}\text { Penicillin/Streptomycin } \\
(1 \%) \\
\text { FCS }(10 \%)\end{array}$ & \\
\hline DMEM ++ & Ampicillin $(100 \mu \mathrm{g} / \mathrm{ml})$ & $\begin{array}{l}\text { Merck (Sigma-Aldrich), } \\
\text { Darmstadt }\end{array}$ \\
\hline TAE Puffer & & $\begin{array}{l}\text { Gibco, Life } \\
\text { Technologies, Darmstadt }\end{array}$ \\
\hline LB-Medium & $\begin{array}{l}\text { Kollagenase IV 1mg/ml } \\
\text { HEPES }(25 \mu \mathrm{m})\end{array}$ & \\
\hline HBBS & & B. Braun, Melsungen \\
\hline HBBS ++ & & \\
\hline $\begin{array}{l}\text { Natriumchlorid-Lösung } \\
(0.9 \%)\end{array}$ & \multicolumn{2}{|l}{} \\
\hline
\end{tabular}

\subsubsection{Kits}

Tabelle 4. Liste der in dieser Arbeit verwendeten Kits

\begin{tabular}{|l|l|}
\hline Kit & Hersteller \\
\hline CD4+ T Cell Isolation Kit, mouse & Miltenyi Biotech, Bergisch Gladbach \\
\hline CD8+ T Cell Isolation Kit, mouse & Miltenyi Biotech, Bergisch Gladbach \\
\hline Mouse IAA ELISA Kit & $\begin{array}{l}\text { Elabscience Biotechnology Co., Ltd., } \\
\text { Texas, Houston, USA }\end{array}$ \\
\hline Pan T Cell Isolation Kit II & Miltenyi Biotech, Bergisch Gladbach \\
\hline $\begin{array}{l}\text { XChange Plasmid Maxi Kit, } \\
\text { peqGOLD }\end{array}$ & Peqlab, Erlangen \\
\hline
\end{tabular}

\subsubsection{Antikörper}

Tabelle 5. Liste der in dieser Arbeit verwendeten Antikörper

\begin{tabular}{|l|l|l|l|}
\hline Antigen & Klon & Fluorochrom & Hersteller \\
\hline CD3e & 17 A2 & eFluor450 & Biolegend \\
& & $\begin{array}{l}\text { APC } \\
\text { FITC } \\
\text { AF700 }\end{array}$ & \\
& & $\begin{array}{l}\text { APC-Cy7 } \\
\text { PE }\end{array}$ & Biolegend \\
BV510 & \\
\hline CD4 & GK1.5 & $\begin{array}{l}\text { FITC } \\
\text { PerCP-Cy5.5 }\end{array}$ & Biolegend \\
& & & \\
\hline CD8 & $53-6.7$ & & \\
& & &
\end{tabular}




\begin{tabular}{|l|l|l|l|}
\hline & & $\begin{array}{l}\text { APC } \\
\text { BV510 }\end{array}$ & \\
\hline PerCP-Cy5.5 & BitC (Mac1) & M1/70 & Biolegend \\
\hline CD24 & M1/69 & BV421 & Biolegend \\
\hline CD25 & PC61.5 & APC & eBioscience \\
\hline CD43 & S11 & APC & Biolegend \\
\hline CD44 & IM7 & AF700 & Biolegend \\
\hline CD45 & $30-F 11$ & $\begin{array}{l}\text { FITC } \\
\text { eFluor450 }\end{array}$ & Biolegend \\
\hline CD45R (B220) & RA3-6B2 & $\begin{array}{l}\text { PE-Cy7 } \\
\text { APC/Cy7 }\end{array}$ & Biolegend \\
\hline CD49d & R1-2 & PE & Biolegend \\
\hline CD62L & MEL-14 & PE & BD Biosciences \\
\hline CD127 & SB/199 & FITC & Biolegend \\
\hline CD197 & 4B12 & PerCP-Cy5.5 & Biolegend \\
\hline CD249 (BP-1) & 6 C3 & PE & Invitrogen \\
\hline CD335 & $29 A 1.4$ & PE-Cy7 & Biolegend \\
\hline FoxP3 & $150 D$ & PE & eBioscience \\
\hline IFNy & XMG1.2 & PE & Biolegend \\
\hline IgD & $11-26 c .2 a$ & BV510 & Biolegend \\
\hline IgM & R6-60.2 & FITC & BD Biosciences \\
\hline Ly-6G (Gr1) & RB6-8C5 & APC & Biolegend \\
\hline MHCl-Dextramer & & PE & Immudex \\
\hline MHCII-Tetramer & I-A(g7) - B:9-23 & PE & $\begin{array}{l}\text { NIH Tetramer } \\
\text { Core Facility }\end{array}$ \\
\hline TCR- $\beta$ Chain & H57-97 & & Biolegend \\
\hline
\end{tabular}

\subsubsection{Mäuse}

Die NOD.CD49df/f.Tie2cre+ Maus wurde in Vorbereitung der hier beschriebenen Arbeit im Labor durch Rückkreuzen der C57BI/6.CD49df/f (Geschenk von Th. Papayannopoulou, Univ. of Washington, Seattle, WA) und C57BI/6.Tie2cre (Jax Laboratory - USA, Bar Harbor, Maine) über 10 Generationen bis zur Reinerbigkeit generiert. ${ }^{53}$ Die NOD.CD49df/f.Tie2cre+ Maus, im Verlauf NOD.a4-/- genannt, und NOD.CD49df/f.Tie2creWurfgeschwister, im Verlauf nur als NOD bezeichnet, wurden im Vivarium der Goethe Universität unter konventionellen (nicht-SPF) Bedingungen in offener Käfighaltung mit Futter und Wasser ad libitum gehalten. Alle Mäuse, die mind. a4 haplosuffizient sind, werden als "NOD" oder "NOD-WT" bezeichnet. Alle Mäuse, die $f / f \mathrm{cre}+, \mathrm{f} / \Delta$ cre+ oder $\Delta / \Delta \mathrm{cre}+$ oder cre- sind und zusätzlich durchflusszytometrisch nachgewiesen auf ihren Leukozyten a4-insuffizient (a4- 
negativ) sind, werden als „NOD.a4-/-,, bezeichnet, obwohl die Ablation sich selbstverständlich inhärent auf die hämato-endotheliale Linie beschränkt, da nur hier die cre-Rekombinase aktiv werden kann.

Die Genotypisierung der Wurfgeschwister erfolgte im Alter von drei Wochen durch Entnahme von Schwanzbiopsien zur Extrahierung und Reinigung genomischer DNA aus dem Mausgewebe. Die genomische DNA wurde daraufhin durch PCR-Untersuchungen analysiert und interpretiert (s. 2.2.4.1).

\subsection{Methoden}

\subsubsection{Tier-Experimente}

\subsubsection{Blutzucker-Messung}

Die Blutzucker-Messung erfolgte durch Punktion der Vena facialis mit einer 20G-Kanüle, der Aufnahme eines Bluttropfens durch Blutzucker-Teststreifen und anschließender Messung durch ACCU-CHECK Aviva. Die DiabetesDiagnose erfolgte nach Blutzucker-Messung über $150 \mathrm{mg} / \mathrm{dl}$ an zwei aufeinanderfolgenden Tagen oder einmaligem Blutzucker über 200 mg/dl. ${ }^{60}$

\subsubsection{Blut- und Organentnahmen}

Blutentnahmen erfolgten durch Punktion der Vena facialis mit einer 20G Kanüle. Das Blut wurde in Natrium/EDTA-Röhrchen (Microvette, Sarstedt, Nümbrecht) gesammelt und bei Raumtemperatur bis zum Gebrauch aufbewahrt. Die Entnahme der inneren Organe erfolgte unmittelbar nach schmerzloser Tötung durch zervikale Dislokation. Auf die Desinfektion der fixierten Spender folgte ein Medianschnitt von Kinn bis Becken und die Präparation von Milz, Pankreas und Glandulae Submandibulares. Zur Präparation von Femur, Tibia und Pelvis erfolgte ein medialer Längsschnitt von Leiste bis Sprunggelenk mit anschließender Freilegung der Knochen und stumpfem Ablösen der umgebenden Muskulatur. Alle Organe wurden anschließend in PBS/BSA bis zur Verarbeitung oder Formalin-Fixierung aufbewahrt. Organe, die histologisch untersucht werden sollten, wurden für 48 
Stunden in 4\% Formaldehydlösung aufgenommen und anschließend in PBS/BSA bis zur Paraffin-Einbettung aufbewahrt.

\subsubsection{Erythrozyten-Lyse}

Erythrozyten wurden durch eine hypotone Ammoniumchlorid-Lösung zersetzt. Durchflusszytometrische Proben wurden hierzu in $2 \mathrm{ml}$ 1x RBC LysisBuffer für 10 min bei RT inkubiert und anschließend zentrifugiert ( $400 \mathrm{~g}, 5 \mathrm{~min}, \mathrm{RT}$ ). Der Überstand wurde verworfen und die Probe anschließend mit PBS/BSA gewaschen. Daraufhin folgte die Antikörperfärbung wie unter 2.2.2.1. beschrieben.

\subsubsection{Präparation von Splenozyten und Knochenmark}

Splenozyten wurden durch stumpfe Extrusion einer ganzen Milz mit 20GKanülen in eine PBS/BSA-Lösung gewonnen. Zur Isolation von Zellen des Knochenmarks wurden zuvor entnommene Knochen mit einer 23G-Kanüle punktiert und mit PBS/BSA gespült. Um größere Gewebereste und Knochensplitter zu entfernen, wurde die entstandene Zellsuspension hiernach durch einen $40 \mu \mathrm{m}$-Filter gegeben und für 5 Minuten mit $400 \mathrm{~g}$ bei RT zentrifugiert. Nachdem der Überstand entfernt wurde, erfolgte die ErythrozytenLyse (s.2.2.1.3) mit $5 \mathrm{ml}$ 1xRBC-LysisBuffer. Die Lyse für Splenozyten- und Knochenmarksuspensionen wurde für 5 Minuten bei $37^{\circ} \mathrm{C}$ im Wasserbad durchgeführt. Nach Zentrifugieren und einem weiteren Waschschritt wurden die Zellen in $5 \mathrm{ml}$ PBS/BSA aufgenommen und die Zellzahl bestimmt (s. 2.2.1.5.).

\subsubsection{Automatische Hämazytometrie}

Proben aus Blut, Milz oder Knochenmark wurden mit einem automatischen Hämazytometer hinsichtlich der zellulären Zusammensetzung analysiert. Für die Erstellung eines großen Blutbildes wurden $40 \mu \mathrm{l}$ Suspension benötigt. Kontrollen zur Überprüfung der Zytometerleistung (MULTI-TROL) wurden täglich durchgeführt. 


\subsubsection{Plasmagewinnung}

Blutproben wurden wie in 2.2.1.2. beschrieben gewonnen und anschließend für 20 Minuten mit $3500 \mathrm{~g}$ bei $4^{\circ} \mathrm{C}$ zentrifugiert. Das Plasma wurde abgenommen und bei $-80^{\circ} \mathrm{C}$ bis zur ELISA-Analyse gelagert. Alle genutzten Proben wurden nur einmal aufgetaut.

\subsubsection{Knochenmark-Transplantation}

Knochenmark-Spender waren zum Interventions-Zeitpunkt zwischen 12 und 20 Wochen alt. Spendern wurden 6 Knochen - jeweils beide Tibiae, Femora und Hemipelves - entnommen und das Knochenmark gründlich mit PBS/BSA herausgespült. Es wurde jeweils Knochenmark von 2-3 Spendern vereinigt, um die Spendervariabilität zu minimieren. Alle Empfänger waren zum Zeitpunkt der Transplantation zwischen 8 und 10 Wochen alt. Diese wurden vor der Transplantation mit einer Dosis von 10,5 Gy einer Caesium-Quelle behandelt und erhielten $2 \times 10^{6}$ NOD oder $10 \times 10^{6}$ NOD.a4-/- Knochenmarkzellen. Das Transplantat wurde innerhalb einer Stunde nach Bestrahlung der Empfänger in einem Volumen von $200 \mu \mathrm{l}$ in die laterale Schwanzvene injiziert. Die ersten vier Wochen nach Transplantation wurden die Empfänger zur Infektionsprophylaxe mit Baytril (0,02\%, Trinkwasser) behandelt. Nach der vierwöchigen Behandlung erfolgten die wöchentlichen Kontrollen des Blutzuckerspiegels.

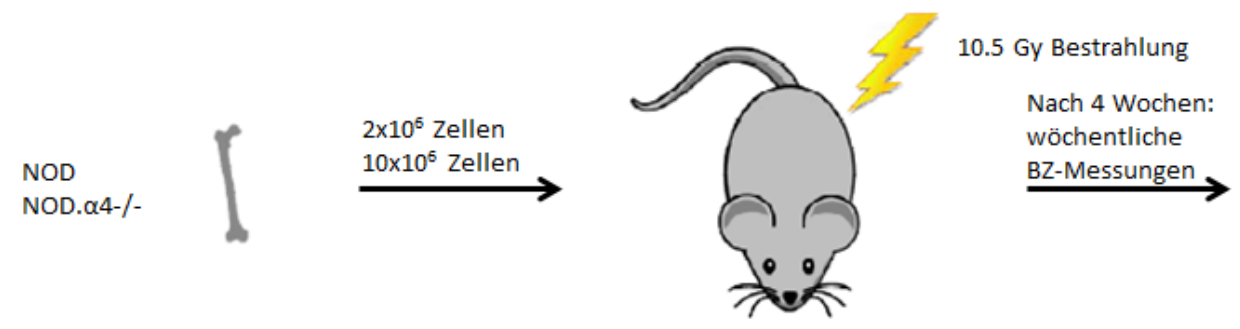

Abbildung 4 Schematische Darstellung des in dieser Arbeit verwendeten Transplantationsregimes.

\subsubsection{Adoptiver T-Zell Transfer}

3-5 weibliche Spender diabetogener T-Zellen wurden nach Diabetes-Diagnose zur Entnahme der Milz schmerzlos getötet. Die Milz wurde entnommen, die 
Splenozyten wurden wie beschrieben (s. 2.2.1.4) stumpf aus der Milzkapsel extruiert und in PBS/BSA gewaschen. Anschließend wurden Erythrozyten mit Ammoniumchlorid lysiert und hiernach eine immunomagnetische CD3Negativselektion mit dem Pan T Cell Kit II nach Herstellerprotokoll durchgeführt. $5 \times 10^{6}$ der so angereicherten CD3+ Zellen wurden den zuvor an einer CaesiumQuelle mit 6,5 Gy subletal bestrahlten Empfängern am selben Tag in die Schwanzvene injiziert. Im Falle des Transfers von angereicherten CD4+ oder CD8+ Zellen erfolgte eine Positivselektion mit dem CD4+T Cell Isolation Kit oder CD8+ T Cell Isolation Kit nach Herstellerangaben. In diesen Transfers wurden $2,5 \times 10^{6}$ Zellen der angereicherten T-Zellen am selben Tag in die Schwanzvene der subletal konditionierten Empfänger injiziert. Nach einer Woche wurden die Empfänger zweimal wöchentlich hinsichtlich ihres Blutzuckers untersucht. Alle NOD und NOD.a4-/- Empfänger-Mäuse waren zum Zeitpunkt des Transfers 8-10 Wochen alt und ausschließlich weiblich.

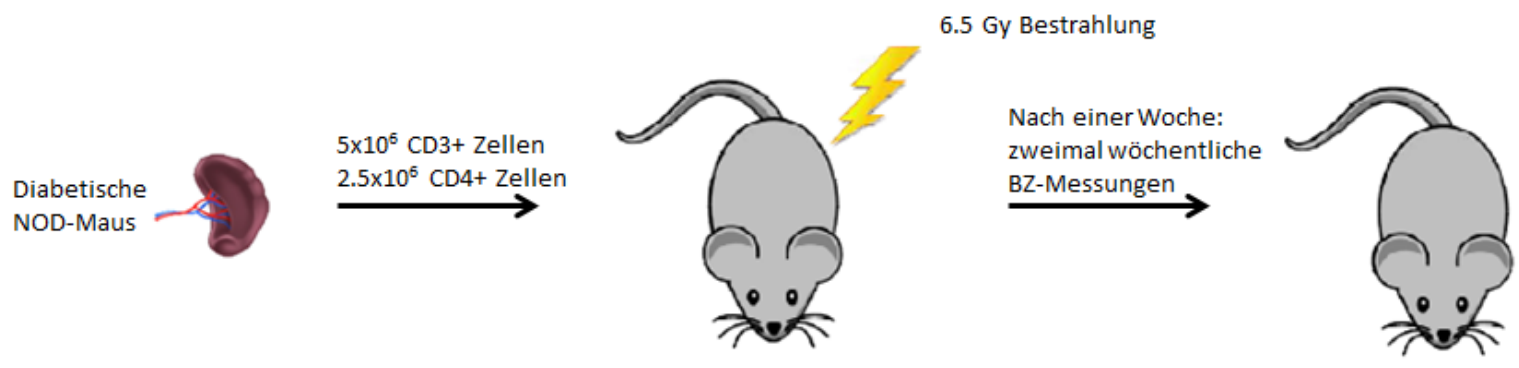

Abbildung 5 Schema des in dieser Arbeit verwendeten adoptiven T-Zell-Transfers

2.2.1.9. Ex vivo Imaging nach adoptivem Transfer von transduzierten CD3+ Zellen

In einem weiteren adoptiven Transfer wurden T-Zellen von diabetischen Spendern mit einem bicistronischen Luciferase/GFP-Vektor transduziert (s. 2.2.4.9.), in der Absicht, ihre Infiltration in lymphatische und anderer Zielorgane ex vivo durch Biolumineszenz-Imaging darstellen zu können. Hierzu wurden nach Transduktion die GFP+-Zellen am FACSAria II sortiert und daraufhin $1 \times 10^{6}$ Zellen in $200 \mu \mathrm{l} 0,9 \% \mathrm{NaCl}$-Lösung in die Schwanzvene jedes Empfängers injiziert.

Zum Zeitpunkt der ersten Diabetes-Diagnose erfolgte die schmerzlose Tötung der erkrankten NOD-Empfängermaus als auch zur Kontrolle einer NOD.a4-/- 
Empfängermaus zur Lokalisierung der transduzierten T-Zellen in beiden Mäusen. Zu behandelnde Mäuse erhielten eine Injektion von Luciferin $(1,5 \mathrm{mg}$ in $100 \mu \mathrm{l}$ PBS) ins subkutane Fettgewebe. Nach zehn Minuten erfolgte eine zweite Injektion. Nach weiteren drei Minuten wurden die behandelten Mäuse durch zervikale Dislokation getötet. Zu untersuchende Organe wurden zügig entnommen und in PBS auf Eis und dunkel gelagert. 40 Minuten nach erster Injektion erfolgte die Biolumineszenz-Aufnahme durch IVIS Lumina II mit einer Exposure Time von $240 \mathrm{~s}$ und einer Object Height von $0,5 \mathrm{~cm}$ und die anschließende Analyse mit der Living Image Software 4.5.4. bei einem Binning von 4 und einem FOV (field of view) von 7,5. ${ }^{65}$

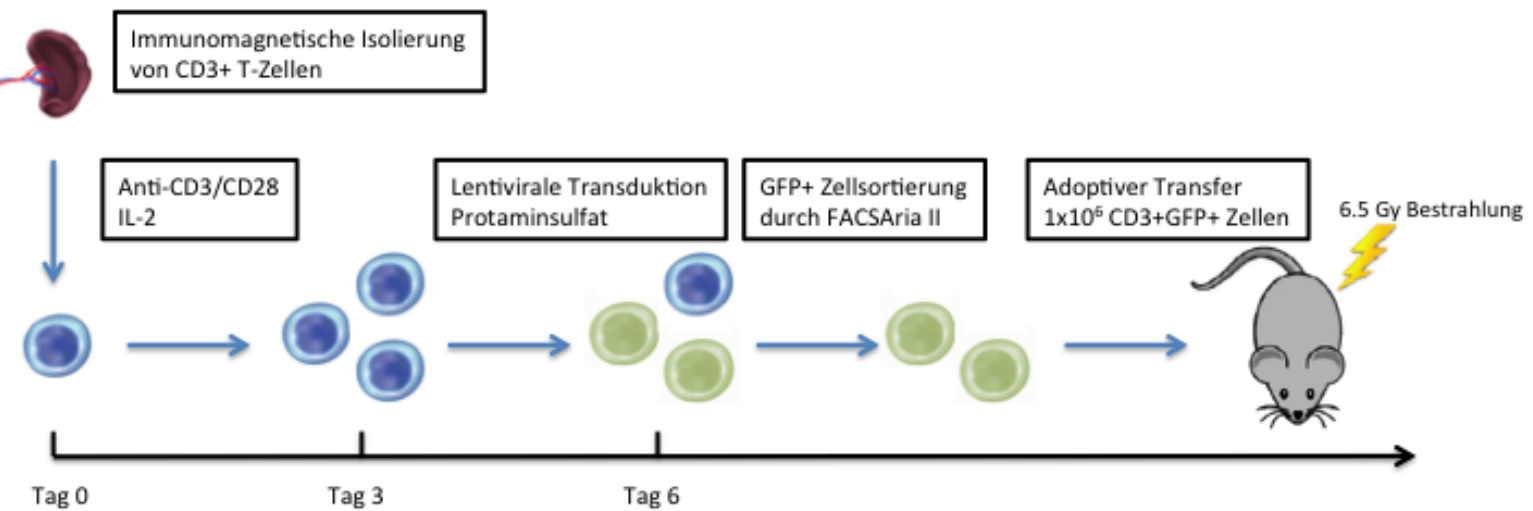

Abbildung 6 Schematische Darstellung des in dieser Arbeit verwendeten Transduktionsregimes

\subsubsection{Präparation Pankreas-infiltrierender Lymphozyten}

Zum fachgerechten Verdau des Pankreas zur Gewinnung von LangerhansInseln wird eine optimale Zufuhr von Kollagenase IV in das Organ benötigt. Diese wird unmittelbar postmortal durch Punktion der Gallenblase mit vorheriger Abklemmung proximal und distal der Papilla major und anschließender Injektion von $1 \mathrm{ml} \mathrm{HBBS++}$ erreicht. Die Pankreata wurden anschließend entnommen und in $50 \mathrm{ml}$-Falcons mit $5 \mathrm{ml}$ HBBS++ aufbewahrt. ${ }^{66 ; 67}$

Zur Aufreinigung der Langerhans-Inseln wurden die Pankreata für 15 Minuten bei $37^{\circ} \mathrm{C}$ im Wasserbad inkubiert und zwei- bis dreimal geschüttelt. Anschließend wurden die Pankreata bis zur Herstellung einer homogenen Suspension geschüttelt. Hiernach folgte die Zugabe von $20 \mathrm{ml}$ HBBS und die 
Lagerung auf Trockeneis, um den Kollagenase-vermittelten Verdau zu stoppen. Eine einminütige Zentrifugation mit $300 \mathrm{~g}$ bei $4{ }^{\circ} \mathrm{C}$ ermöglichte das Dekantieren des Überstands. Dieser Waschschritt erfolgte ein weiteres Mal, bevor die möglichst gründlich homogenisierte Suspension durch einen $70 \mu \mathrm{m}$-Filter gegeben wurde. Die gefilterte Suspension wurde in eine Petri-Schale gegeben und die unter dem Mikroskop sichtbaren Langerhans-Inseln mit einer Pipette einzeln in ein RPMl++ Medium überführt. In diesem Medium wurden die Langerhans-Inseln über Nacht in einem $5 \% \quad \mathrm{CO}_{2}$ Inkubator bei $37{ }^{\circ} \mathrm{C}$ aufbewahrt, um die Emigration der Leukozyten in das Medium zu ermöglichen. Am nächsten Tag erfolgte die Antikörper-Färbung und durchflusszytometrische Analyse wie in Kapitel 2.2.2.1 beschrieben.

\subsubsection{Prüfung der humoralen Immunkompetenz von NOD und NOD.a4-/- Mäusen}

Zur Untersuchung der humoralen Funktionalität der B-Zellen in unserem Mausmodell wurde eine Immunisierungsstudie mit dem zugelassenen Hepatitis B Impfstoff HBVaxPro durchgeführt. Die Injektion von HBVaxPro erfolgte nach Isofluran-Narkose der zu behandelnden Mäuse mit einem Gesamtvolumen von $100 \mu \mathrm{l}$ Impfstoff. Dies entspricht 10\% einer Erwachsenendosis. Hierzu wurden jeweils $50 \mu \mathrm{l}$ des Impfstoffs intramuskulär in beide Mm. Quadriceps injiziert. Zur Immunisierung erhielten zu behandelnde Mäuse ab der achten Lebenswoche drei wöchentliche Injektionen und eine weitere drei Monate nach der letzten Injektion, um die Bildung von B-Gedächtniszellen zu untersuchen. Die Blutentnahmen zur Plasma-Gewinnung erfolgten jeweils eine Woche nach der letzten Injektion als auch eine Woche vor der Impfauffrischung. Anti-HBs-AKTiter wurden durch den ARCHITECT i1000SR bestimmt.

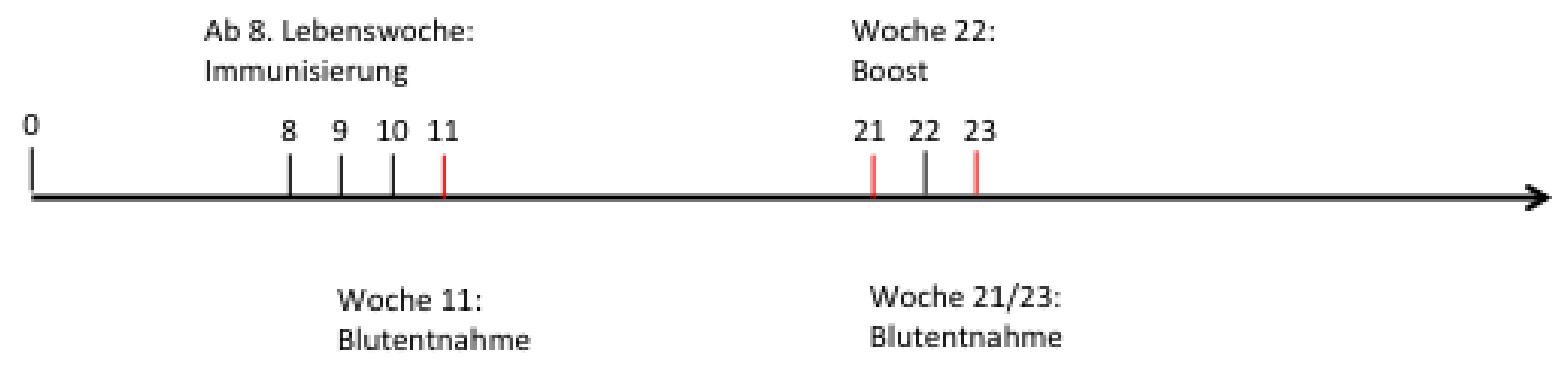

Abbildung 7 Schematische Darstellung der Hepatitis-B Immunisierungsstudie 


\subsubsection{Mikrobiota-Analysen}

Systematische Analysen haben gezeigt, dass die Mikrobiota von Mäusen im Wesentlichen eine umgebungsspezifische Flora widerspiegeln, die relativ unabhängig vom Mausstamm ist. Andererseits wird eine (reziproke) Beziehung zwischen Diabetes und Mikrobiota beschrieben.68:69 Zur Überprüfung des Einflusses einer diabetischen Stoffwechsellage auf die Mikrobiota des Darms, bzw. zur Beantwortung der Frage, in wieweit bei kohabitierenden diabetesresistenten NOD.a4-/- Mäusen und diabetischen NOD Mäusen die Mikrobiota gegenüber dem Ausgangszustand verändert wird, wurden Stuhlproben nichtdiabetischer, prä-diabetischer und diabetischer Mäuse, sowie von ihren Diabetes-resistenten Wurfgeschwistern gesammelt.

Zu Beginn wurden hierzu Mäuse in Käfige mit frischem Streu umgesetzt und das Gewicht des Futters und der jeweiligen Maus festgehalten. Nach 48 Stunden erfolgte eine weitere Messung des Gewichts von Futter und Maus und die Sammlung der Stuhl-Proben in 1,5 ml Reaktionsgefäßen. Diese wurden anschließend bis zum Versand an das MMPC (Mouse Metabolic Phenotyping Center, University of California, Davis) bei $-80^{\circ} \mathrm{C}$ gelagert.

Unsere Kooperationspartner aus dem MMPC extrahierten die DNA aus den Stuhlproben mit dem Mo-Bio PowerFecal Kit (Qiagen). Die aufgereinigte DNA wurde mit den F319 und R806 Primern in der V4 Region der 16S rRNA-Gen durch eine PCR amplifiziert. Die High-throughput-Sequenzierung wurde mit Illumina MiSeq durchgeführt. Die Analyse der hierdurch generierten Daten wurde mittels QIIME2 und DADA2 prozessiert. ${ }^{70}$ OTUs/features (Quality filtering and feature) für die 319F-806R-Region wurden taxonomisch klassifiziert. ${ }^{71}$ Schließlich wurden Diversitäts-Analysen der resultierenden OTU/feature durchgeführt, um phylogenetische als auch nicht-phylogenetische Aussagen zu $\alpha$ - und $\beta$-Diversität des Mikrobioms zu treffen. ${ }^{72}$

\subsubsection{Durchflusszytometrie}

Für durchflusszytometrische Analysen wurden zwischen $30 \mu \mathrm{l}$ und $50 \mu \mathrm{l}$ Peripherblut bzw. zwischen $0,5 \times 10^{6}$ und $2 \times 10^{6}$ Knochenmark - oder Milzzellen 
eingesetzt. Zur Färbung wurden den Herstellerangaben entsprechend optimale Antikörperkonzentrationen eingesetzt. Die Proben wurden mit entsprechenden Antikörperkombinationen für $20 \mathrm{~min}$ bei $4{ }^{\circ} \mathrm{C}$ im Dunkeln inkubiert. In Peripherblutproben wurden die Erythrozyten lysiert (s. 2.2.1.3) und die Proben einmal mit PBS/BSA gewaschen. Die Vermessung der Proben erfolgt am LSR Fortessa II. Direkt vor der Messung wurden Knochenmarks- und Milzproben durch einen $35 \mu \mathrm{m}$ Filter filtriert. Das Durchflusszytometer wird hierzu mit ungefärbten Proben und FMO-Kontrollen eingestellt. Zur Kompensation werden Einzelfärbungen verwendet. Die Analyse wurde mit der FACSDiva Software durchgeführt.

\subsubsection{Oberflächenanalyse}

Abbildung 8 zeigt eine typische Messung der a4-Expression von PBMCs einer NOD Maus. Hierzu wurde Peripherblut lysiert und mit PBS/BSA gewaschen. Darauf folgte die Antikörperfärbung mit jeweils $1 \mu \mathrm{l}$ CD45, CD3, B220, CD11b, Gr1 und CD49d für 20 Minuten bei $4^{\circ} \mathrm{C}$. Nach erneutem Waschen wurden die Zellen in $300 \mu \mathrm{l}$ PBS/BSA aufgenommen und analysiert. Weitere Oberflächenfärbungen erfolgten nach demselben Verfahren. 

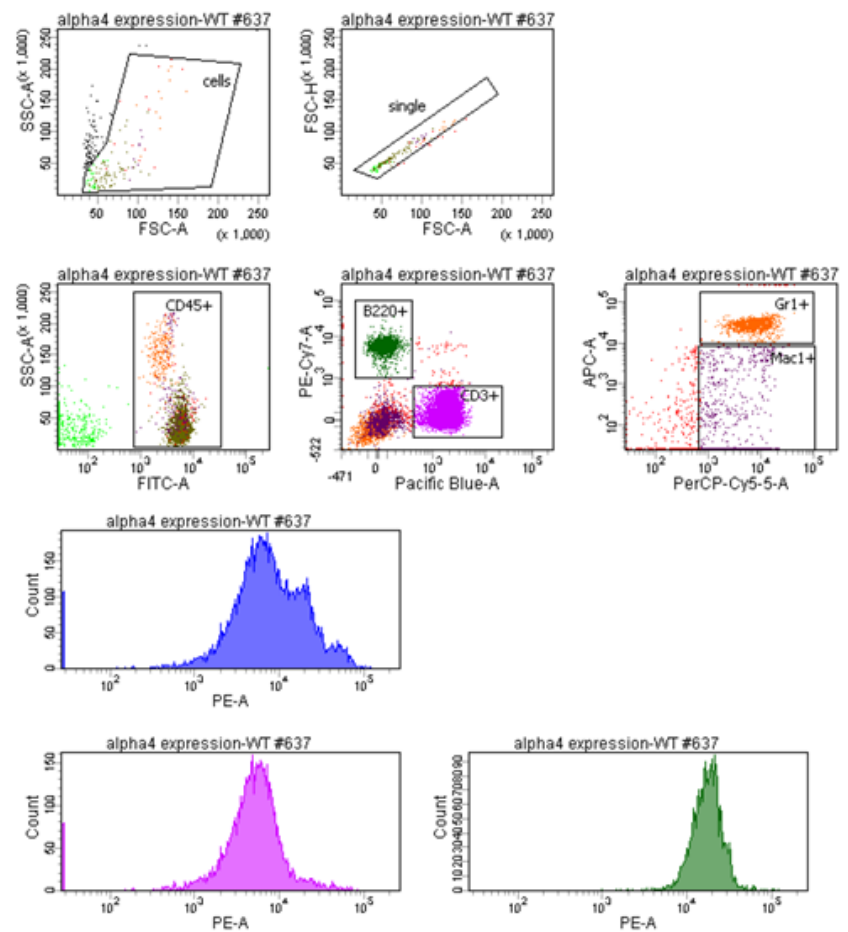

Tube: WT \#637
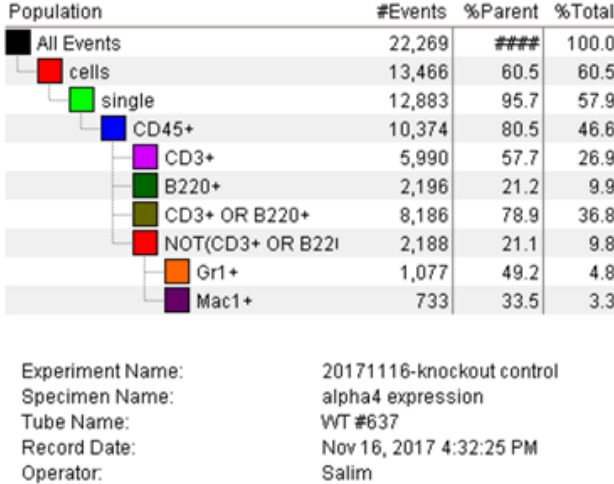

Record Date:

GUID:

\begin{tabular}{|l|r|r|r|r|r|} 
& & & & PE-A & PE-A \\
\hline Population & \#Events & \%Parent & Mean & Median \\
\hline All Events & 22,269 & 13,466 & 60.5 & 10,418 & 5,703 \\
\hline cells & 12,883 & 95.7 & 9,525 & 5,564 \\
\hline single & 10,374 & 80.5 & 11,601 & 7,066 \\
\hline CD45+ & 5,990 & 57.7 & 6,660 & 4,977 \\
\hline CD3+ & 2,196 & 21.2 & 18,136 & 16,959 \\
\hline B220+ & 8,186 & 78.9 & 9,739 & 6,460 \\
\hline CD3+ OR B220+ & 2,188 & 21.1 & 18,567 & 9,677 \\
\hline NOT(CD3+ OR B220+) & 1,077 & 49.2 & 10,201 & 7,882 \\
\hline Gr1+ & 733 & 33.5 & 33,901 & 35,529
\end{tabular}
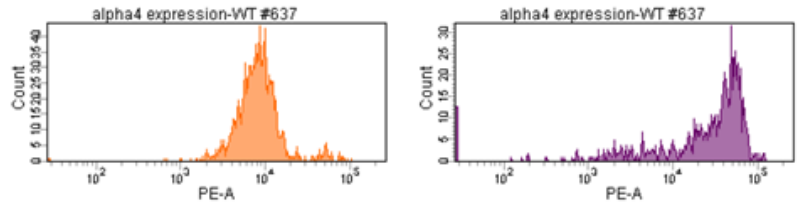

Abbildung 8 Repräsentatives Beispiel für die a4-Expression auf PBMCs der wildtypischen NOD Maus. Nach einem morphologischen Gate und Doubletten-Ausschluss wurde auf $\mathrm{CD}_{4} 5^{+}$-Zellen und hiervon auf $\mathrm{CD}^{+}, \mathrm{B}^{220} \mathrm{O}^{+}, \mathrm{CD} 11 \mathrm{~b}^{+}$und $\mathrm{Gr} 1$ gegatet. Die a4Expression der jeweiligen Zellpopulationen ist im PE-Kanal zu sehen.

\subsubsection{Intrazelluläre Färbung (IFNy)}

Der Färbung von intrazellulärem IFNy ging die zuvor beschriebene Oberflächenfärbung voraus. In diesem Falle wurde die Oberflächenfärbung jedoch 30 Minuten lang durchgeführt. Nach dem anschließenden Waschen mit PBS/BSA und Zentrifugieren wurden die Zellen für 30 Minuten mit $1 \mathrm{ml}$ Fix/Perm Solution $\left(4{ }^{\circ} \mathrm{C}\right.$, im Dunkeln) inkubiert. Alle darauffolgenden Waschschritte wurden mit $1 \mathrm{ml}$ 1xPerm Solution durchgeführt. Nach Waschen mit 1xPerm-Solution erfolgte die intrazelluläre Färbung mit $1 \mu \mathrm{IFN}$-Antikörper für weitere 40 Minuten $\left(4^{\circ} \mathrm{C}\right.$, im Dunkeln). Die Zellen wurden schließlich ein letztes Mal gewaschen und daraufhin analysiert.

\subsubsection{Dextramer/Tetramerfärbung}


Zur Färbung von IGRP-spezifischen CD8+-Zellen wurden Peripherblut und Splenozyten genutzt. Diese wurden nach Herstellerangaben zuerst mit dem $\mathrm{MHCl}$-Dextramer (10 Minuten, $4^{\circ} \mathrm{C}$, im Dunkeln) inkubiert. Daraufhin erfolgte die Oberflächenfärbung wie zuvor beschrieben (s.2.2.2.1).

Zur Darstellung Insulin-spezifischer CD4+-Zellen wurden Peripherblut und Splenozyten genutzt. Diese wurden initial mit I-A(g7) MHC Class II Tetramer $(20 \mu \mathrm{g} / \mathrm{ml})$ als auch einem unkonjugierten T-Zell-Rezeptor Cß-spezifischen Antikörper $(1 \mu \mathrm{g} / \mathrm{ml})$ im Brutschrank $\left(2 \mathrm{~h}, 37^{\circ} \mathrm{C}\right.$, im Dunkeln) inkubiert. Letzteres ist als Adjuvant in Tetramer-Färbungsprotokollen etabliert, um unspezifische Bindungen zu verhindern. ${ }^{73}$ Nach einem Waschschritt mit PBS/BSA erfolgte eine Oberflächenfärbung wie zuvor beschrieben.

\subsubsection{Biochemische Methoden}

\subsubsection{IAA-Sandwich-ELISA}

Ein Sandwich-ELISA ist eine robuste und etablierte Methode zur Detektion und Quantifizierung von Antikörpern. Hierzu erfolgte eine Immobilisierung des Antigens auf einer 96-Well-Platte und die Blockierung unspezifischer Bindungsstellen. Im Falle des IAA-ELISA wurde dieser Schritt bereits durch den Hersteller durchgeführt. Anschließend werden sowohl die Proben als auch eine Verdünnungsreihe von aufgereinigten Antikörpern zur Erstellung einer Standardkurve dazugegeben. Ungebundene Antikörper werden durch mehrere Waschschritte entfernt. Durch die Zugabe eines spezifischen biotinylierten Sekundärantikörpers wird das Sandwich komplettiert. Daraufhin wird eine Avidin-Horseradish Peroxidase hinzugegeben und freie Komponenten durch wiederholtes Waschen entfernt. Nach Zugabe des Substrats kommt es zur HRP-vermittelten Chemilumineszenz-Reaktion. Durch Zugabe einer Stop Solution wird die Reaktion beendet. Die OD (optical density) kann nun spektrophotometrisch bei einer Wellenlänge von $450 \mathrm{~nm}$ gemessen werden. Die Messung erfolgte durch VICTORX4. Der OD-Wert ist proportional zu der Konzentration der Mouse IAA. Durch die mitgeführte Standardreihe kann somit die Konzentration der Proben errechnet werden. 


\subsubsection{HBs-ELISA}

Zur Untersuchung der humoralen Antwort der Mäuse wurde der auch bei Menschen verwendete Impfstoff HBVAXPRO zur Immunisierung gegen das HBV Kapsidprotein HBs genutzt. Zur Messung von Anti-HBs-Titern wurden Plasmaproben der jeweiligen Mäuse 1:3 mit 0,9\% NaCl-Lösung verdünnt. Initial wurde das entsprechende Programm zur Messung der HBs-Antikörper gewählt. Ein Minimum von $120 \mu \mathrm{l}$ wurde daraufhin in entsprechende Reaktionsgefäße des ARCHITECT i1000SR pipettiert.

\subsubsection{Zytokin-Assay}

Zur Untersuchung der Sensibilisierung von T-Zellen gegenüber Inselzellantigenen der NOD und NOD.a4-/- Maus wurde die Reaktion von Splenozyten beider Mäuse auf ein für den T1D relevantes Inselzell-Autoantigen namens IGRP getestet. ${ }^{74}$ Hierzu wurden $1 \times 10^{6}$ frisch entnommene Splenozyten von gleichaltrigen männlichen Mäusen in $1 \mathrm{ml}$ RPMI Medium ohne Zusätze in einer 28-Well-Platte kultiviert und mit IGRP $(9,1 \mu \mathrm{M})$ stimuliert. Zur Positivkontrolle wurden PMA (50 ng/ml) und lonomycin $(750 \mathrm{ng} / \mathrm{ml})$ hinzugegeben, während die Negativkontrolle unbehandelt blieb.

2 Stunden nach Zugabe des Antigens oder PMA+lonomycin wurde $1 \mu \mathrm{l}$ GolgiStop in alle wells gegeben. Nach weiteren 4 Stunden wurden die Zellen mit $2 \mathrm{ml}$ PBS/BSA gewaschen. Es folgte eine Oberflächenfärbung mit anschließender Fixierung und Permeabiliserung der Zellen. Letztlich wurde eine intrazelluläre Färbung von IFNy durchgeführt. Nach anschließendem Waschen wurden die Zellen analysiert.

\subsubsection{Immunomagnetische Zellanreicherung}

Zur Anreicherung bestimmter T-Zellpopulationen wurden immunomagnetische beads genutzt. Dabei sind superparamagnetische Partikel kovalent an spezifische Antikörper gebunden. Im Falle der CD3+ Negativselektion markieren diese Antikörper CD11b, CD11c, CD19, CD45R (B220), CD49b (DX5), CD105, Anti-MHC-class II und Ter-119. Dies ermöglicht eine Anreicherung von T-Zellen, ohne dabei den T-Zell-Rezeptor zu binden und 
diesen hierdurch zu stimulieren. Im Falle der CD4+ oder CD8+ Positivselektion ist dies nicht notwendig, da eine Bindung an CD4 oder CD8 keine Auswirkungen hat. Die Kits wurden entsprechend den Herstellerangaben verwendet. Die Anreicherung erfolgt automatisch durch den AutoMACS pro Separator.

\subsubsection{Molekularbiologische Methoden}

\subsubsection{PCR}

Zur Identifizierung der Mäuse mit Cre-Rekombinase-vermittelter a4-Ablation wurde sowohl die Cre-Region als auch die wildtypische, gefloxte oder deletierte Region des a4-Gens durch eine Polymerase-Kettenreaktion amplifiziert. ${ }^{53}$

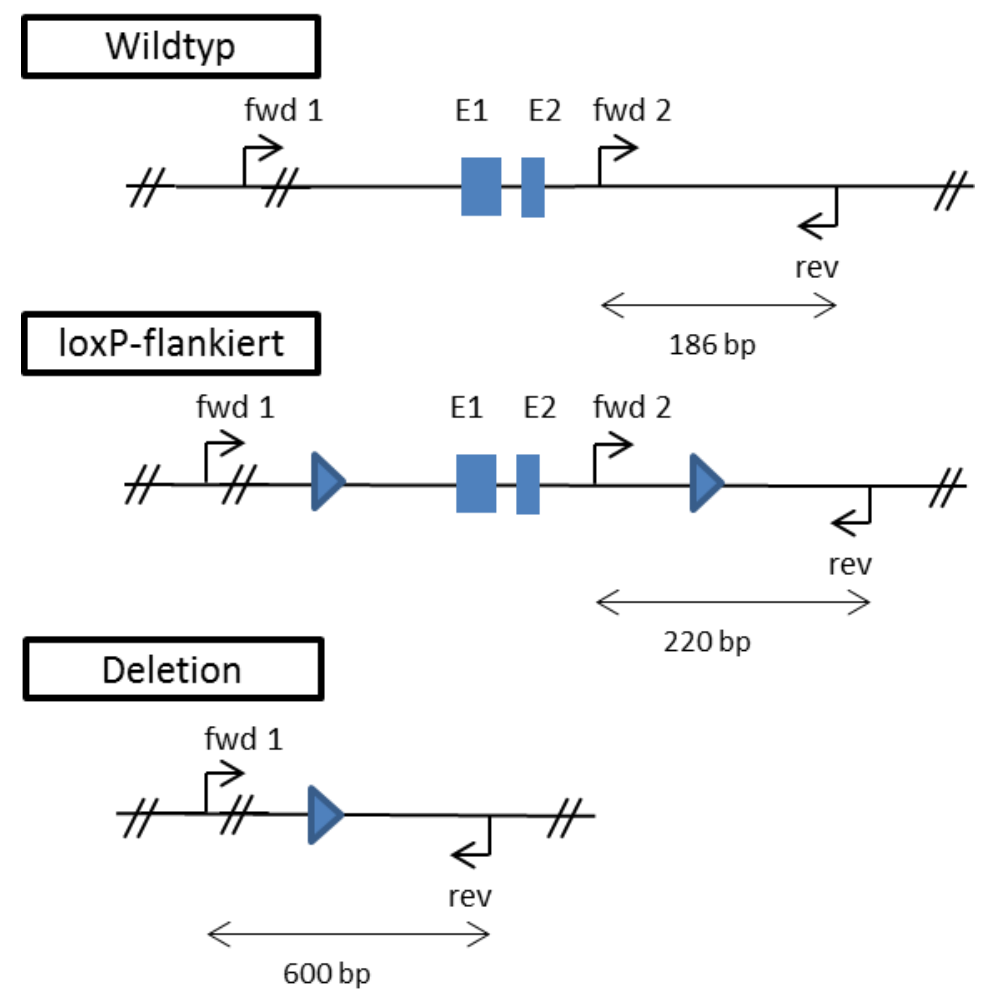

Abbildung 9 Konstruktion der loxP-flankierten a4-Allele und Genotypisierungsstrategie. Es handelt sich um eine Drei-Primer-Strategie mit den Primern Forward 1, Forward 2 und Reverse, welche das Wildtyp-Allel als 186bp-Bande, das loxP-flankierte Allel als 220bp-Bande und das Wildtyp-Allel als 600bp-Bande identifiziert. (Scott et al. 2003)

Hierfür wurden Schwanzbiopsien der zu untersuchenden Mäuse über Nacht bei $56{ }^{\circ} \mathrm{C}$ in $200 \mu \mathrm{l}$ DirectPCR lysis Reagent (Viagen) mit darin enthaltenen $2 \mu \mathrm{l}$ Proteinase $\mathrm{K}$ verdaut. Am nächsten Morgen wurde die Probe dann für 45 
Minuten auf $85{ }^{\circ} \mathrm{C}$ erhitzt, um die Proteinase zu inaktivieren, bevor die Proben bei $-20{ }^{\circ} \mathrm{C}$ gelagert oder sofort für eine PCR-Analyse verwendet wurden. Für die PCR wurden 0,5 $\mu \mathrm{l}$ der jeweiligen Probe zusammen mit 19,5 $\mu \mathrm{l}$ eines Mastermixes, der alle Komponenten zur Amplifikation des zu untersuchenden Gens beinhaltet, genutzt. Die in der Tabelle beschriebenen Volumina wurden so gewählt, dass eine vom Hersteller empfohlene finale Primer-Konzentration von jeweils $0,4 \mu \mathrm{M}$ vorlag.

Tabelle 6. Reaktionsansatz und PCR-Programm zur Genotypisierung

\begin{tabular}{|c|c|c|c|}
\hline Inhalte des Mastermix & Volumen pro Probe in $\mu \mathrm{l}$ & PCR Zyklus & \\
\hline Forward Primer 1 & 0,5 & $95^{\circ} \mathrm{C} \quad 2 \mathrm{~min}$ & \\
\hline (a4g1986) & 0,5 & $95^{\circ} \mathrm{C} \quad 30 \mathrm{I}$ & \\
\hline Forward Primer 2 & 0,5 & $60^{\circ} \mathrm{C} \quad 30 \$$ & $40 x$ \\
\hline (a4g2011) & 10 & $72^{\circ} \mathrm{C} \quad 60 \mathrm{~s}$ & \\
\hline Reverse Primer & 8 & $72^{\circ} \mathrm{C} \quad 10 \mathrm{~min}$ & \\
\hline (a4g2191) & & & \\
\hline Red Extract & & & \\
\hline $\mathrm{dd} \mathrm{H}_{2} \mathrm{O}$ & & & \\
\hline
\end{tabular}

\begin{tabular}{|c|c|c|}
\hline Inhalte des Mastermix & Volumen pro Probe in $\mu \mathrm{l}$ & PCR Zyklus \\
\hline Forward Primer (Cre1) & 0,5 & $95^{\circ} \mathrm{C} 2 \mathrm{~min}$ \\
\hline Reverse Primer (Cre2) & 0,5 & $95^{\circ} \mathrm{C} \quad 30 \mathrm{\Xi}$ \\
\hline Red Extract & 10 & $60^{\circ} \mathrm{C} 30 s$ \\
\hline $\mathrm{dd} \mathrm{H}_{2} \mathrm{O}$ & 8,5 & $72^{\circ} \mathrm{C} \quad 60 \mathrm{~s}$ \\
\hline & & $72^{\circ} \mathrm{C} \quad 10 \mathrm{~min}$ \\
\hline
\end{tabular}

Tabelle 7. Eingesetzte Oligonukleotidpaare in der Genotypisierungs-PCR

\begin{tabular}{|l|l|}
\hline Primer & Sequenz von 5‘-3 \\
\hline Forward 1 (a4g1986) & -CCA CCT GGT GTA TGA AAG C- \\
\hline Foward 2 (a4g2011) & -CGG GAT CAG AAA GAA TCC A- \\
\hline Reverse (a4g2191) & -CTG GCA TGG GGT TAA AAT TG- \\
\hline Forward (Cre1) & -ACC TGA AGA TGT TCG CGA TTA- \\
\hline Reverse (Cre2) & -ACC GTC AGT ACG TGA GAT ATC \\
\hline
\end{tabular}


Nach der Amplifikation der Zielgene wurden die Proben auf ein 2\%iges Agarose-Gel geladen. Die Elektrophorese wurde bei $110 \mathrm{~V}$ für 40 Minuten durchgeführt. Schließlich folgte die Visualisierung der DNA-Fragmente durch die Anfärbung mittels Ethidiumbromid unter UV-Licht.

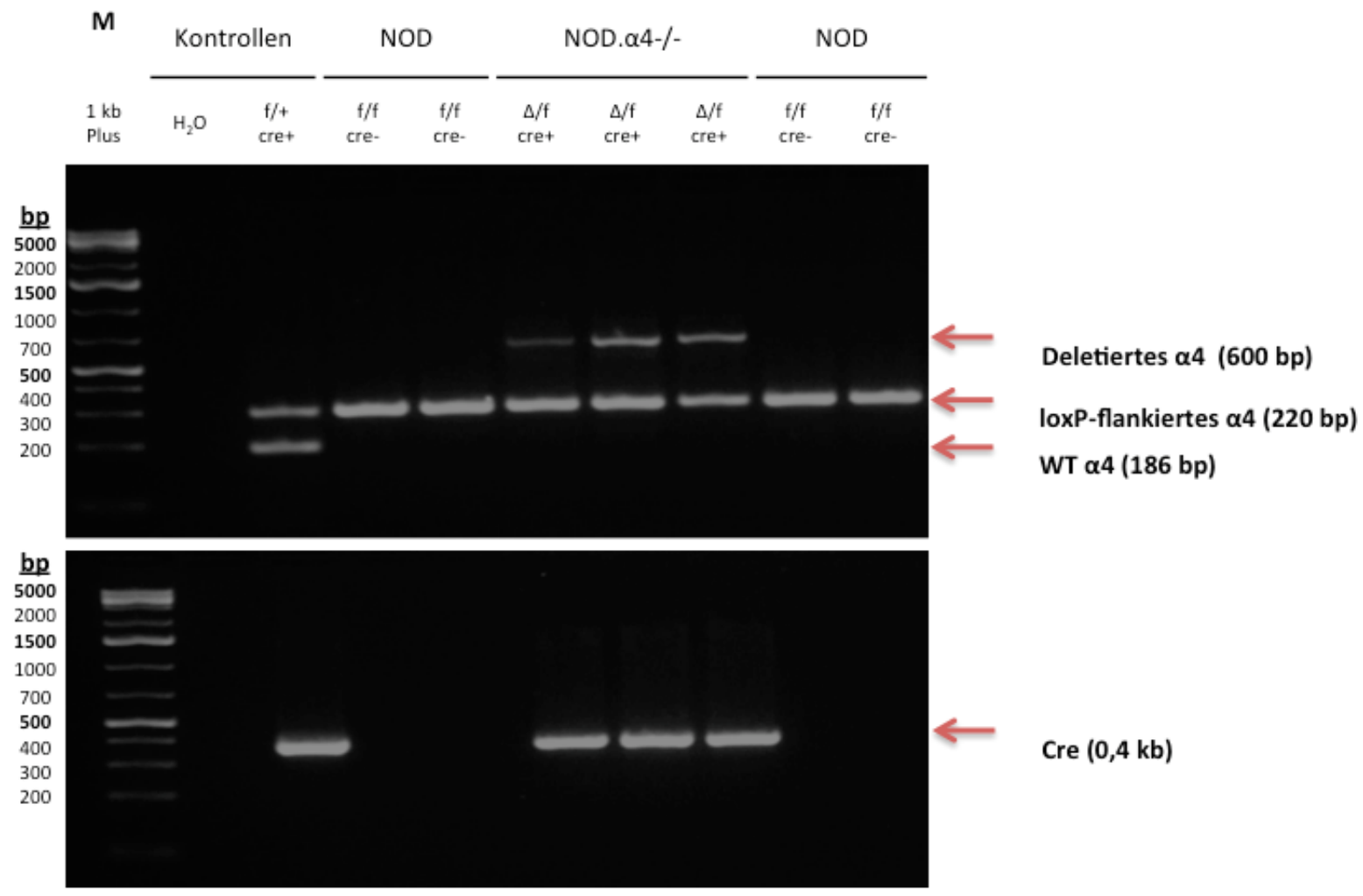

Agarosegel (2\%);

$40 \mathrm{~min} ; 110 \mathrm{~V}$

Abbildung 10 a4- und Cre-Genotypisierung. Aufgetragen sind Marker (M), $\mathrm{H}_{2} \mathrm{O}-K o n t r o l l e$, eine Positivkontrolle mit wildtypischen und loxP-flankierten Allel $(\mathrm{f} /+)$, in der gleichen Spalte eine cre-positive Probe als Kontrolle und in den übrigen Geltaschen (4-10) ein repräsentativer Wurf (7) aus einer gemischten Verpaarung. Es zeigen sich vier loxP-flankierte $(\mathrm{f} / \mathrm{f})$ und cre-negative (cre-) Proben und drei loxP-flankierte und teilweise deletierte a4-Allele $(\Delta / f)$ sowie cre-positive (cre+) Proben.

\subsubsection{Kultivierung von E. coli}

Die Kultivierung von E. coli erfolgte in lysogeny broth (LB) -Medium. Für die Selektion über eine Ampicillin-Resistenz wurde das Medium mit dem Antibiotikum in einer Endkonzentration von $100 \mu \mathrm{g} / \mathrm{ml}$ versetzt. Das Ampicillin 
wurde jeweils vor dem Gebrauch frisch hinzugefügt. Zur Herstellung von LBAgar-Platten wurden vor dem Autoklavieren $35 \mathrm{~g}$ LB-Agar zu einem Liter LB-Medium hinzugefügt, sodass sich eine Endkonzentration von $3,5 \%(\mathrm{w} / \mathrm{v})$ ergab. Die LB- Platten wurden bis zu ihrer Nutzung bei $4{ }^{\circ} \mathrm{C}$ aufbewahrt.

\subsubsection{Transformation von E. coli}

Die Transformation diente der Vervielfältigung des pSEW-lucs2 Plasmids, das freundlicherweise von Prof. Buchholz zu Verfügung gestellt wurde. ${ }^{75}$ Ein $50 \mu \mathrm{l}$ Aliquot hitzekompetenter E. coli-Bakterien (NEB Turbo Competent E. coli, New England BioLab), welches zuvor bei $-80{ }^{\circ} \mathrm{C}$ gelagert wurde, wurde hierzu auf Eis aufgetaut. Anschließend wurden $50 \mathrm{ng}$ des pSEW-luc2 Plasmids hinzugegeben und das Gemisch für weitere 30 Minuten auf Eis inkubiert. Daraufhin erfolgte ein 30-sekündiger Hitzeschock zur Einbringung des Plasmids in die Bakterien in einem zuvor auf $42{ }^{\circ} \mathrm{C}$ erwärmten Heizblock. Nach einer fünfminütigen Abkühlung der Bakterien auf Eis wurde die E. coli-Suspension mit $950 \mu \mathrm{l} \mathrm{SOC-Medium} \mathrm{vermischt} \mathrm{und} \mathrm{für} 60$ Minuten im Schüttler $\left(250 \mathrm{rpm}, 37^{\circ} \mathrm{C}\right.$ ) inkubiert. Schließlich wurden die Bakterien auf vorgewärmte LB-Agar-Platten mit Selektionsmarker (Ampicillin) verteilt und über Nacht bei $37^{\circ} \mathrm{C}$ im Inkubator gehalten. Am nächsten Tag (nach ca. 16h) wurden Klone mit sterilen Pipettenspitzen von der Agar-Platte in jeweils $5 \mathrm{ml}$ LB-Amp-Medium überführt und für 12-16 Stunden $\left(250 \mathrm{rpm}, 37^{\circ} \mathrm{C}\right)$ im Schüttler inkubiert. 


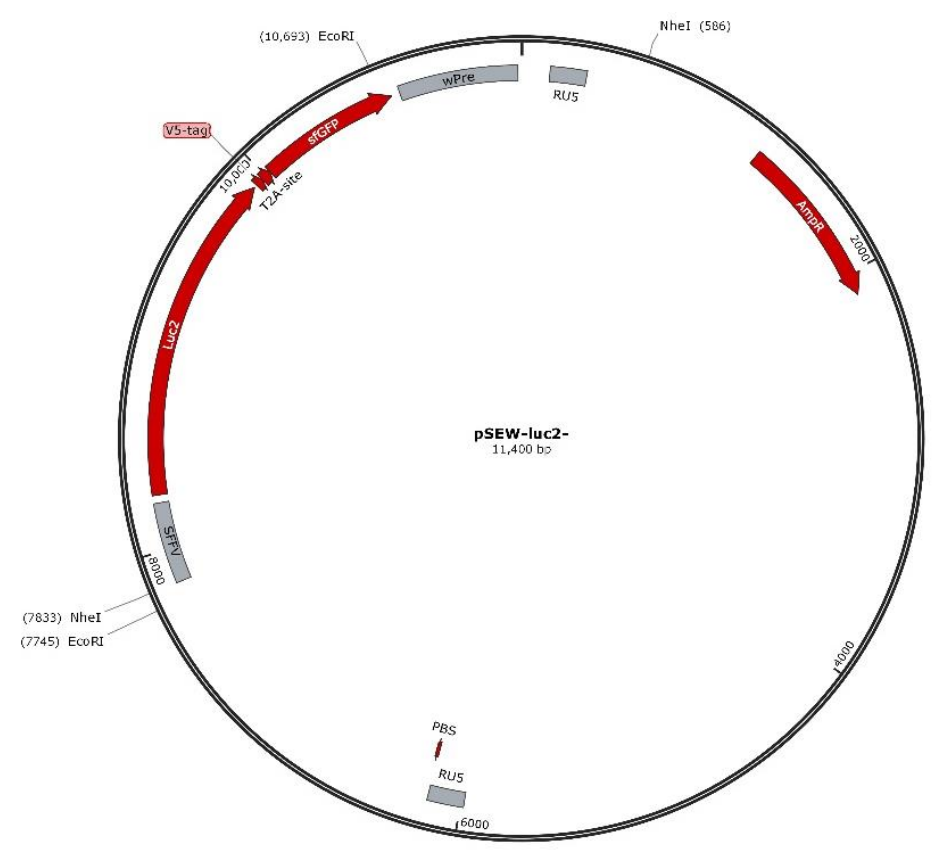

Abbildung 11 Plasmid-Karte des pSEW-lucs2-Vektors mit Darstellung der Schnittstellen für Restriktionsenzyme. Plasmid und Plasmidkarte wurden freundlicherweise von Prof. Christian Buchholz (Paul Ehrlich Institut, Langen) zur Verfügung gestellt.

\subsubsection{Testrestriktion}

Zur Überprüfung der produzierten Plasmid-DNA wurde anhand der Plasmidkarte (s. Abbildung 11) ein Testverdau mit den Enzymen BamHI und Notl angesetzt. Hierzu wurde FD Green Buffer zusammen mit FastDigest BamHI und FastDigest Notl (alle von ThermoFisher Scientific, Inc., Rockford, IL, USA) entsprechend Tabelle 8 mit destill. Wasser resuspendiert. Der angesetzte Verdau wurde hiernach für 15 Minuten durch den Heizblock auf $37^{\circ} \mathrm{C}$ erwärmt. Schließlich wurden die Proben auf ein 1\%iges Agarose-Gel geladen und bei $110 \mathrm{~V}$ für 40 Minuten elektrophoretisch aufgetrennt.

Tabelle 8. Reaktionsansatz zum Testverdau

\begin{tabular}{|l|l|}
\hline Reagenzien & Volumen $(\mu \mathrm{l})$ \\
\hline Plasmid-DNA $(500 \mu \mathrm{g} / \mathrm{ml})$ & 1 \\
\hline FastDigest BamHI & 1 \\
\hline FastDigest Notl & 1 \\
\hline $10 x$ FD Green Buffer & 2 \\
\hline
\end{tabular}




\subsubsection{DNA-Isolation}

Die Plasmid-DNA aus den E. coli Zellen wurde mit dem XChange Plasmid Maxi Kit (PeqLab, Erlangen) nach Angaben des Herstellers isoliert. Die Anzucht der Kultur erfolgte hierfür in $150 \mathrm{ml}$ LB-Medium bei $37^{\circ} \mathrm{C}$ und $250 \mathrm{rpm}$ über Nacht. Nach der Isolation wurden die Konzentration und die Reinheit der DNA am Nanodrop Spektralphotometer bestimmt. Die isolierten Plasmide wurden bei $-20^{\circ} \mathrm{C}$ aufbewahrt.

\subsubsection{Kultivierung von HEK293T Zellen}

HEK293T Zellen wurden von Takara Bio (USA) erworben. Es wurden Cellstar T175 Kulturflaschen der Firma Greiner Bio-One $\mathrm{GmbH}$, welche geeignet für die Kultivierung adhärenter Zellen sind, genutzt. Nach dem Auftauen wurden die Zellen in DMEM++ Medium kultiviert und alle 2 Tage gesplittet. Dichte und Morphologie waren ausschlaggebend für die Wahl der genutzten Kulturflasche und Zeitpunkte des Splittings. Hierfür wurden die Zellen durch einmaliges Waschen mit $20 \mathrm{ml}$ PBS und anschließendem Verdau mit $3 \mathrm{ml}$ 1xTrypsin für 5 Minuten im Brutschrank abgelöst. Hiernach wurde der trypsinvermittelte Verdau mit $10 \mathrm{ml}$ DMEM++ gestoppt und die Zellzahl mittels Neubauerkammer ermittelt. Abschließend wurden die Zellen bei einer Konzentration von 0,5 x106 in einer T175-Zellkulturflasche ausgesät.

\subsubsection{Transfektion}

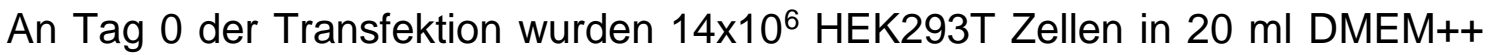
in einer T175-Zellkulturflasche ausgesät. An Tag 1 erfolgte ein Mediumwechsel mit DMEM++ und etwa 4 Stunden danach die Transfektion. Hierbei war die Dichte und Morphologie entscheidend für den Zeitpunkt. Zur Transfektion wurden zwei OPTI-MEM-Lösungen nach dem in Tabelle 9 dargestellten Schema angesetzt und für 20 Minuten bei RT inkubiert. 
Tabelle 9. Ansatz der OPTI-MEM-Lösungen zur Transfektion

\begin{tabular}{|c|c|c|c|}
\hline \multicolumn{2}{|l|}{ Lösung A } & \multicolumn{2}{|l|}{ Lösung B } \\
\hline OPTI-MEM & $2437,9 \mu \mathrm{l}$ & OPTI-MEM & $2359,65 \mu \mathrm{l}$ \\
\hline pSEW-luc2 (1 & $18 \mu \mathrm{l}$ & L-PEI $(1 \mu \mathrm{g} / \mu \mathrm{l})$ & $140,35 \mu \mathrm{l}$ \\
\hline$\mu \mathrm{g} / \mu \mathrm{l})$ & & total & $2500 \mu \mathrm{l}$ \\
\hline $\begin{array}{l}\text { pMD2.VSV-G } \\
\text { (1ug/ } / \mu l)\end{array}$ & $7,7 \mu \mathrm{l}$ & & \\
\hline 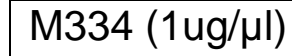 & $14,4 \mu \mathrm{l}$ & & \\
\hline total & $2500 \mu \mathrm{l}$ & & \\
\hline
\end{tabular}

Die Zugabe des Transfektions-Gemischs erfolgte möglichst gleichmäßig auf der Mediumoberfläche, um eine gute Verteilung der Plasmide zu gewährleisten. 12 Stunden nach der Transfektion erfolgte ein Austausch des Mediums. Diesmal wurden $15 \mathrm{ml}$ DMEM++ hinzugegeben. 24 Stunden nach diesem Mediumwechsel erfolgte die Virusernte.

\subsubsection{Aufkonzentrierung der Viruspartikel}

24 Stunden nach der Transfektion wurde das Zellmedium in $50 \mathrm{ml}$ Falcons überführt und anschließend für 5 Minuten bei $400 \mathrm{~g}$ zentrifugiert. Der Überstand wurde daraufhin in sterile Ultrazentrifugationsröhrchen überführt. Anschließend wurde der Virus-haltige Überstand mit $5 \mathrm{ml}$ 20\%iger Saccharose-Lösung unterschichtet, sodass eine klare Phasentrennung sichtbar wurde. Nach finalem Austarieren unter sterilen Bedingungen mit DMEM++ Medium, wurden die Röhrchen für 2 Stunden (20000 g und $4^{\circ} \mathrm{C}$ ) zentrifugiert. Schließlich wurde der Überstand verworfen und die Röhrchen für 10 Minuten getrocknet. Das VirusPellet wurde daraufhin in $200 \mu \mathrm{lRPMI+++}$ pro Zentrifugenröhrchen, möglichst ohne die Bildung von Luftblasen, resuspendiert und aus allen Röhrchen zusammengeführt und bei $-80^{\circ} \mathrm{C}$ bis zur Verwendung gelagert.

\subsubsection{Transduktion}

Mit dem Pan $\mathrm{T}$ Cell Kit aufgereinigte NOD-T-Zellen wurden in einer

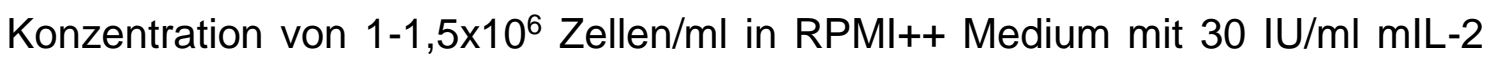
kultiviert. Am Tag der Gewinnung der T-Zellen wurden zudem CD3/CD28 
Dynabeads in einem Verhältnis von 1:1 nach Herstellerangaben für 3 Tage dazugegeben. An Tag 3 wurden diese magnetisch entfernt. Anschließend wurde die Zellsuspension mit Protaminsulfat in einer Endkonzentration von $4 \mathrm{ug} / \mathrm{ml}$ versetzt. Es wurden verschiedene Volumina des produzierten Virus zur Titrierung dazugegeben. 24 Stunden nach Zugabe des Virus erfolgte ein Mediumwechsel mit RPMI++ und $30 \mathrm{IU} / \mathrm{ml} \mathrm{mlL}-2$. 48 Stunden später erfolgte die FACS-Analyse wie unter 2.2.2.1 beschrieben.

\subsubsection{Datenanalyse und Software}

Die erhobenen Daten wurden mit Microsoft Excel verarbeitet und ausgewertet. Zur Berechnung statistischer Signifikanzen und zur Erstellung der Abbildungen wurde Graphpad Prism 5.0.1 (San Diego, CA, USA) verwendet. Zur Unterscheidung von zwei Wertepaaren wurde der Student t-Test genutzt. Inzidenzkurven wurden mit Hilfe des Log-rank (Mantel-Cox) Tests ausgewertet. Zur Erstellung von Schemata wurde Powerpoint und zum Layout der Arbeit wurde Word verwendet (Windows 10.0 mit Office 13.2; Microsoft, Redmont, WA, USA). Die Erstellung des Literaturverzeichnisses erfolgte mit Reference Manager 12 (Clarivate, Philadelphia, PA, USA).

\section{Ergebnisse}

\subsection{Primärprävention}

Die NOD.a4-/- Maus wurde durch unabhängige Züchtung von jeweils $\alpha 4 f / f$ und Tek-cre Mäusen mit NOD Mäusen über 10 Generationen generiert. Die a4Expression in a4-/- Leukozyten ist bis auf eine minimale Restaktivität ablatiert, wobei andere Genotypen ( $\alpha 4 \mathrm{f} /+$ oder $\alpha 4+/+. c r e+$, als auch cre-negative Nachkommen, zusammenfassend als "NOD Mäuse" bezeichnet) qualitativ und quantitativ identisch im Hinblick auf ihre a4-Expression sind (nicht gezeigt). 12 NOD.a4-/- und 19 NOD Weibchen wurden über 40 Wochen durch wöchentliche Blutzucker-Messungen auf die Entwicklung von Typ 1 Diabetes untersucht. Während die 19 NOD Mäuse mit der erwarteten Frequenz Diabetes entwickelten (84\% nach 40 Wochen bei typischer Kinetik), erkrankte keine der 
12 NOD.a4-/- Mäuse innerhalb des Beobachtungszeitraums $(p<0,0001)$. Diese Daten korroborieren die Beobachtungen von Frau Dr.med. Sarah K. Wegner.

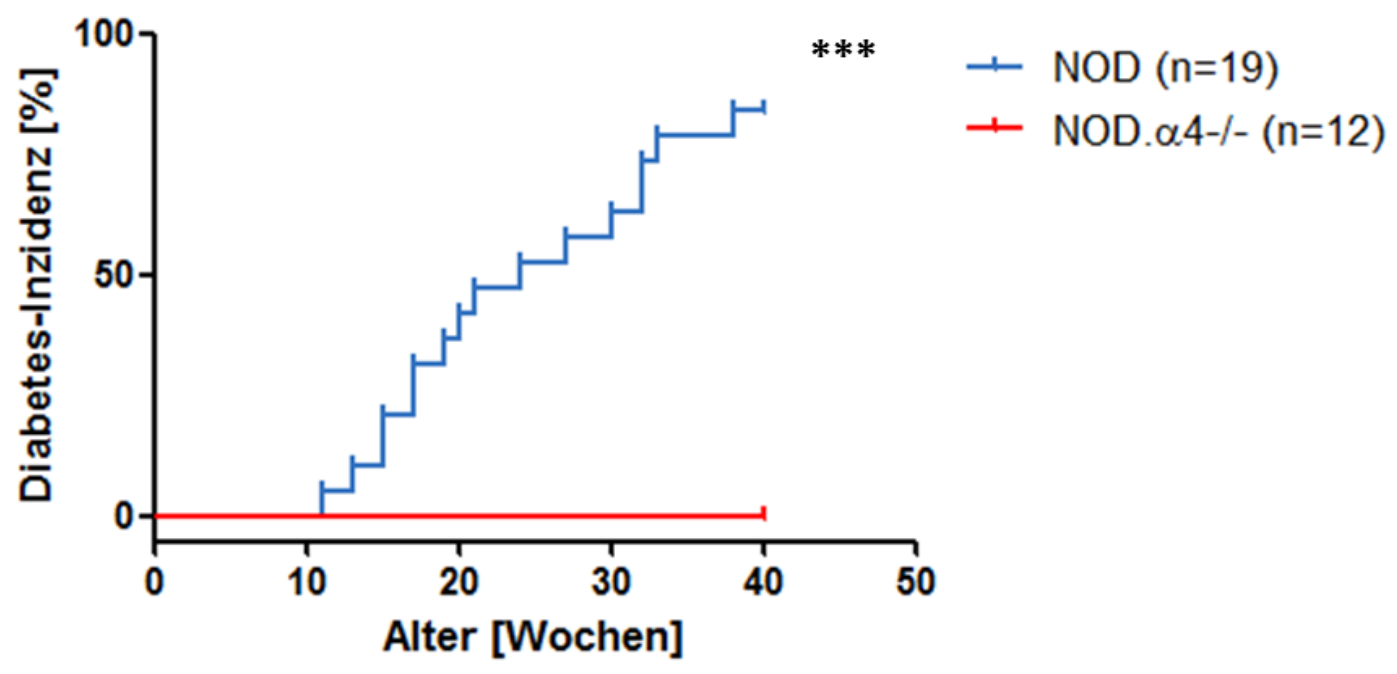

Abbildung 12 T1D-Primärprävention. Diabetes-Prävalenz a4-kompetenter weiblicher NOD Mäuse $(n=19)$ und weiblicher NOD.a4-/- Mäuse $(n=12) .84 \%$ der NOD aber keines der NOD.a4-/- Weibchen entwickelte eine diabetische Stoffwechsellage innerhalb der ersten 40 Lebenswochen. $(p<0,0001)$

\subsection{Sialitis-Histologie}

Die NOD Maus zeigt mit altersabhängig zunehmender Prävalenz und Ausprägung lymphozytäre Infiltrationen in mehreren drüsigen Organen, unter anderem in Pankreas, Kolon und Speicheldrüsen. ${ }^{40}$ Zur Untersuchung der Auswirkungen der embryonalen a4-Ablation in hämatopoetischen Zellen auf die bekannten Speicheldrüsen-Infiltrate der NOD Maus wurden die Gl. submandibulares von 20 Wochen alten NOD $(n=5)$ und NOD.a4-/- $(n=6)$ Mäusen, einem Zeitpunkt, an dem gemäß der Literaturlage die zahlreichen Infiltrate histologisch schon nachweisbar und funktionelle Beeinträchtigungen im Sinne eines Sicca-Syndroms schon nachzuweisen sein sollten, histologisch untersucht. 62 


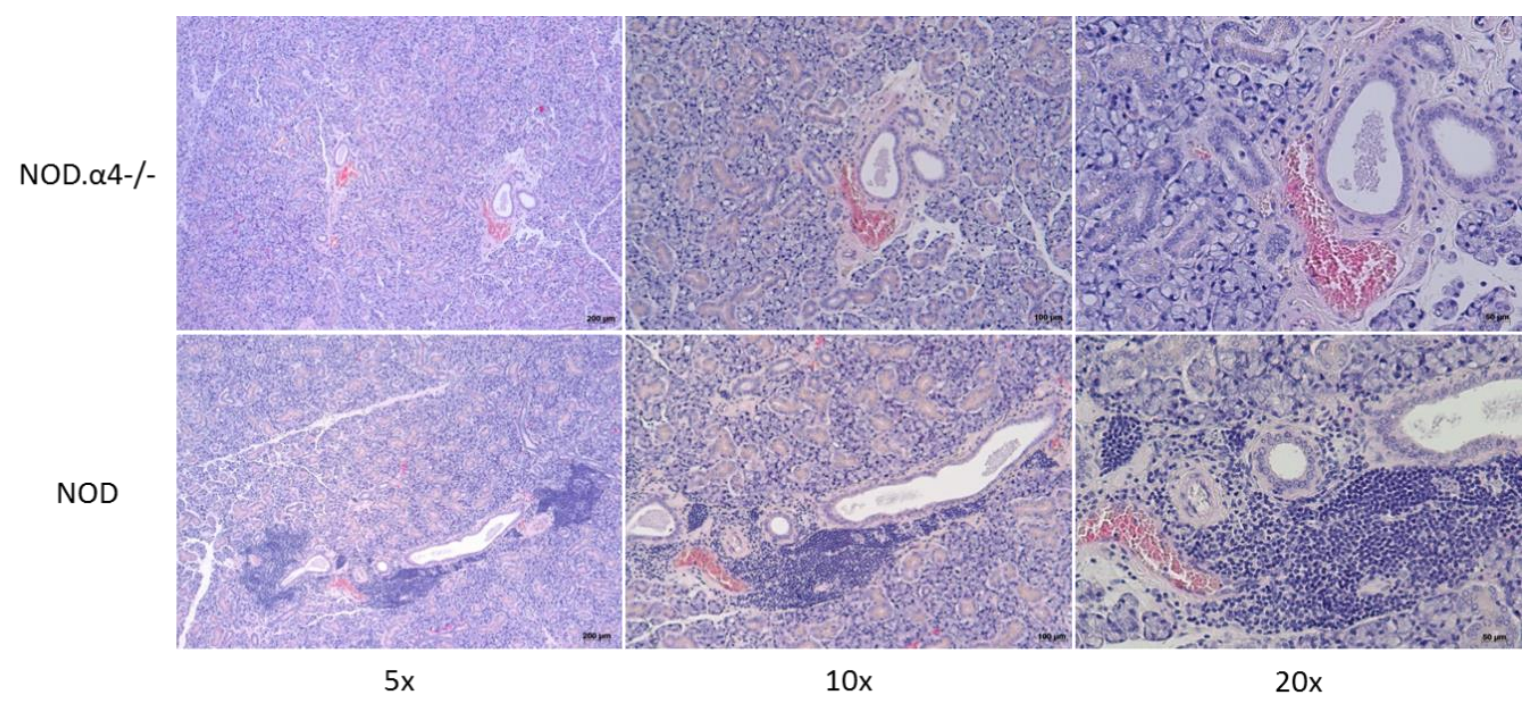

Abbildung 13. Sialitis-Histologie. Exemplarische Darstellung histologischer Schnitte mit HEFärbung der Gl. submandibularis von je einer 20 Wochen alten NOD (untere Zeile) und NOD.a4-/- (oben) Maus in verschiedenen mikroskopischen Vergrößerungen (v.l.n.r. 5x,10x, 20x). Während die Gl. submandibularis der NOD-Maus charakteristische lymphozytäre Infiltrate und eine zum Teil vollständig zerstörte seröse Acinusstruktur unter Erhalt der Ductuli aufweist, ist die Drüse der NOD.a4-/- Mäuse frei von Infiltraten und histologisch gänzlich unauffällig.

Pro Maus wurden 10 nicht-serielle Schnitte der Gl. submandibularis hergestellt, angefärbt und histologisch analysiert. Nach Zählung der Infiltrate im serösen Drüsengewebe ergibt sich eine mittlere Summe von $19 \pm 1$ Infiltraten pro histologischem Schnitt der Gl. submandibularis in den 6 untersuchten NOD Mäusen, während in keiner der 5 untersuchten NOD.a4-/- Mäuse ein Infiltrat vorhanden ist (s. Abb. 3, p<0,0001). 


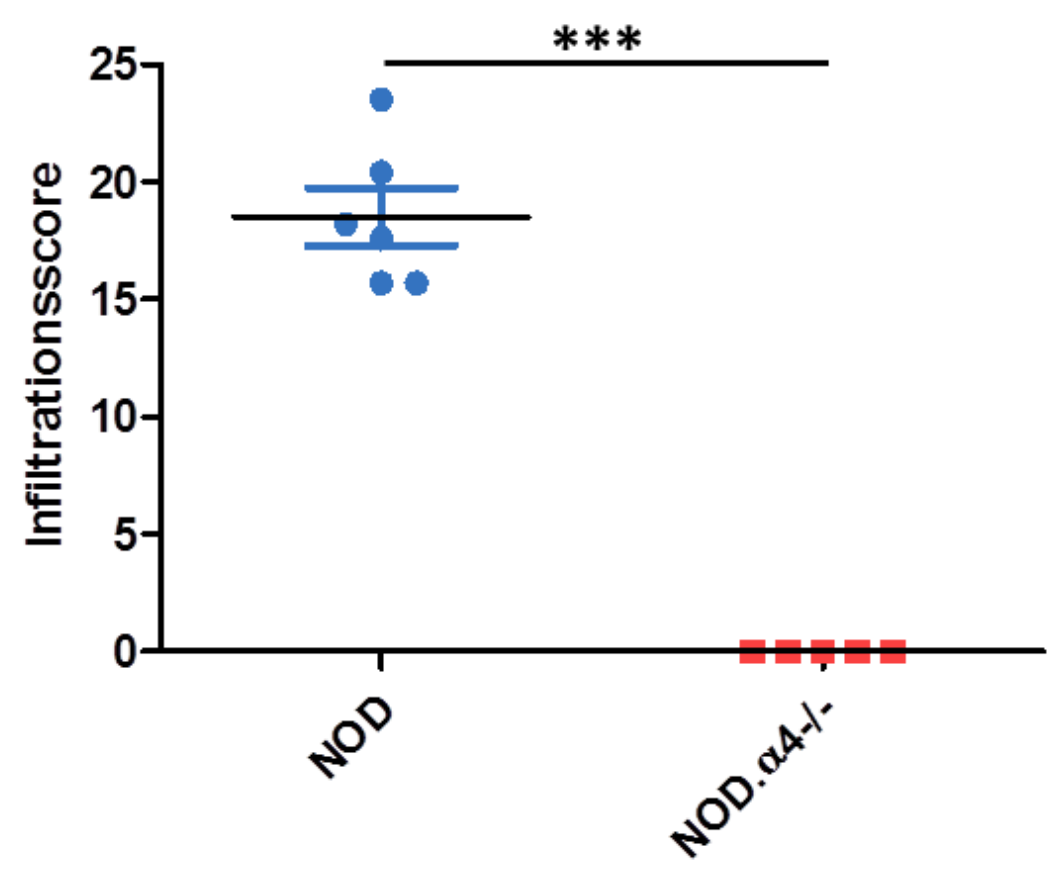

Abbildung 14. Sialitis-Primärprävention. Infiltrationsscore (Mittlere Anzahl an Leukozyteninfiltraten pro histologischem Schnitt. Für jede Gl. submandibularis wurden 10 nichtserielle histologische Schnitte auf Leukozyteninfiltrate untersucht) in a4-kompetenten weiblichen NOD $(n=6)$ und weiblichen NOD.a4-/- $(n=5)$ Mäusen. Alle NOD aber keine der NOD.a4-/Mäuse entwickelte eine Sialitis. Die Versuchstiere waren zum Untersuchungszeitpunkt 24 Wochen alt $(p<0,0001)$.

\subsection{Mikrobiom}

Jüngst konnte gezeigt werden, dass an T1D erkrankte Kinder eine veränderte Darmflora besitzen, ohne jedoch einen kausalen Zusammenhang aufzeigen zu können. ${ }^{76}$ Hier steht vor allem die Frage im Raum, ob ein verändertes Mikrobiom T1D auslöst und/oder ob die diabetische Stoffwechsellage und durch diese bedingte Veränderungen des Stuhls möglicherweise eine (De-)Selektion bestimmter Bakterien bewirkt. Um diese Frage zu beantworten, ließen wir 8-12 Wochen alte gesunde NOD $(n=5)$ und Diabetes-resistente NOD.a4-/- Weibchen $(n=5)$ zusammen mit diabetischen NOD Mäusen $(n=9)$ in gemischten Käfigen leben. Die Mikrobiom-Analysen einschließlich der Bioinformatik wurden durch unsere Kooperationspartner im UC Davis MMPC Microbiome and Host Response Core durchgeführt. Abbildung 15 zeigt die deutlich eingeschränkte alpha-Diversität des Mikrobioms (Abb. 15.A) als auch eine deutlich veränderte B-Diversität der diabetischen NOD Maus (Bray-Curtis und Jaccard Methode, nicht gezeigt) im Vergleich zu den prädiabetischen a4-kompetenten und 
diabetes-resistenten a4-defizienten Mäusen welche wiederum eine sehr ähnliche alpha- und beta-Diversität zeigen.
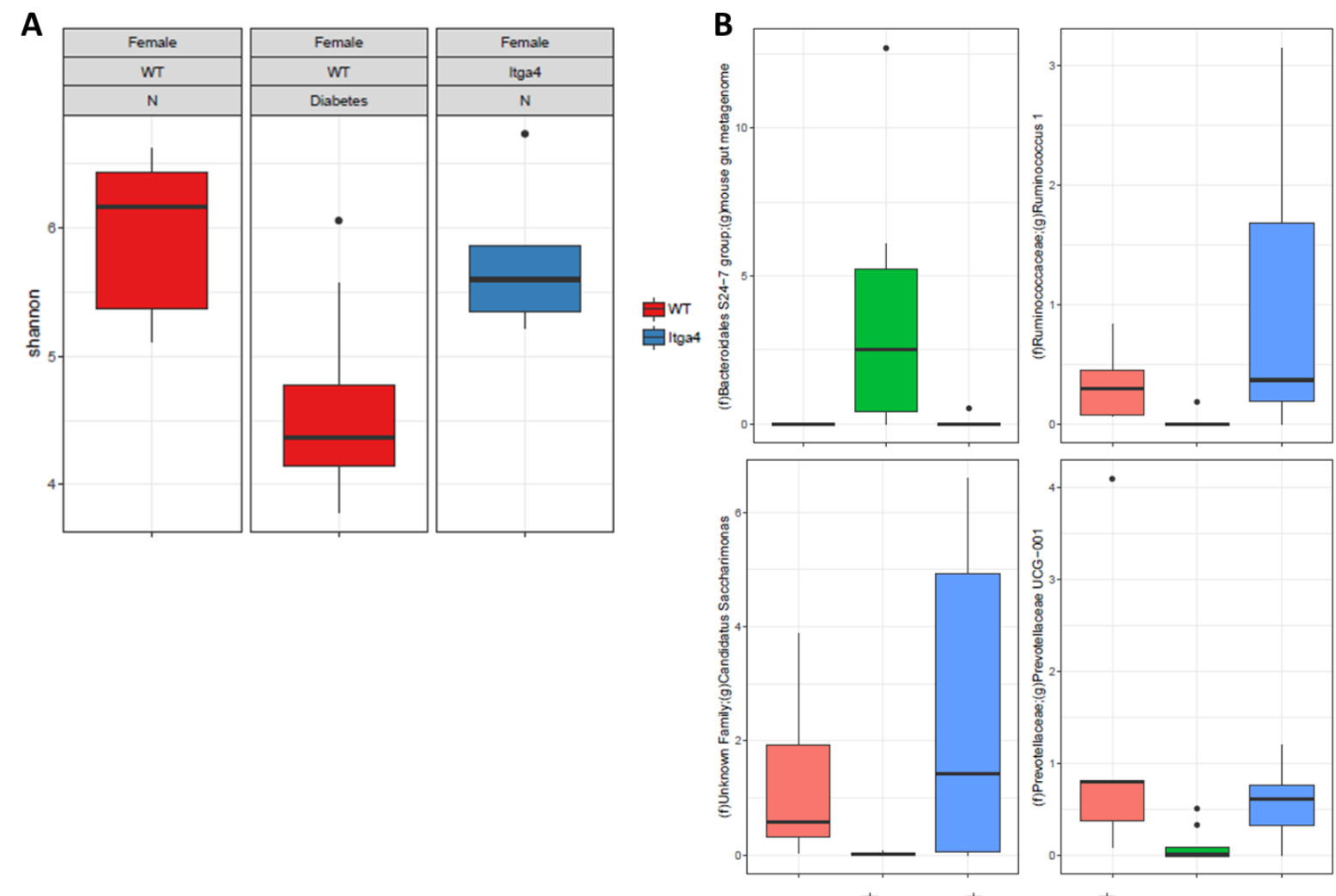

Abbildung 15 Mikrobiom-Analyse in nicht-diabetischen und diabetischen a4kompetenten NOD sowie in Diabetes-resistenten NOD. a4-/- Mäusen. A: Shannon-Index der alpha-Diversität je nach Genotyp und Erkrankung zeigt ein vergleichsweise eingeschränktes Mikrobiom in der diabetischen NOD Maus. B: Analyse der Abundanz verschiedener Taxa zeigt das Erscheinen von Bacteroides und den fast vollständigen Verlust von Ruminococci, Candidatus Saccharimonas und Prevotellaceae in der diabetischen NOD Maus.

Auffällig ist außerdem die in Abbildung 15B gezeigte Nachweisbarkeit von Bacteroides im Mikrobiom der diabetischen NOD-Kohorte, einem Bakterium, welches im Mikrobiom der gesunden Kohorten völlig abwesend ist. Andererseits sind die Taxa Ruminococci, Candidatus Saccharimonas und Prevotellaceae, welche in unseren gesunden a4-kompetenten und a4-defizenten Kohorten konsistent vorhanden sind, völlig ausgelöscht. Weder wird die physiologische, möglicherweise „schützende“ Flora auf die diabetischen Mäuse noch die möglicherweise „ansteckende“ Flora der diabetischen Mäuse auf die nichtdiabetischen Mäuse übertragen, was eine umgekehrte Kausalität impliziert, der zufolge die diabetische Stoffwechsellage (mutmaßlich indirekt) die Mikrobiota im Darm verändert. 


\subsection{Analyse des zellulären Immunsystems der NOD.a4-/- Maus}

Der Typ 1 Diabetes ist eine primär T-Zell vermittelte Erkrankung. ${ }^{41}$ Diese Erkenntnis rührt initial daher, dass ein adoptiver T-Zell Transfer Diabetes in murinen Empfängern auslösen kann. Trotz des gewonnenen Wissens über die Rolle von B-Zellen und Makrophagen in der Pathogenese des Typ 1 Diabetes bleibt das Hauptaugenmerk auf die Interaktion von T-Zellen gegenüber Inselzellantigenen gerichtet. Unsere Daten (Anwesenheit von Antikörpern in der NOD.a4-/- Maus, wenn auch quantitativ weniger, reicht nicht aus, um eine Insulitis oder Diabetes auszulösen; Transfer von CD3+ Zellen alleine reicht aus um Diabetes in NOD.a4-/- Empfängern auszulösen; Abwesenheit von endogenen a4-inkompetenten Makrophagen in den Pankreata der T-Zell Transfer-Empfänger) beschreiben eine exklusive Rolle der T-Zellen für die Diabetes Entstehung. In den letzten Jahren konnten immer genauere Aussagen über Sensibilisierung, Expansion und Epitope-Spreading von Inselzellantigenspezifischen T-Zellen lange vor dem Auftreten erster Blutzucker-Entgleisungen getroffen werden. ${ }^{74 ; 77 ; 78}$ Um die Auswirkungen der embryonalen a4-Ablation auf hämatopoetischen Zellen in der NOD Maus zu untersuchen, wurden durchflusszytometrische Analysen von T-Zell-Subtypen in verschiedenen hämatopoetischen Kompartimenten, von autoreaktiven zytotoxischen T-Zellen und T-Helfer-Zellen als auch von intrazellulärem IFNy nach in vitro Stimulation mit IGRP, einem für die zelluläre Autoimmunität (sowohl CD8+ als auch CD4+ vermittelt) kritischen inselzellspezifischen Antigen, durchgeführt. Schließlich wurde überprüft, ob die per se vor Diabetes geschützte NOD.a4-/- Maus nach adoptivem CD3+ als auch nach CD4+ T-Zell Transfer von diabetischen Spendern erkrankt. Im Falle des CD3+ T-Zell Transfers erfolgte zusätzlich ein ex vivo Biolumineszenz-Imaging in der Absicht, die Migration der T-Zellen in ausgewählte Gewebe zu untersuchen.

\subsubsection{T-Zell-Subtypen}

Im Mausmodell können sowohl CD4+ als auch CD8+ T-Zellen basierend auf ihre Expression von Oberflächenproteinen in Effektor, Gedächtnis als auch naive Zellen unterteilt werden. Naive T Zellen exprimieren vermehrt CD62L und 
kaum CD44 auf ihrer Oberfläche, während Gedächtnis T-Zellen hohe Level CD44 und kaum CD62L exprimieren. Effektor $\mathrm{T}$ Zellen exprimieren wie Gedächtnis T-Zellen kaum CD62L und gleichzeitig weniger CD44 (CD44 dim).

Das in Abbildung 3.5. dargestellte Gating zeigt die durchflusszytometrische Analyse von NOD Splenozyten beispielhaft analog der Arbeiten von Barclay und Janeway. ${ }^{79 ; 80}$

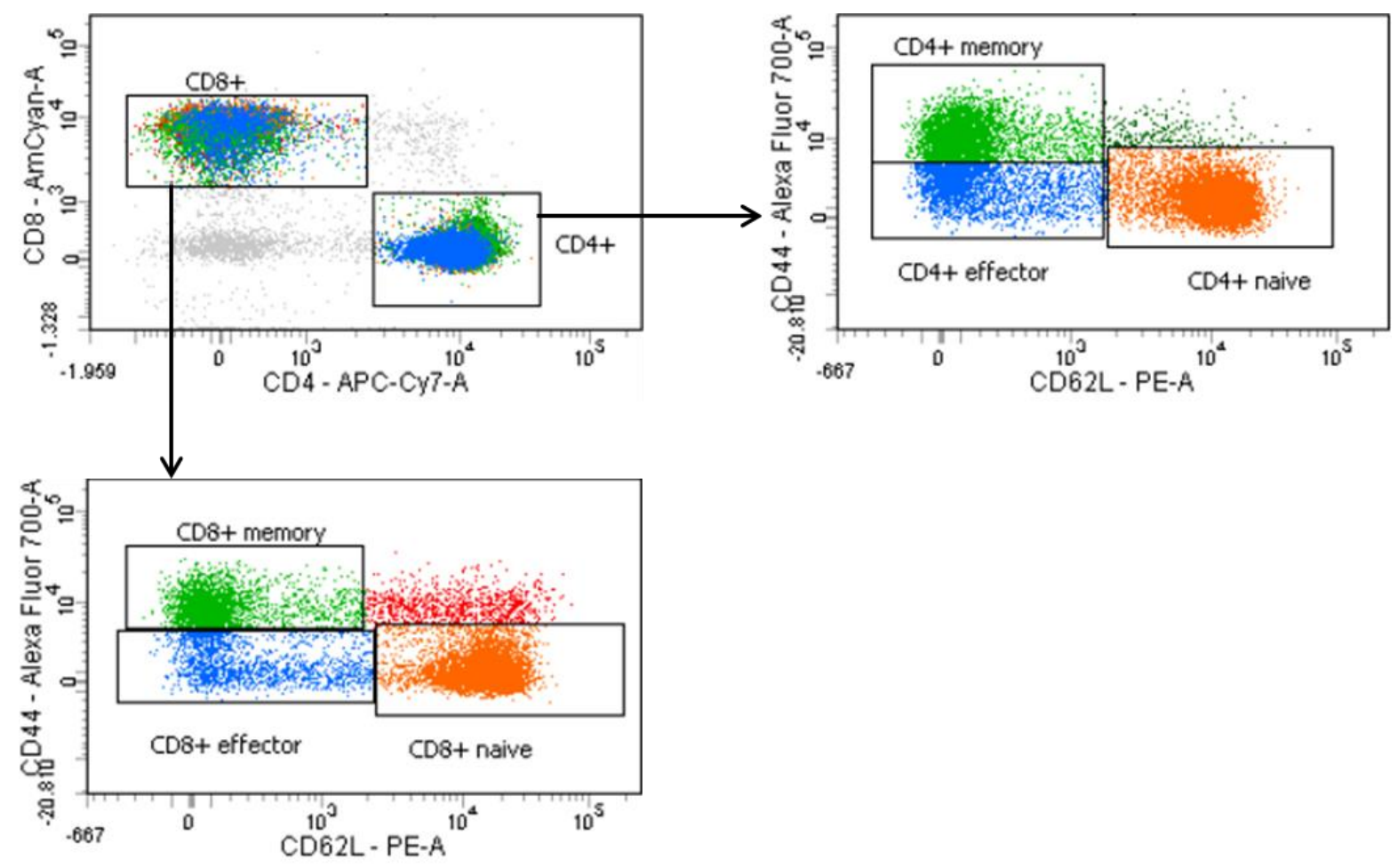

Abbildung 16. Gating-Strategie für T-Zell-Subtypenanalyse. Nach initialem morphologischem Gating und Doubletten-Ausschluss erfolgte eine sequentielle Auftrennung in CD45 und CD3. CD3+ Zellen wurden in CD4+ oder CD8+ Zellen unterteilt, welche jeweils auf ihre CD44 und CD62L Expression hin analysiert wurden. Gedächtnis T-Zellen wurden als CD44high und CD62low, naive T-Zellen als CD62L high und CD44low und Effektor T-Zellen als CD44dim und CD62low erkannt.

In der Betrachtung der Gesamtheit von CD3+ Zellen an Leukozyten zeigt sich im Peripherblut eine geringfügig verminderte Frequenz von $47,1 \pm 2,8 \%$ in der untersuchten NOD.a4-/- Maus im Vergleich zu den NOD Kontrolltieren $(55,1 \pm$ $1,0 \%$ in der NOD Maus; $p=0,04$ ), während die Frequenz an CD3+ Zellen in der Milz keinen Unterschied in beiden Kohorten ergab (s. Abb 17.). In einer zusätzlichen Färbung von CD335 wurde die Frequenz von NK-Zellen an der Gesamtanzahl an Leukozyten in Peripherblut und Milz erfasst, ohne dabei signifikante Unterschiede in Abhängigkeit von der a4 Kompetenz festzustellen (s. Abb. 18). 

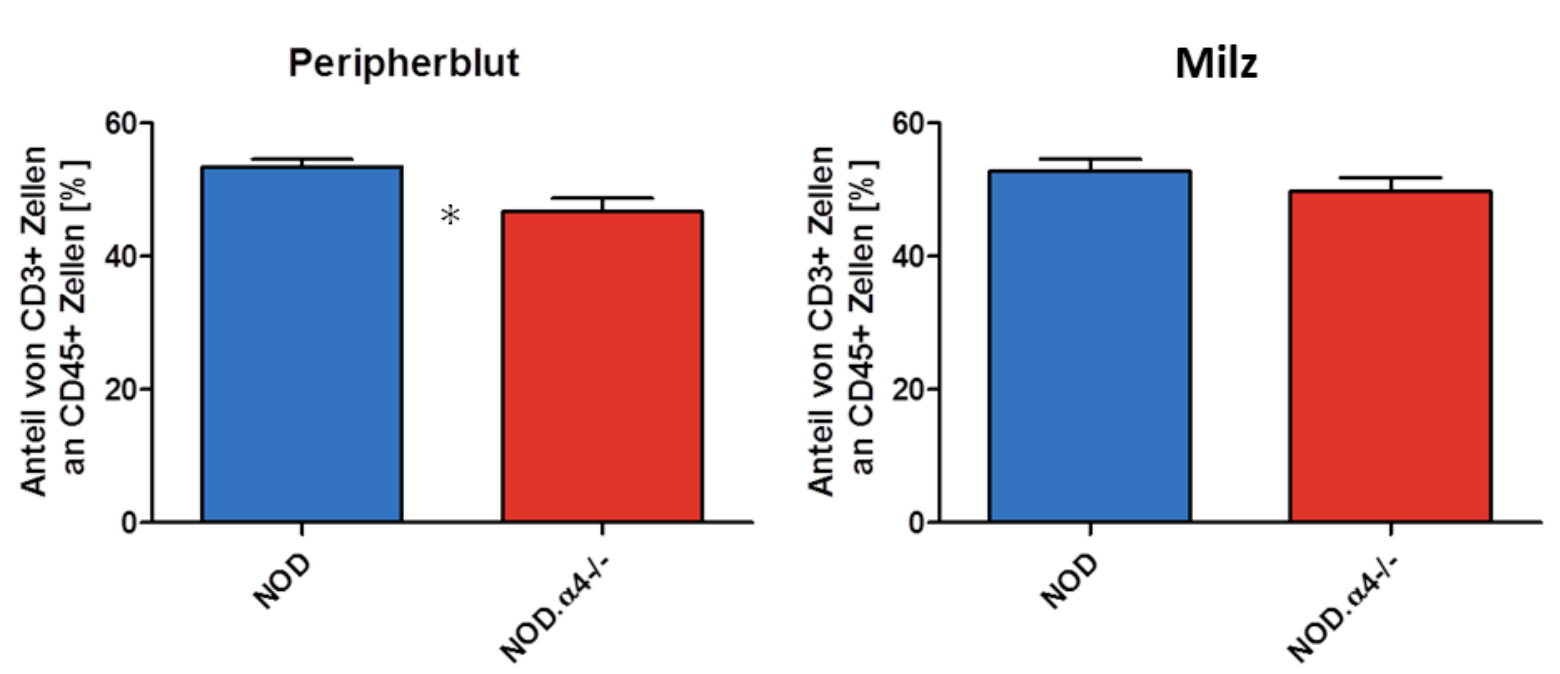

Abbildung 17. Frequenz von CD3+ T-Zellen unter den Leukozyten. Mittlere Frequenz \pm SEM in NOD $(n=4)$ und NOD.a4-/- $(n=5)$. Links ist die Verteilung im Peripherblut, rechts in der Milz dargestellt.
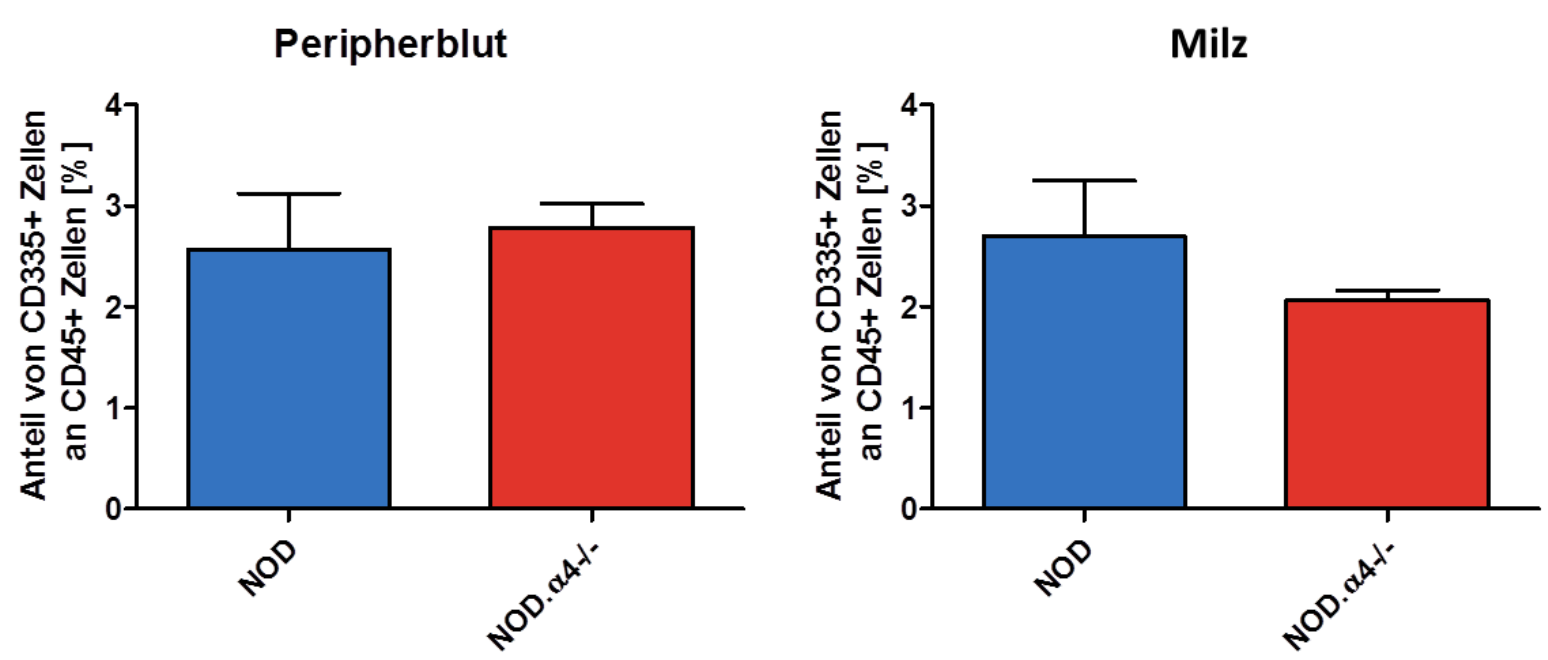

Abbildung 18. Frequenz der NK-Zellen (CD335+) unter den Leukozyten. Mittlere Frequenz \pm SEM in NOD ( $n=4)$ und NOD.a4-/- $(n=5)$. Links ist die Verteilung im Peripherblut, rechts in der Milz dargestellt.

Offensichtliche qualitative Unterschiede im T-Zell-Kompartiment zwischen der NOD und der NOD.a4-/- Maus sind nicht zu erkennen. Bei der quantitativen Betrachtung der Verteilung von CD8+ und CD4+ Zellen innerhalb der CD3+ Population ergibt sich im Peripherblut der NOD.a4-/- Maus eine leicht verminderte Frequenz CD8+ Zellen mit 21,4 $\pm 0,2 \%$ im Vergleich zu 25,9 $\pm 1,7 \%$ in der NOD Maus $(p=0,04)$ zugunsten der Frequenz von CD4+ Zellen mit $75 \% \pm 0,3 \%$ im Vergleich zu $70,9 \pm 1,7 \%$ in der NOD Maus $(p=0,06)$. In den 
Subtypen unter den CD8+ und CD4+ Zellen ergab sich abgesehen von einer erhöhten Frequenz CD4+ Gedächtniszellen mit 22,6 $\pm 1,8 \%$ im Vergleich zu $15,5 \pm 1,9 \%$ in der NOD Maus $(p=0,03)$ keine weiteren statistisch signifikanten Unterschiede. Biologisch signifikante Konsequenzen aus diesen eher geringen quantitativen Unterschieden erscheinen wenig wahrscheinlich.

Bezüglich der Verteilung der T-Zell Subtypen in der Milz zeigt sich ebenfalls eine verminderte Frequenz CD8+ Zellen (20,2 $\pm 0,5 \%$ vs. $26,8 \pm 1,5 \%, p=0,002)$ zugunsten einer erhöhten Frequenz CD4+ Zellen $(75,3 \pm 0,4 \%$ vs. $67,5 \pm 1,4 \%$, p $=0,0005)$. Unter den CD8+Zellen zeigt sich eine deutlich verminderte Frequenz naiver CD8+ Zellen (11,8 $\pm 0,4$ vs. $19 \pm 1,3 \%)$ und eine leicht erhöhte Frequenz CD8+ Effektor Zellen $(4,1 \pm 0,4 \%$ vs. $2,5 \pm 0,5 \%, p=0,03)$. Innerhalb der CD4+ Zellen zeigte sich ebenfalls eine verminderte Fraktion naiver CD4+ Zellen $(34,7 \pm 1 \%$ vs. $39,1 \pm 0,4, p=0,02)$ und eine erhöhte Frequenz an Effektor CD4+ Zellen (24,5 $\pm 0,3$ vs. $14 \pm 1,4 \%, p=0,001)$. Die Unterschiede sind jeweils quantitativ wenig beeindruckend und funktionell mutmaßlich irrelevant.
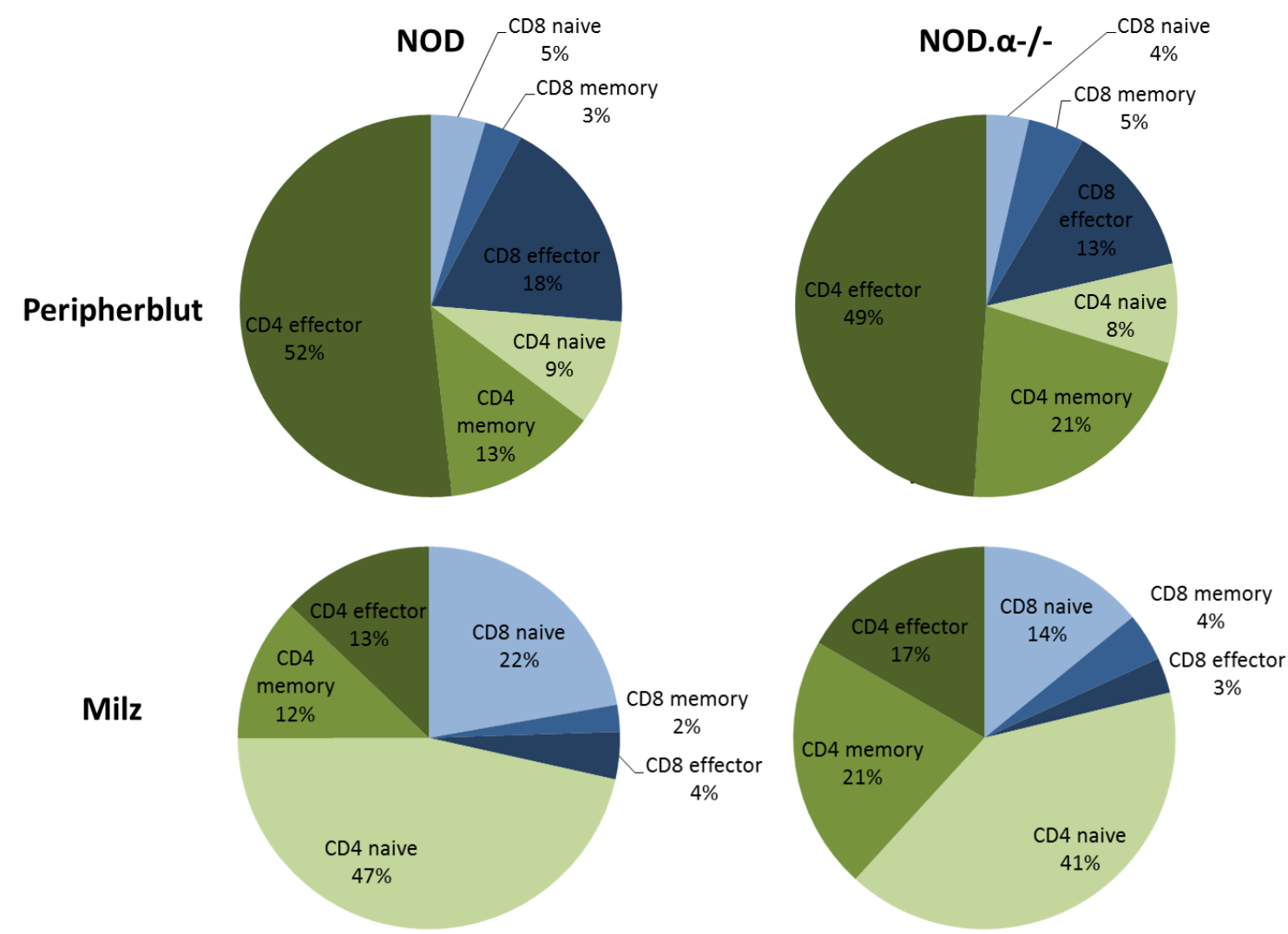

Abbildung 19 Relativer Anteil der T-Zell-Subtypen in NOD (links, $n=4$ ) und NOD.a4-/Mäusen (rechts, $n=5$ ) bezogen auf $\mathbf{C D} 3+T$-Zellen. In der oberen Zeile ist Verteilung im 
Peripherblut, in der unteren Zeile in der Milz dargestellt. Das grüne Kompartiment beinhaltet die verschiedenen CD4+ Populationen, während das blaue Kompartiment die CD8+ Populationen aller CD3+ T-Zellen darstellt. CD4+ und CD8+ Zellen wurden jeweils in naive, Gedächtnis- oder Effektor-Zellen unterteilt. 


\subsubsection{Inselzell-reaktive zytotoxische T-Zellen}

Eine stattgehabte humorale Sensibilisierung lässt sich unschwer durch den Nachweis spezifischer Antikörper auch quantitativ diagnostizieren, wobei die vorherrschende Isotyp-Klasse Aussagen über Zeit und Ort der Sensibilisierung machen kann. Im Gegensatz dazu bleibt der T-Zell-Rezeptor zellständig, ist niedrigaffin (Dissoziationskonstante $50 \mu \mathrm{M}$; 10000-fach schwächer als eine typische Antikörper-Antigen Interaktion) und ist durch seine MHC-Restriktion zusätzlich nur mit MHC-angepassten Spezialreagenzien zu erkennen. ${ }^{81}$ Alternativ kann nach Antigenexposition eine Zytokinfreisetzung (auch auf Einzelzellniveau) gemessen werden, wobei Antigene in ihrer Fähigkeit, proinflammatorische Zytokine zu induzieren, erheblich variieren. Multimerisierte Peptid (Antigen)-MHC-Komplexe zum Nachweis Antigen-spezifischer T-Zellen, insbesondere Klasse II-Reagenzien, wurden erst kürzlich verfügbar und so konnte die Rolle des a4-Integrins für die Sensibilisierung oder die antigenabhängige Expansion und Gewebeinfiltration bisher noch nicht untersucht werden. ${ }^{73}$ 


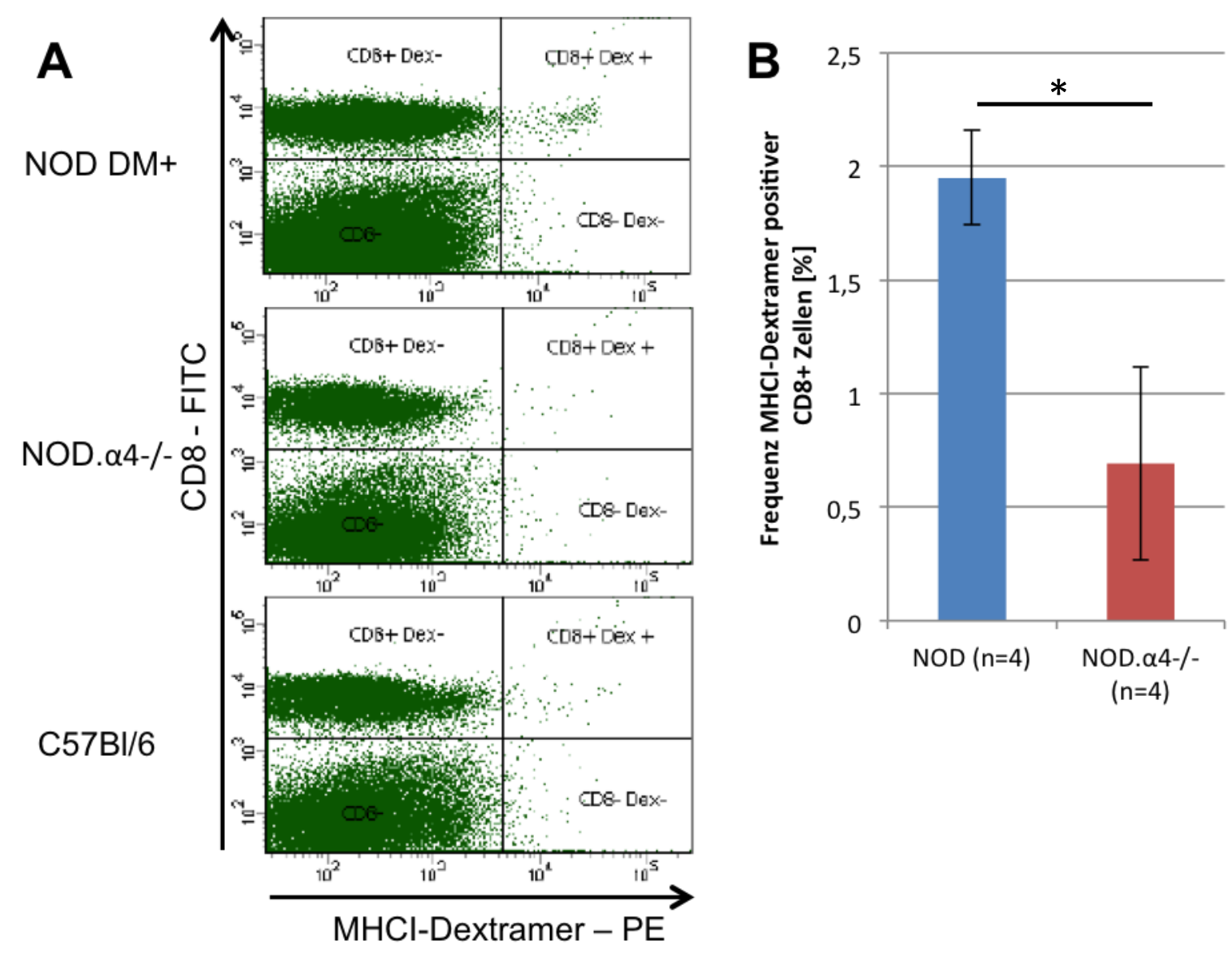

Abbildung 20 Detektion inselzellreaktiver zytotoxischer T-Zellen. A: Exemplarische FACSAnalysen von T-Zellen im Peripherblut, welche mit MHC-I Dextramer H-2Kd/VYLKTNVFL gefärbt wurden. Das MHC-I Reagenz bindet nur an T-Zellen, welche das präsentierte InselzellAntigen erkennen und somit bereits gegen dieses (immundominante und frühe) InselzellAntigen sensibilisiert sind. Von oben nach unten sind Dotplots von je einer diabetischen NOD, einer 40 Wochen alten NODa4-/- und als Negativkontrolle einer MHC-disparaten C57BI/6 Maus dargestellt. B: Frequenz MHC-I Dextramer H-2Kd/VYLKTNVFL positiver zytotoxischer T-Zellen in diabetischen a4-kompetenten NOD und NODa4-/- Weibchen unter allen CD8+ Zellen nach Subtraktion des Mittelwerts der Negativkontrolle (MW \pm SEM $p=0.04$; NOD, NOD.a4-/- und C57BI/6 jeweils $n=4$ ). Inselzellantigen-reaktive T-Zellen werden also in $\alpha 4-/-$ Mäusen induziert, Sensibilisierung ist demnach a4-unabhängig, während die offenbar a4-abhängige Expansion bei den a4-/- Mäusen ausbleibt.

Bei der Detektion autoreaktiver zytotoxischer T-Zellen in der NOD Maus wurde das kommerziell erhältliche MHC-I Dextramer H-2Kd/VYLKTNVFL (einem Epitop der katalytischen Untereinheit der Inselzell-spezifischen Glucose-6Phosphatase, einem kritischen Autoantigen in der Pathogenese des T1D ${ }^{74}$ genutzt, das spezifisch an T-Zell-Rezeptoren bindet, welche das inselzellspezifische Peptid-MHC Dextramer Komplex H-2Kd/VYLKTNVFL erkennen. Hierzu wurden pro Maus etwa 200000 Leukozyten aus dem Peripherblut durchlusszytometrisch analysiert. Neben Blutproben von jeweils 4 NOD und NODa4-/- Mäusen wurden als Negativkontrolle (unspezifische 
Dextramerbindung) ebenfalls 4 MHC-disparate C57BI/6 Mäuse mit dem Reagenz untersucht. Die Färbungen MHC-disparater C57BI/6 Mäuse wurden als biologische Negativkontrollen genutzt und die Frequenz der PE-positiven Ereignisse im $\mathrm{CD} 8+$ wurde von den beiden zu untersuchenden Kohorten subtrahiert. Abbildung 20.A zeigt exemplarische durchflusszytometrische Analysen von Peripherblutleukozyten, die mit anti-CD3, anti-CD8 und dem MHC-I Reagenz gefärbt wurden. CD3+ Zellen wurden gegatet und nach den Kriterien CD8+ (Y-Achse) und MHC I-Reagenz (X-Achse) weiter analysiert. Oben ist die Probe einer bereits an Diabetes erkrankten NOD Maus zu sehen, während darunter Proben einer 40 Wochen alten NOD.a4-/- Maus und einer C57BI/6 Maus abgebildet sind. Nur die diabetische NOD Maus zeigt eine distinkte Population MHC-I Dextramer positiver CD8+ Zellen, aber auch die NOD.a4-/- Maus hat eine kleine Frequenz MHC-I Dextramer-positiver CD8+ Zellen. Abbildung 20.B zeigt die durchschnittliche Frequenz MHC-I Dextramer positiver CD8+ Zellen in der untersuchten NOD $(1,9 \pm 0,2 \%)$ und NODa4-/Kohorte $(0,7 \pm 0,4 \% ; p=0,04)$.

\subsubsection{Inselzell-reaktive T-Helfer-Zellen}

Die Detektion von antigenspezifischen T-Helfer-Zellen stellte sich anfangs im Vergleich zu MHC-I-spezifischen CD8+ Zellen wegen der Molekülstruktur von MHC II als technologisch schwieriger dar. Hier gelang der Durchbruch durch Fixierung der Peptide in einem definierten Register innerhalb des MHC-II Moleküls durch eine Disulfid-Bindung, um das Übergehen in andere, für eine Bindung instabilere Register zu verhindern. ${ }^{81}$ Crawford et al. haben 2011 das Insulin B Peptid (EALYLVCGE) in verschiedenen MHC Bindungsregistern untersucht und konnten dabei erfolgreich T-Helfer Zellen aus den InsulitisInfiltraten der NOD Maus detektieren. ${ }^{73}$ Dieses experimentelle Reagenz wurde uns von der NIH TETRAMER FACILITY (Atlanta, GA) für diese Arbeit zur Detektion gegen Insulin B sensibilisierter autoreaktiver T-Helfer Zellen im Peripherblut zur Verfügung gestellt. Abbildung 3.10.A zeigt exemplarische FACS-Analysen von CD4+ T-Zellen im Peripherblut, welche mit dem angesprochenen MHC-II Tetramer angefärbt sind. Links sind Färbungen mit einem Kontrollpeptid (AMKRHGLDNYRGYSL) im MHC-II Molekül und rechts 
mit dem Insulin B Peptid dargestellt. Oben sind Blutproben von einer 20 Wochen alten NODa4-/- und unten einer gleichaltrigen NOD Maus dargestellt. Abbildung 3.10.B zeigt die durchschnittliche Frequenz der MHC-II Tetramer positiven CD4+ Zellen der NODa4-/- $(1,3 \pm 0,2 \%, n=6)$ und NOD $(0,7 \pm 0,1 \%, n=4)$ Kohorte nach Abzug der Frequenz der Negativkontrolle (irrelevantes Peptid) im Peripherblut an $(p=0,07)$.
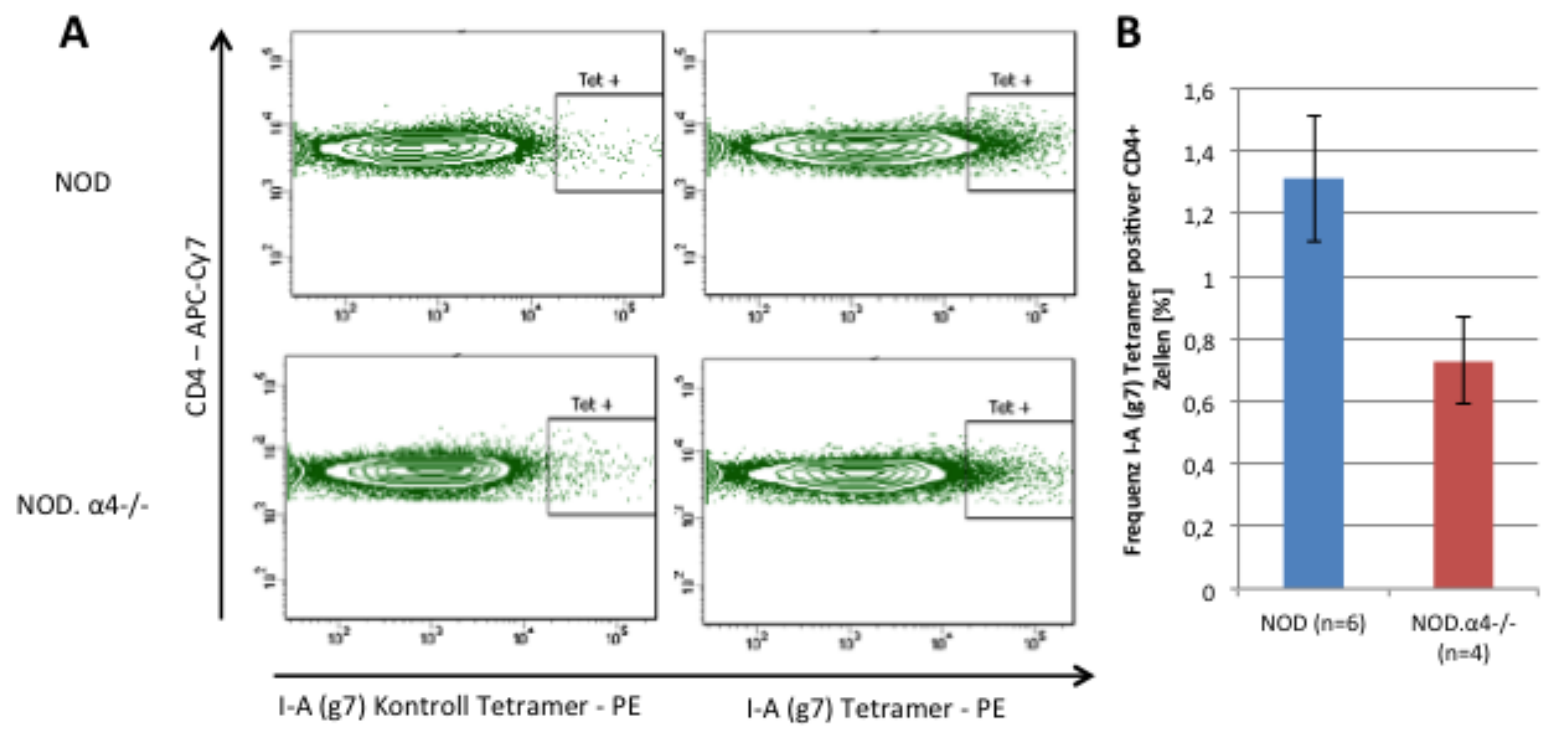

Abbildung 21. Detektion Inselzell-reaktiver T-Helfer-Zellen. A: Exemplarische FACSAnalysen von CD4+ T-Zellen im Peripherblut, welche mit MHC-II Tetramer gefärbt wurden (nach Gaten auf CD3+/CD4+ Zellen). Das MHC-II Reagenz bindet nur an T-Zellen, welche das präsentierte Insulin-Antigen erkennen und somit bereits gegen Insulin sensibilisiert sind. Oben sind Analysen von einem 20 Wochen alten NOD Weibchen und unten von einem ebenfalls 20 Wochen alten NOD.a4-/- Weibchen dargestellt. Links sind MHC-II-Reagenzien gekoppelt mit einem irrelevanten Kontrollpeptid (AMKRHGLDNYRGYSL) und rechts gekoppelt mit dem zu untersuchenden Insulin-B-Peptid (EALYLVCGE) dargestellt. B: Frequenz MHC-II Tetramer positiver T-Helfer-Zellen in 20 Wochen alten NOD und NOD.a4-/- -Weibchen nach Subtraktion der individuellen Kontrollfärbung mit MHC-II Kontroll-Tetramer (MW \pm SEM; $p=0,07 ; n=6$ NOD und $n=5$ NOD $a 4-/-)$.

Nach der Detektion einer erhöhten Frequenz autoreaktiver T-Helfer Zellen wurde, um die phänotypischen Analysen auch funktionell zu korroborieren, ein funktioneller IFNY-Sekretions-Assay durchgeführt, um die IFNY-Sekretion nach Antigenkontakt zu untersuchen. PMA und lonomycin führen über Querverlinkung von Oberflächenproteinen und Blockade von Calciumkanälen zu unspezifischer T-Zell-Aktivierung und damit einhergehender IFNy Sekretion, welche hier als Positivkontrolle eingesetzt wurden. ${ }^{82}$ Hierbei sollte untersucht werden ob NOD Splenozyten und allen voran NOD CD4+ Splenozyten nach Kontakt zu einem inselzellspezifischen Antigen (IGRP) in einer erhöhten 
Frequenz IFNy sezernieren. Hierzu wurden Splenozyten aus Milzen gewonnen und in vitro stimuliert. Daraufhin wurden die Splenozyten fixiert, permeabilisiert und anschließend eine Oberflächenfärbung sowie die intrazelluläre IFNY Färbung angesetzt. Abbildung 22.A zeigt die exemplarische durchflusszytometrische Analyse von CD4+ Splenozyten nach sechsstündiger Exposition zu PMA+ Ionomycin (linke Spalte) oder zu dem inselzellspezfischen Antigen IGRP (rechte Spalte). Oben sind Proben aus der Milz einer NODa4-/und unten einer NOD Maus aufgetragen. Abbildung 22.B zeigt die Frequenz $\mathrm{CD} 4+\mathrm{IFNy}+$ Splenozyten. Zuvor wurden die Frequenzen in den unstimulierten Negativkontrollen von den individuellen $\mathrm{CD} 4+\mathrm{IFN} \gamma+$ Frequenzen subtrahiert. Die allesamt 16 Wochen alten NOD.a4-/- Männchen $(n=5)$ weisen in der Positivkontrolle eine Frequenz von $5,6 \pm 1,3 \%$ und mit dem zu untersuchenden IGRP Peptid eine Frequenz von $3 \pm 1 \%$ an CD4+IFNy+ Zellen auf. Selbige Frequenzen von NOD CD4+IFNy+ Zellen an NOD Splenozyten lagen bei $6,1 \pm 1,2 \%$ und für das zu untersuchende IGRP Peptid bei 1,8 $\pm 0,5 \%(n=7, p=$ $0,5)$ und zeigten somit keine signifikant erhöhte IFNy Sekretion nach Antigenkontakt auf. NOD.a4-/- T-Zellen sind somit sowohl insgesamt ähnlich kompetent, IFNy zu sezernieren wie a4-kompetente NOD T-Zellen, als auch ihre IGRP-Reagibilität ähnlich hoch ist. Der Umstand, dass NOD.a4-/- Mäuse gegen Diabetes gefeit sind, ist also nicht einer T-Helferzell-Anergie zuzuschreiben.
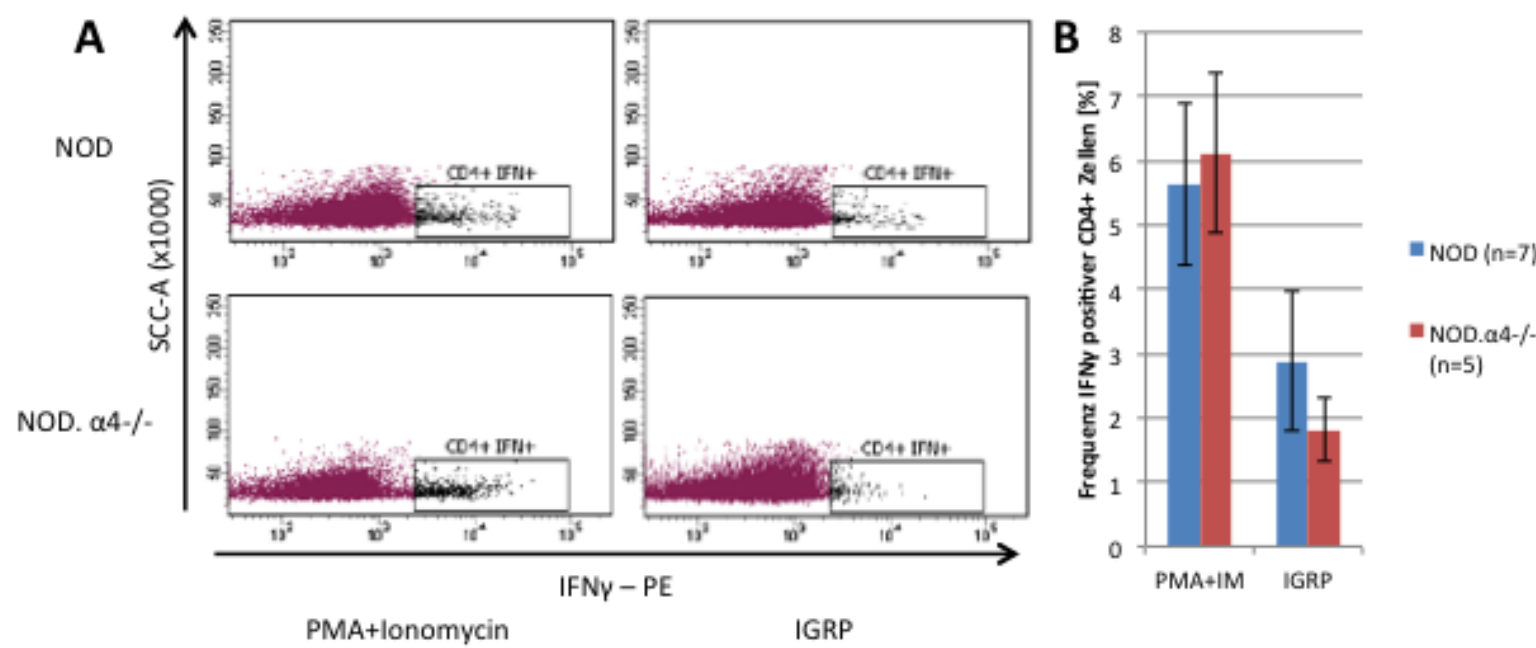

Abbildung 22 Induzierte IFNy-Sekretion von T-Helfer-Zellen. A: Exemplarische FACS Analysen von CD4+ Splenozyten, welche zuvor 6 Stunden in vitro mit PMA und lonomycin als Positivkontrolle oder einem Peptid (VYLKTNVFL) der katalytischen Untereinheit der murinen inselzellspezifischen Glucose-6-Phosphatase inkubiert wurden. Oben sind Analysen von einem 
16 Wochen alten NOD Männchen, unten von einem gleichaltrigen NOD.a4-/- Männchen dargestellt. In der linken Spalte befinden sich die Positivkontrollen und in der rechten die mit inselzellspezifischem Antigen inkubierten Proben (IGRP). B: Frequenz IFNy positiver T-HelferZellen in 16 Wochen alten NOD $(n=7)$ und NOD.a4-/- $(n=5)$ Männchen nach Subtraktion der individuellen Färbung der Negativkontrolle (MW \pm SEM; $p=0,5$ ). 


\subsubsection{Adoptiver CD3+ T-Zell-Transfer}

Wie in Abbildung 12 gezeigt, ist die NOD.a4-/- Maus gegenüber der Entstehung des NOD-charakteristischen Autoimmun-Diabetes gefeit. Auch die von der NOD-Maus abgeleitete, MHC-idente und alle "Diabetes Susceptibility Loci“ tragende, aber wegen Defekten bei der Antigenrezeptor-Rekombination B- und T-Zell-depletierte NOD.scid Maus entwickelt keinen Diabetes. Im Gegensatz zur NOD.scid Maus besitzt die NOD.a4-/- Maus jedoch ein Immunsystem mit grundsätzlich immunkompetenten Lymphozyten. ${ }^{42}$ NOD.scid Mäuse werden nach Transfer von CD4+ und CD8+ Zellen diabetischer NOD Mäuse, nicht aber bei Transfer nur einer der beiden Populationen, mit kurzer, bedingt dosisabhängiger Latenz und hoher Penetranz diabetisch. Um zu überprüfen, ob die NOD.a4-/- Maus ebenfalls in der Lage ist, nach Transfer a4-kompetenter diabetogener T-Zellen einen Typ 1 Diabetes zu entwickeln, wurde ein adoptiver CD3+ T-Zell Transfer, wie in Kapitel 2.2.1.8. beschrieben, durchgeführt. Während zwischen Tag 14 und 20 nach CD3+ T-Zell Transfer alle 4 NOD Empfänger an Diabetes erkrankten, erkrankten alle NOD.a4-/- Mäuse etwa 2 Wochen später zwischen Tag 27 und $34(p=0,02)$.

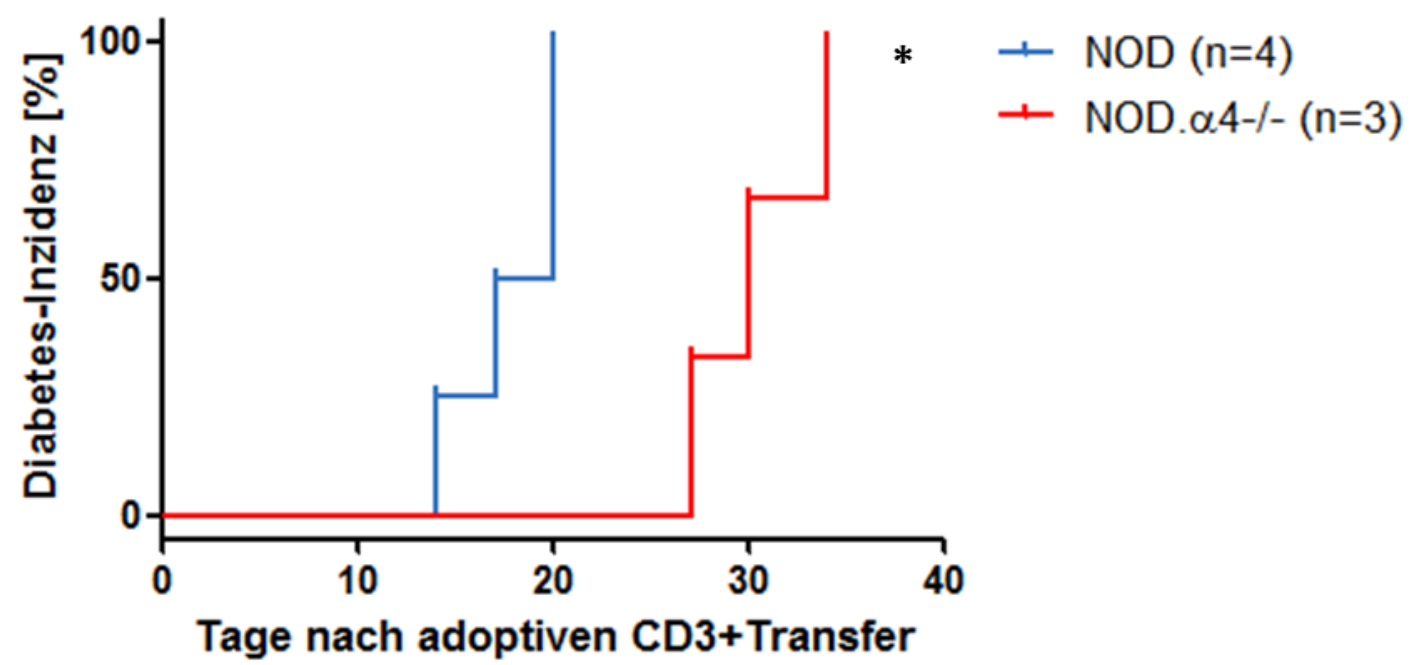

Abbildung 23. Adoptiver CD3+ T-Zell-Transfer. Diabetes-Prävalenz von weiblichen 8-12 Wochen alten NOD (blau, $n=4$ ) und NOD.a4-/- (rot, $n=3$ ) Empfängern. Nach subletaler Bestrahlung der Empfänger mit 6.5 Gy wurden $5 \times 10^{6} \mathrm{CD} 3+$ Splenozyten von diabetischen Spendern transferiert $(p=0,02)$. 
Die a4-Defizienz der T-Zellen der NOD.a4-/- Empfänger erlaubte die einfache durchflusszytometrische Differenzierung von Empfänger- und Spender-T-Zellen nach CD3+ T-Zell Transfer. An Tag 33 nach Transfer von NOD Splenozyten in NOD.a4-/- Mäuse waren 13,6\% der Peripherblut-T-Zellen vom Spendertyp (Abbildung 24). Wie oben gezeigt, sind NOD.a4-/- Pankreata frei von lymphozytären Infiltraten. Um zu untersuchen, ob die adoptiv transferierten diabetogenen NOD T-Zellen im Rahmen der Insel-Infiltration auch a4-/Empfänger-T-Zellen in das entzündete Pankreas rekrutieren können, wurden die Pankreata der 3 inzwischen diabetischen NOD.a4-/- Mäuse an Tag 33 nach Transfer entnommen und verdaut, um die CD3+ T Zellen in den Organen durchflusszytometrisch auf a4 Expression zu untersuchen. Wie in Abb. 24. gezeigt, war trotz des erheblichen Überschusses an a4-/- T-Zellen im Blut keine erkennbare Population von Empfängertyp-T-Zellen aus den Pankreata zu isolieren. Diese Daten belegen einen qualitativen Migrationsdefekt a4-/- TZellen auch in entzündeten Geweben. Nachdem a4-kompetente T-Zellen allein ausreichen, um in NOD.a4-/- einen Diabetes zu induzieren, können wir weiterhin schlussfolgern, dass die Rolle etwaiger anderer Blutzellen (Makrophagen, B-Zellen) bei der Diabetesentstehung a4-unabhängig, wenn nicht sogar vollständig redundant ist.

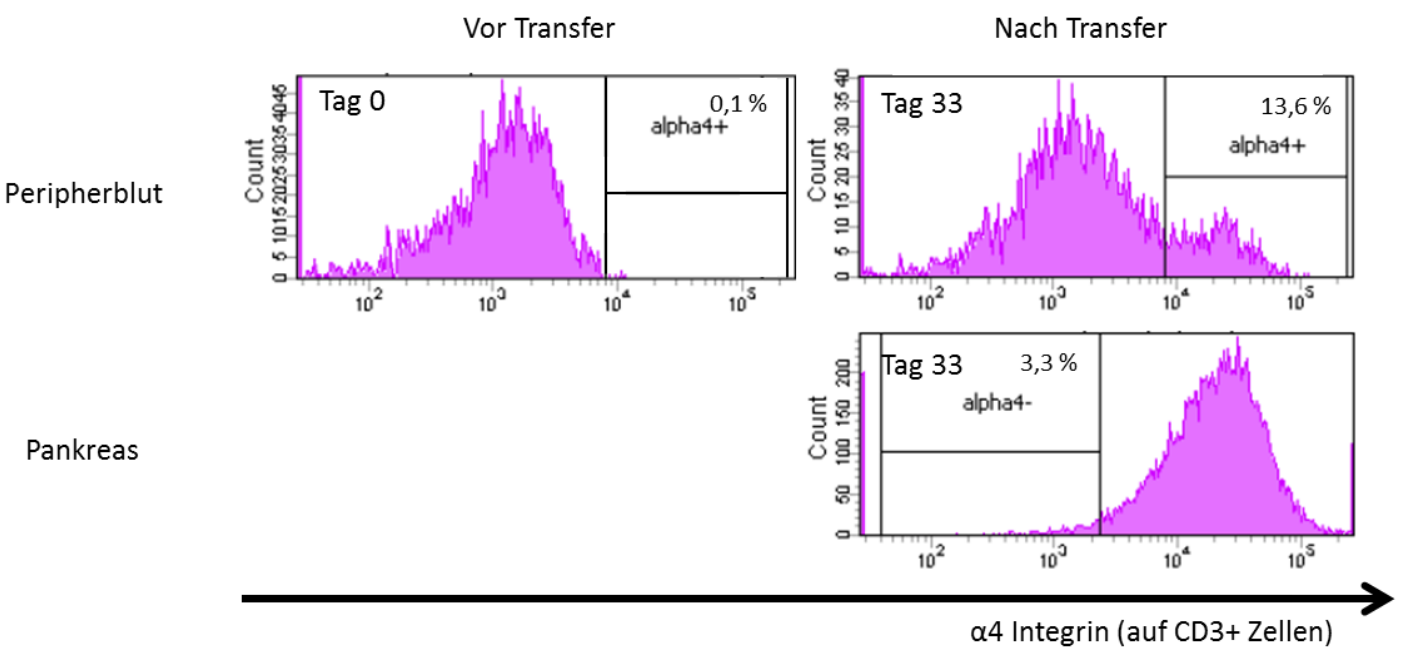

Abbildung 24 a4-Expression von Peripherblut- und Pankreas-infiltrierenden Lymphozyten von NOD.a4-/- Mäusen nach adoptivem CD3+ T-Zell-Transfer diabetischer Spender. Obere Reihe: Vor Transfer (links) vollständig a4-negativ, findet sich einen Monat nach Transfer eine deutliche Population (ca. 13,6\%) a4-positiver Spenderlymphozyten im Peripherblut. Untere Reihe: Aus verdauten Pankreata extrahierte infiltrierende Lymphozyten sind a4-positiv, d.h. ausschließlich vom Spendertyp. (X-Achse: Relative a4Fluoreszenzintensität, Y-Achse: Zahl der Ereignisse. Für die Untersuchungen wurde wegen der 
geringen Gesamt-Lymphozytenzahl, die aus einem Pankreas isoliert werden kann, Probenmaterial von jeweils drei Tieren vereinigt (ein Experiment).

\subsubsection{Ex vivo Luminographie nach adoptivem CD3+ T-Zell-Transfer}

Nachdem sich im adoptiven CD3+ T-Zell Transfer ein signifikanter Unterschied in der Kinetik der Diabetes-Prävalenz zeigte, sollte untersucht werden, ob auch eine verlangsamte Migration der a4-kompetenten CD3+ T-Zellen in die Zielorgane Pankreas und Gl. submandibularis in der NOD.a4-/- Maus nachgewiesen werden kann. Aufgrund der Tatsache, dass in der NOD.a4-/Maus keine Insulitis nachgewiesen werden kann, erscheint es wahrscheinlich, dass transferierte CD3+ T-Zellen schneller in die entzündlich veränderten Langerhans-Inseln der NOD Kontrollgruppe migrieren als in die gesunden Langerhans-Inseln der NOD.a4-/- Maus.

Zur Detektion der CD3+ T-Zellen wurde eine ex vivo Luminographie nach CD3+ T-Zell Transfer durchgeführt. Hierzu musste eine möglichst hohe Frequenz an mit Luciferase transduzierten CD3+ T-Zellen generiert werden. Zu diesem Zweck wurde ein Luciferase/GFP Vektor, welcher uns freundlicherweise von Prof. Buchholz (Paul-Ehrlich-Institut, Langen) zur Verfügung gestellt wurde, verwendet. ${ }^{75}$ Abbildung 25 zeigt die Generierung einer zu 52\% positiven CD3+GFP+ Population nach Transduktion mit dem pSEW-luc2 Vektor. Diese Zellen wurden durch Zellsortierung am FACSAria II zu einer homogen GFP+ (und somit Luciferase+) Population angereichert.

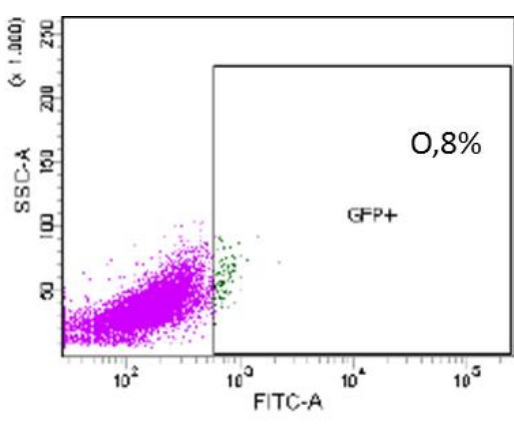

Negativkontrolle

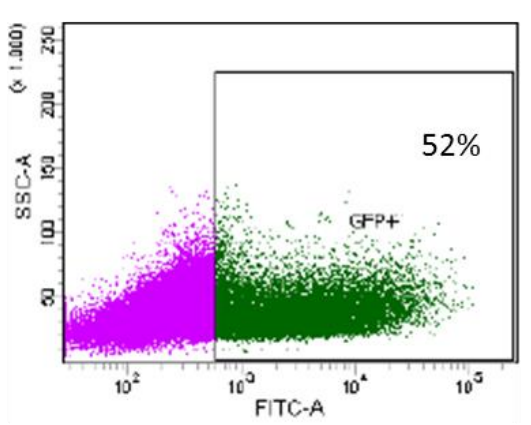

Transduktion mit Luciferase/GFP-Vektor

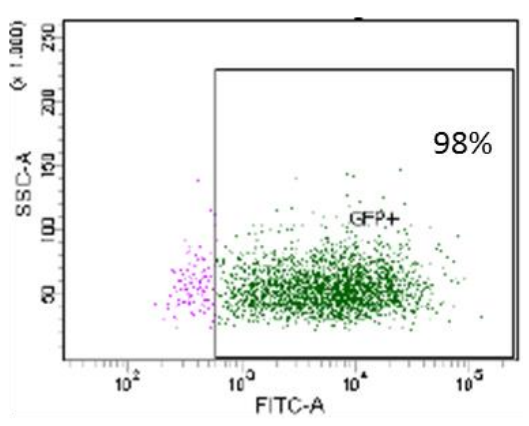

Nach Zellsortierung an FACSAria II

Abbildung 25. FACS-Analysen von Splenozyten vor und nach lentiviraler Transduktion mit dem pSEW-lucs2 Vektor und nach FACS-basierter Zellsortierung. 
CD3+GFP+ Zellen wurden in einer Dosis von $1 \times 10^{6}$ Zellen in jeweils 3 weibliche 8-12 Wochen alte subletal (6.5 Gy) bestrahlte NOD und NOD.a4-/- Empfänger transferiert. Nach Diabetes-Diagnose einer NOD Maus an Tag 16 erfolgte die schmerzlose Tötung dieser NOD und einer NOD.a4-/- Maus, sowie eines weiteren NOD Empfängers als Negativkontrolle (Ex vivo Luminographie ohne Luciferin Injektion) und an Tag 35 eine weitere schmerzlose Tötung von je einer weiteren NOD.a4-/- bzw. NOD Maus, beide zu diesem Zeitpunkt nichtdiabetisch. Abbildung 26A zeigt die ex vivo Luminographie 40 Minuten nach Luciferin-Gabe, anschließender schmerzloser Tötung und Organentnahme.

Trotz der Tatsache, dass es sich hierbei um einen Pilotversuch handelt und keine statistische Auswertung möglich ist, fällt auf, dass die höchste Zelldichte in den Gl. submandibularis der a4-kompetenten, diabetischen NOD Maus an Tag 16 nachgewiesen werden kann. Dies wird in Abbildung 27 in der graphischen Darstellung der Radiance der drei Gl. submandibularis an Tag 16 deutlich. Zweitens konnte unabhängig von Zeitpunkt und Genotyp eine bestenfalls minimale Radiance in den Pankreata gezeigt werden (s. Abb. 26). Möglicherweise ist die relative Fläche der Inseln innerhalb des Pankreas zu klein, um mit in-situ Lumineszenz Lymphozyteninfiltrate in Langerhans-Inseln darzustellen. Drittens zeigt sich zu beiden Zeitpunkten eine deutlich erhöhte Radiance in den Milzen der NOD.a4-/- Mäuse, die auch in den Aufnahmen in Abbildung 26. klar zu sehen ist. Dies liegt mutmaßlich daran, dass die a4kompetenten CD3+GFP+ Zellen nach subletaler Bestrahlung einen Repopulationsvorteil gegenüber den endogenen NOD.a4-/- Lymphozyten haben. Im Falle der a4 kompetenten NOD Maus fällt dieser Vorteil weg und es zeigt sich eine geringere Radiance als bei der NOD.a4-/- Maus. 
A

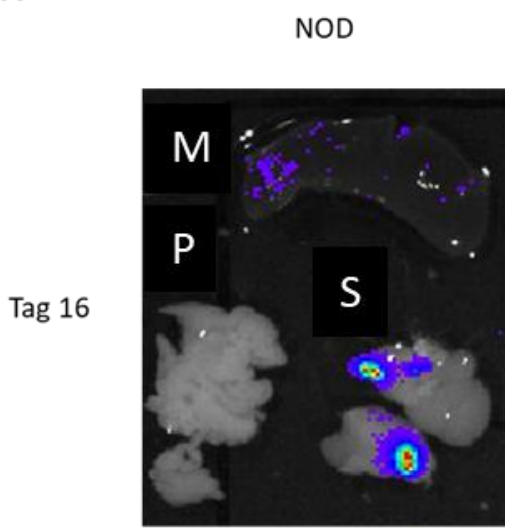

NOD

NOD. $\alpha 4-/-$

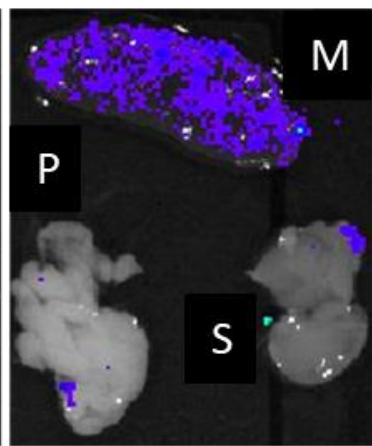

\section{$\mathrm{M}$}

Tag 32
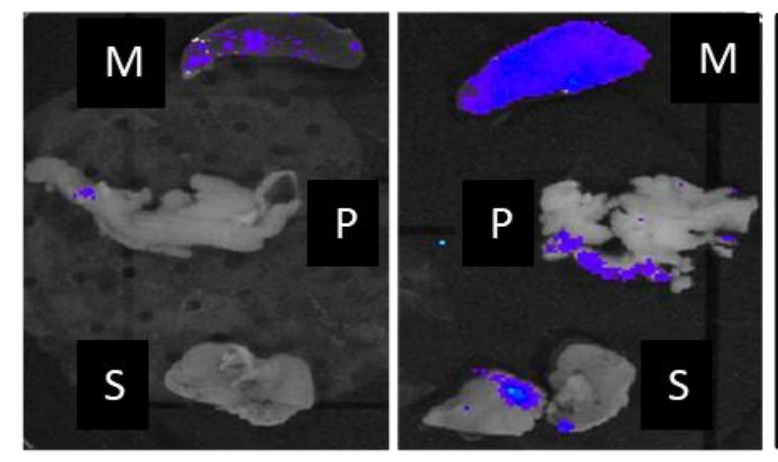

Negativkontrolle
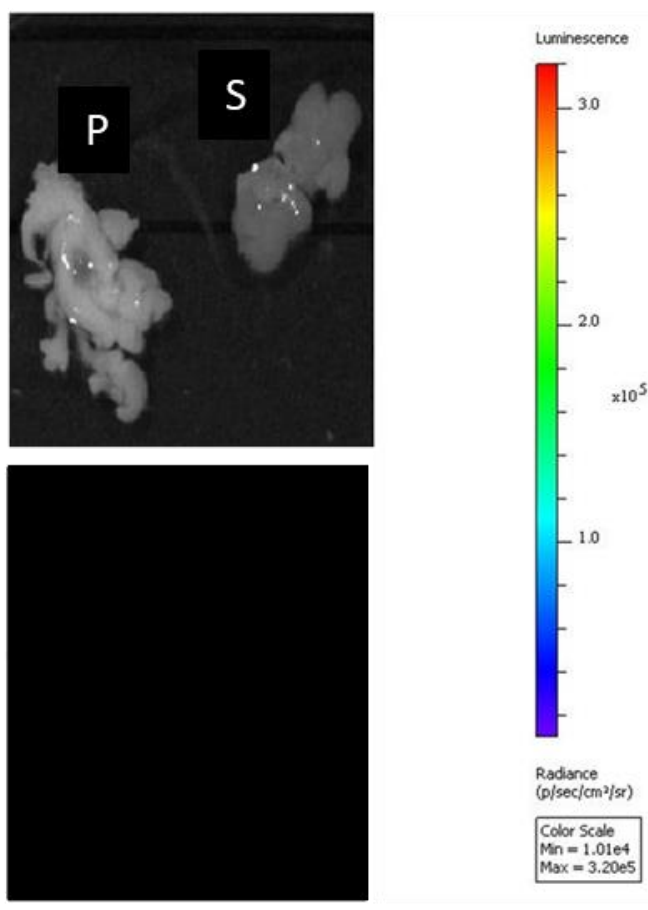

Abbildung 26. Ex-vivo Luminographie A: Luminogramm von Milz, Pankreas und Gl. submandibularis an zwei Zeitpunkten nach adoptivem CD3+ T-Zell-Transfer. In der ersten Zeile sind Organe von 3 Mäusen 16 Tage nach Transfer dargestellt (NOD links, NOD.a4-/- Mitte, Negativkontrolle rechts). In der zweiten Zeile sind Organe von zwei Spendern (NOD, NOD.a4-/) an Tag 32 nach Transfer dargestellt. B: Lumineszenz-Farbskala in Radiance (p/sec/ $\mathrm{cm}^{2} / \mathrm{sr}$ ) wurde auf einen dynamischen Bereich von 1.01e4 - 3.20 e5 eingestellt. Je Zeitpunkt und Genotyp wurden Organe (M: Milz, P: Pankreas, S: Glandula submandibularis) einer Maus untersucht (vgl. quantitative Analysen in Abb. 16). 


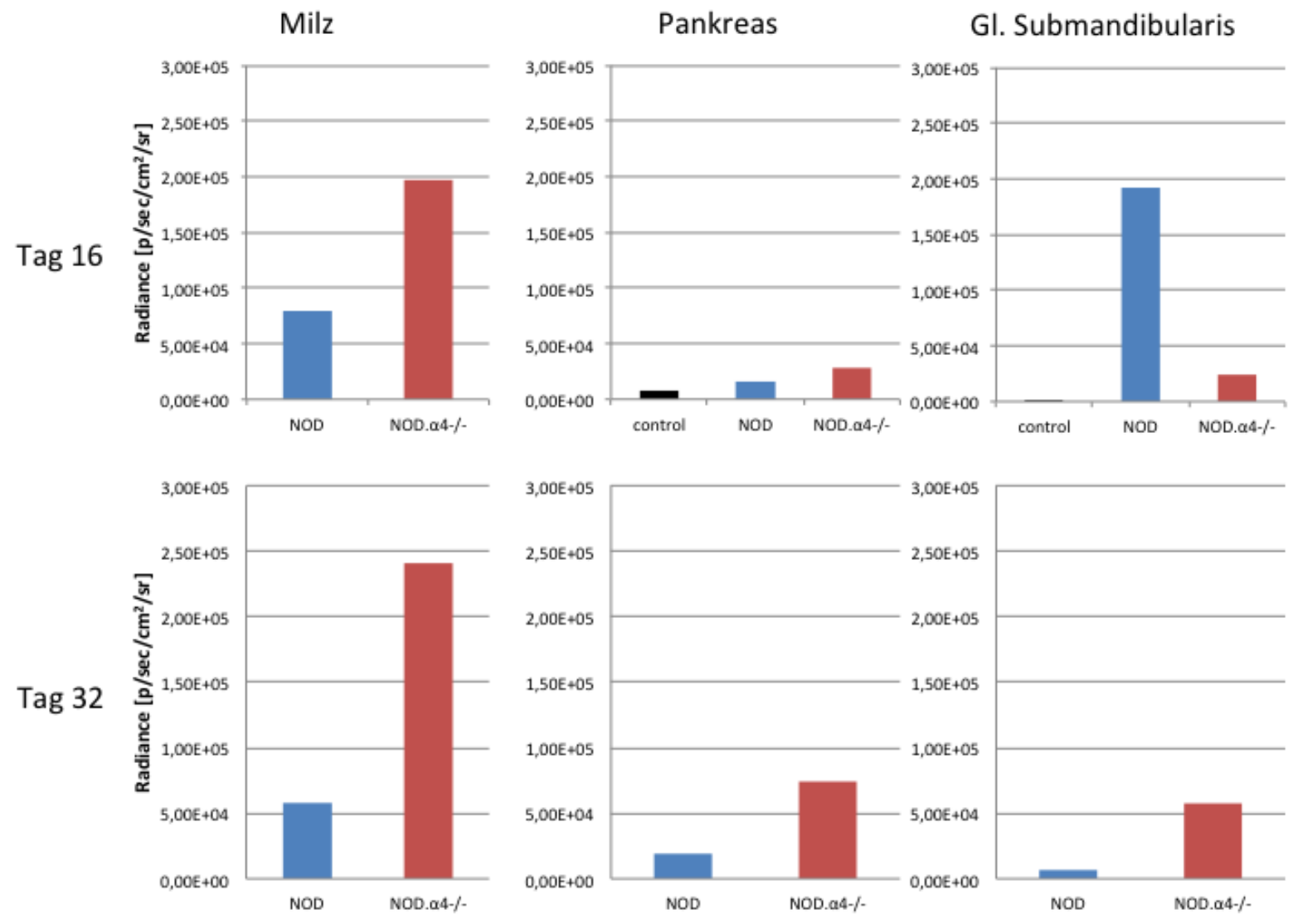

Abbildung 27. Quantitative Analyse der Radiance nach in vivo Transfer Luciferasegenmarkierter T-Zellen diabetischer Spendertiere. In der oberen Zeile ist die Radiance der Organe von Tag 16, in der unteren Zeile von Tag 32 dargestellt. In den drei Spalten sind die jeweiligen Organe zum Vergleich nebeneinander dargestellt (von links nach rechts: Milz, Pankreas und Gl. submandibularis). Je Zeitpunkt und Genotyp wurden Organe einer Maus untersucht (vgl. ex vivo Luminogramme in Abb. 3.15., 1 Maus pro Genotyp und Zeitpunkt).

\subsubsection{Adoptiver CD4+ T-Zell Transfer}

Christianson et al. konnten 1993 zeigen, dass neben adoptiven Transfers von Helfer- und zytotoxische T-Zellen enthaltenden Präparationen auch ein alleiniger CD4+ T-Zell Transfer in der Lage ist, in NOD.scid Mäusen (ohne endogene T-Zellen, also ohne notwendigerweise zytotoxische T-Zellen zu benötigen) Diabetes auszulösen, während CD8+ T-Zell Transfers alleine nicht dazu in der Lage waren. ${ }^{41}$

In den immunkompetenten NOD bzw. NOD.a4-/- Mäusen würden die CD4+ Helferzellen jedoch im Gegensatz zu den Experimenten mit NOD.scid Mäusen jeweils auf endogene CD8+ T-Zellen treffen und diese potenziell rekrutieren können, und so möglicherweise diabetogen wirken können. Im Gegensatz zu der Vielzahl bisher gezeigter Experimente, die theoretisch auch mit seriell 
injizierten anti-funktionellen Antikörpern hätten gemacht werden können, wurden die adoptiven Transferexperimente mit Co-Existenz a4-kompetenter und a4-defizienter hämatopoetischer Zellen erst durch das neu entwickelte genetische Modell möglich. Um zu untersuchen, ob und in welcher Kinetik NOD.a4-/- Mäuse im Vergleich zur NOD-Kontrollgruppe Diabetes entwickeln würden, wurden neben den adoptiven CD3+ T-Zell Transfers auch isolierte CD4+ T-Zell Transfers durchgeführt. Abbildung 28 zeigt die Diabetes-Prävalenz von weiblichen, 8-12 Wochen alten NOD $(n=6)$ und NOD.a4-/- $(n=3)$ Empfängern nach subletaler Bestrahlung in einer Dosis von 6.5 Gy und

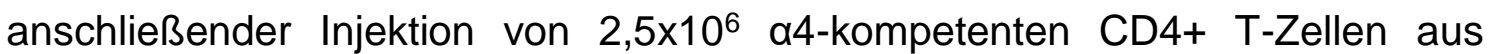
diabetischen Spendern. In Kontrast zum CD3+ T-Zell Transfer (Abbildung 23) entwickelte keiner der 3 NOD.a4-/- Empfänger Diabetes innerhalb des Beobachtungszeitraums von 42 Tagen. 5 der 6 NOD Empfänger entwickelten zwischen Tag 7 und 22 Diabetes, der sechste an Tag $36(p=0,01)$. NOD CD4+ Zellen sind also offenbar nicht in der Lage, NOD.a4-/- CD8+ Zellen zu rekrutieren, was offenbar für die Diabetes-Entstehung kritisch ist.

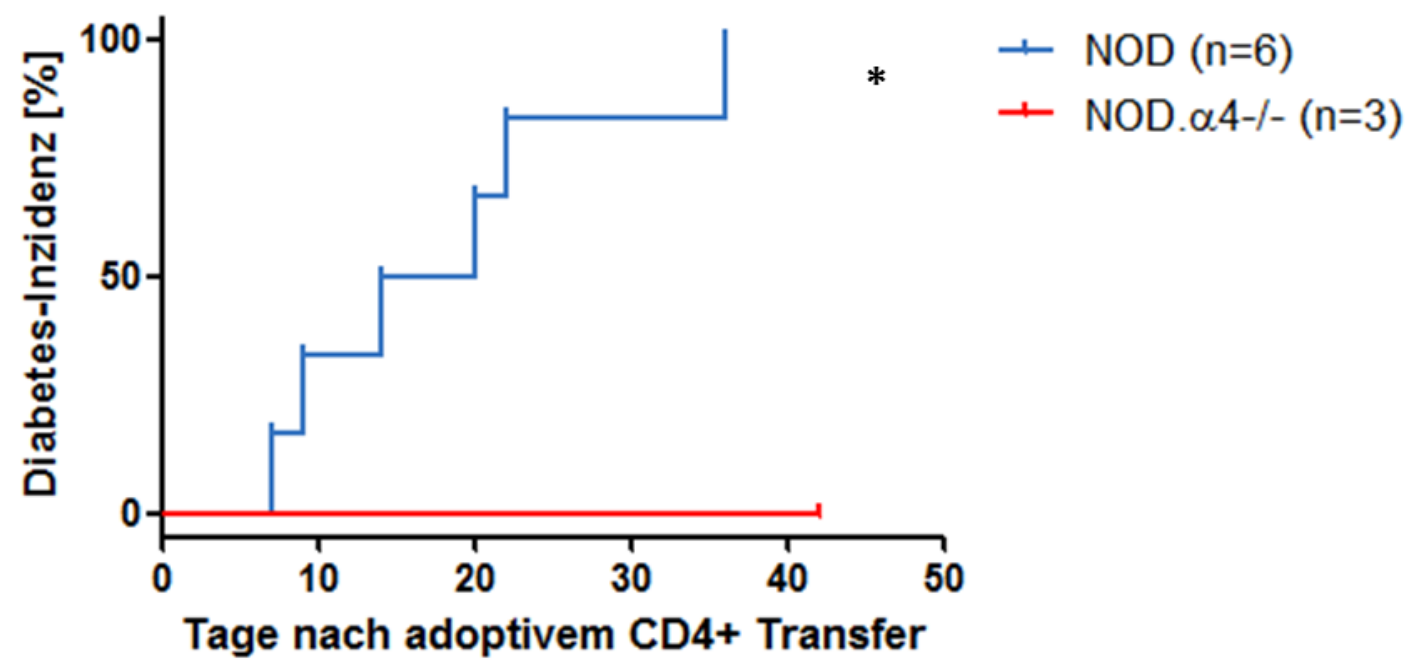

Abbildung 28 Adoptiver CD4+ T-Zell-Transfer diabetischer Spender auf nicht-diabetische, a4-kompetente oder -defiziente Empfänger. Kinetik der Diabetesentstehung und DiabetesPrävalenz weiblicher 8-12 Wochen alter NOD (blau, $n=6$ ) und NOD.a4-/- (rot, $n=3$ ) Empfängern von $2.5 \times 10^{6} \mathrm{CD} 4+$ Milz-T-Zellen diabetischer Spender nach subletaler Bestrahlung der Empfänger mit 6.5 Gy ( $p=0.01$ ) (zwei Experimente). 


\subsection{Analysen der humoralen Achse des Immunsystems der NOD.a4-/- Maus}

Eine Vielzahl von Untersuchungen hat sich der zellulären Immunkompetenz der NOD.a4-/- Mäuse gewidmet. Die Ausbildung antigenspezifischer T-Zellen ist grundsätzlich a4 Integrin-unabhängig, die gestörte Gewebepenetration a4negativer T-Zellen führt jedoch $\mathrm{zu}$ einer Attenuierung von Autoimmunkrankheiten und Asthma bronchiale. ${ }^{49 ; 57}$ Analoge Untersuchung zur humoralen Immunkompetenz wurden bisher nicht durchgeführt; da der „reife BZell-Rezeptor“, das Immunglobulin, sezerniert wird, sollte die humorale Immunkompetenz von NOD.a4-/- Mäusen ausschließlich von der Abhängigkeit der Reifung, Sensibilisierung und Expansion der B-Zellen von a4 bestimmt werden. Einmal produziert werden Immunglobuline a4-unabhängig im Gesamtorganismus äquilibrieren und in typischer Weise zur Immunabwehr beitragen. Um die Auswirkungen der embryonalen a4-Ablation auf die B-Zellen der NOD Maus zu untersuchen, wurden daher zunächst durchflusszytometrische Analysen der B-Zellpopulationen in verschiedenen hämatopoetischen Kompartimenten durchgeführt. Zusätzlich wurde eine Immunisierungsstudie angesetzt, um die Funktionalität der B-Zellen, und somit die generelle Fähigkeit zu testen, Antigenspezifität zu erwerben und spezifische Antikörper zu produzieren. Schließlich wurden Insulin-Autoantikörper gemessen, um der Frage nachzugehen, inwieweit die B-Zellen der a4Mangelmutante Antikörper gegen inselzellspezifische Antigene produzieren.

\subsubsection{B-Zell-Reifung}

B-Zellen durchlaufen eine Anzahl an Entwicklungsstadien vor und nach dem Kontakt zu Antigenen. ${ }^{83 ; 84}$ Im Laufe ihrer Reifung und Differenzierung entstehen verschiedene funktionell distinkte Populationen, die sich anhand differenter Expression von Oberflächenproteinen unterscheiden lassen. B-Zellen stammen von hämatopoetischen Stammzellen im Knochenmark ab, wo auch sie ihre ersten Entwicklungsschritte vollziehen. Die noch unreifen B-Zellen migrieren anschließend in sekundäre lymphatische Gewebe und vollziehen ihre weitere Reifung zu follikulären B-Zellen. Sobald der B-Zell-Rezeptorkomplex einer reifen $\mathrm{B}-Z$ Zelle, bestehend aus membrangebundenem $\lg \mathrm{M}$ und $\lg \mathrm{D}$, ein fremdes 
Antigen bindet, wird die B-Zelle aktiviert und differenziert zu einer Antikörpersezernierende Plasmazelle.

Durch die Kombination von Oberflächenmarkern können unterschiedliche Reifestadien der B-Zellen differenziert werden. PreproB-Zellen werden als $\mathrm{CD}_{4}{ }^{+} \mathrm{CD} 24^{-}$, preB/proB als $\mathrm{CD}^{-1 /+} 3^{-} \mathrm{CD} 24+\operatorname{lgM} \mathrm{IgD}^{-}$, unreife B-Zellen als CD43$\mathrm{CD}^{2} 4^{+} \lg \mathrm{M}^{\text {dim }} \operatorname{lgD}$, transitionale $\mathrm{B}-Z$ ellen als $C D 43^{-} \mathrm{CD}^{-} 4^{+} \lg \mathrm{M}^{+} \lg \mathrm{D}^{-}$, ein frühes $\mathrm{B}^{-}$ Zellreifestadium als $\mathrm{CD}^{-} 3^{-} \mathrm{CD} 24^{+} \operatorname{lgM}{ }^{+} \lg \mathrm{D}^{+}$und ein spätes B-Zellreifestadium als $\mathrm{CD}^{2}{ }^{-} \mathrm{CD} 24^{+} \operatorname{lgM} \mathrm{M}^{\text {dim/low }} \mathrm{IgD}^{+}$definiert. ${ }^{85 ; 86}$ Abbildung 29 zeigt die adaptierte Gating-Strategie am Beispiel einer NOD Knochenmark-Probe.
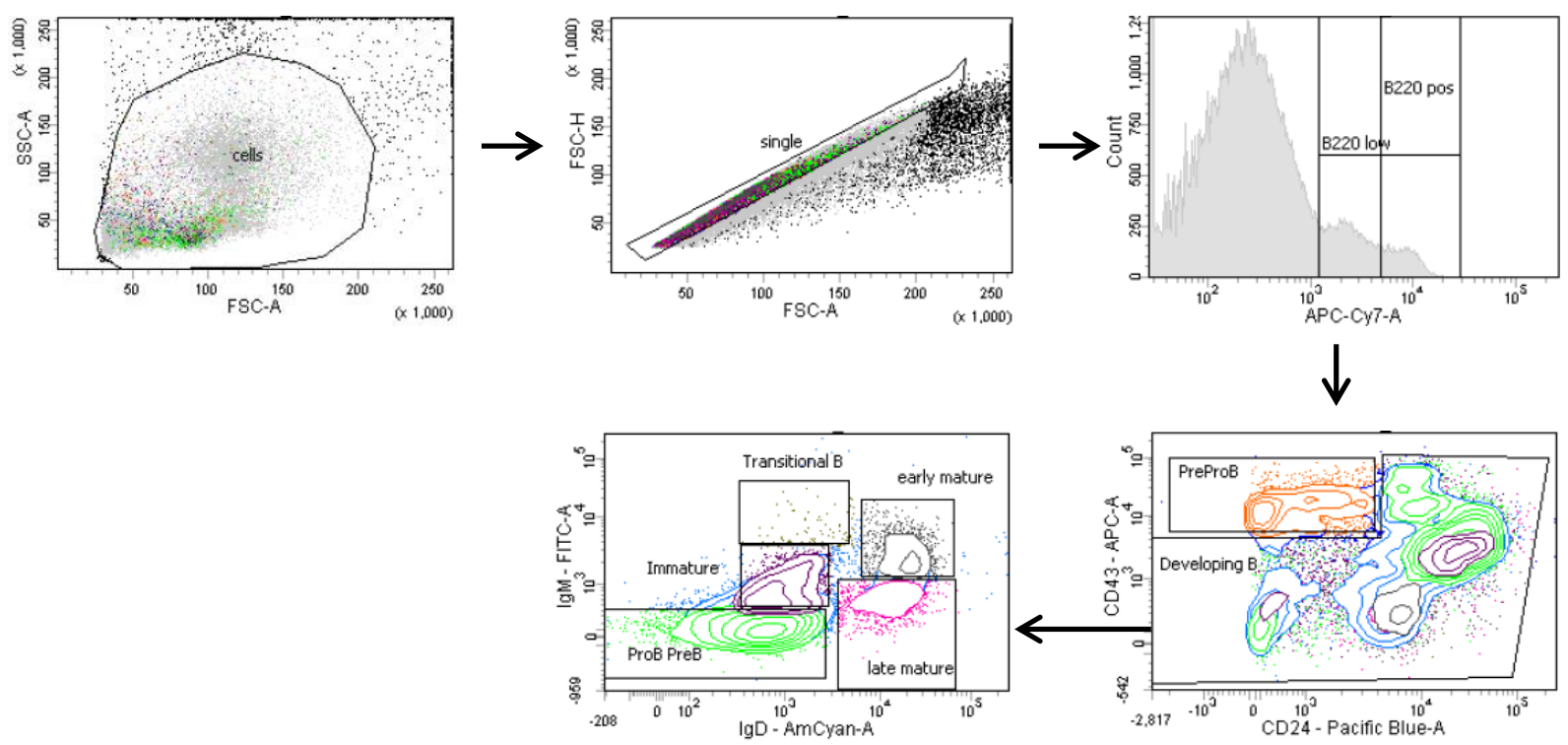

Abbildung 29. Gating-Strategie der B-Zell-Entwicklungsstadien. Nach dem initialen morphologischen Gating auf „alle Leukozyten“ und Doubletten-Ausschluss über FSC-A/FSC-HAbgleich erfolgte eine Färbung mit anti-B220. B220+ Zellen wurden auf ihre CD43 und CD24 Expression hin untersucht. PreProB Zellen wurden als B220+CD43+CD24- erkannt, während die restlichen Zellen auf ihre IgM und IgD Expression hin weiter untersucht wurden.

Anhand der B220-Expression kann zwischen B220 dim und B220high-Zellen unterschieden werden und somit der relative Anteil unreifer B-Zellen bestimmt werden. ${ }^{84}$ In Abbildung 30 sind die relativen Anteile unreifer B-Zellen in Knochenmark, Peripherblut und Milz dargestellt. Der relative Anteil unreifer BZellen (B220 dim) an der Gesamt-B-Zelllinie im Knochenmark zeigt sich in der NOD.a4-/- Maus mit 65,3 $\pm 1,9 \%$ gegenüber der NOD Maus mit einem Anteil von $59,7 \pm 0,8 \%$ leicht erhöht $(p=0,04)$. Ein ähnlicher Trend zeigt sich im Peripherblut, erreicht aber hier keine statistische Signifikanz $(30,6 \pm 6,7 \%$ vs. 
$19,1 \pm 2,5 \%, p=0,19)$. Der relative Anteil unreifer B-Zellen in der Milz zeigt keine Abhängigkeit vom a4-Status und liegt jeweils bei etwa $20 \%$.
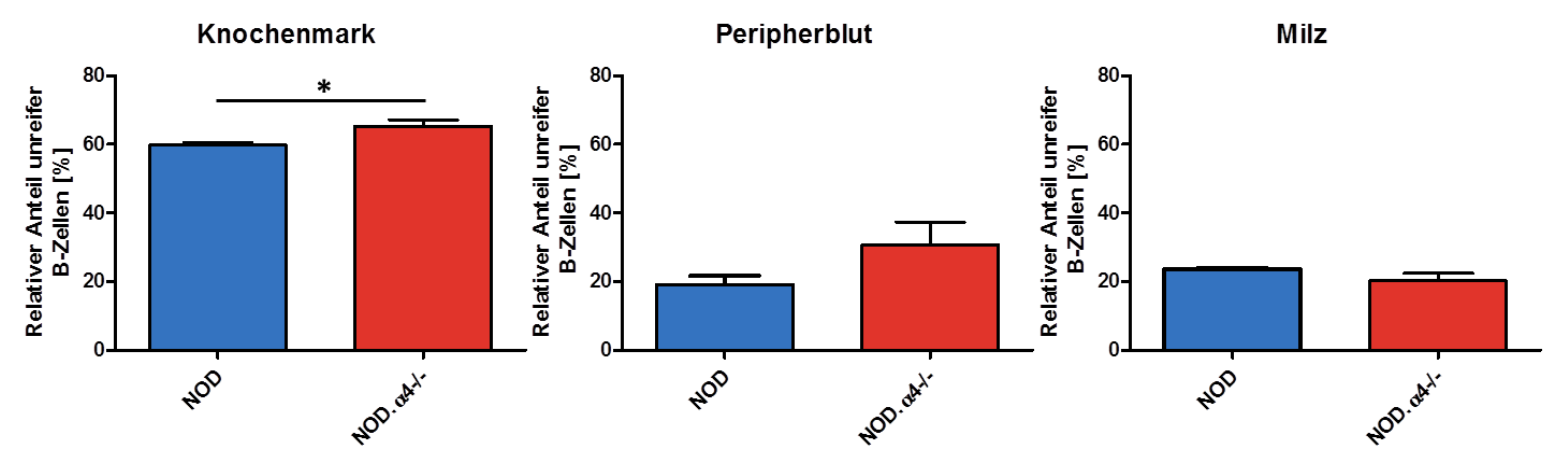

Abbildung 30 Relativer Anteil unreifer B-Zellen an B220+ Zellen der NOD ( $n=4)$ und NOD.a4-/- $(n=5)$ Mäuse in Knochenmark, Peripherblut und Milz.

In Abbildung 31. sind die erfassten Entwicklungsstadien der B-Zell-Reifung abgebildet. Durch den Einsatz mehrerer Antikörper ist es möglich, die verschiedenen B-Zell-Entwicklungsstadien genauer zu differenzieren. Anhand dieser Methode zeigt sich im Knochenmark der NOD.a4-/- Maus eine verminderte Frequenz unreifer B-Zellen $\left(\mathrm{CD}^{2} 3^{-} \mathrm{CD}^{2} 4^{+} \lg \mathrm{M}^{\mathrm{dim}} \operatorname{lgD}{ }^{-}\right.$, nicht $\mathrm{zu}$ verwechseln mit der B220 dim Population nach Montecino-Rodriguez et al, 2006) von $16,2 \pm 0,5 \%$ zu. $18 \pm 0,4 \%(p=0,03)$, transitionaler B-Zellen von $0,7 \pm 0,03 \%$ zu $1,4 \pm 0,08 \%(p<0,001)$ und B-Zellen im späten Reifestadium von $4,9 \pm 0,5 \%$ zu $7,0 \pm 0,5 \%(p=0,02)$ im Vergleich zur NOD Kontrollmaus. Im Peripherblut

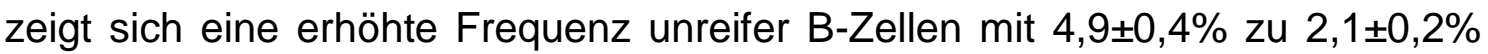
$(p=0,001)$ in der NOD Maus, in Übereinstimmung mit der Beobachtung, dass mit Natalizumab (medizinaler anti-funktioneller a4-Antikörper) behandelte Multiple Sklerose-Patienten erhöhte Konzentrationen zirkulierender unreifer BZellen haben, was $\alpha 4$ als Retentionsfaktor für unreife B-Zellen im Knochenmark identifiziert. ${ }^{87}$ In der Milz zeigt die NOD.a4-/- Maus gegenüber der NOD Maus eine leicht verminderte Frequenz von unreifen B-Zellen mit $7,6 \pm 0,6 \%$ vs. $10,8 \pm 0,3 \%(p=0,003)$ und transitionalen B-Zellen $6,5 \pm 0,3 \%$ vs. $10,0 \pm 0,6 \%(p<$ $0,001)$. 


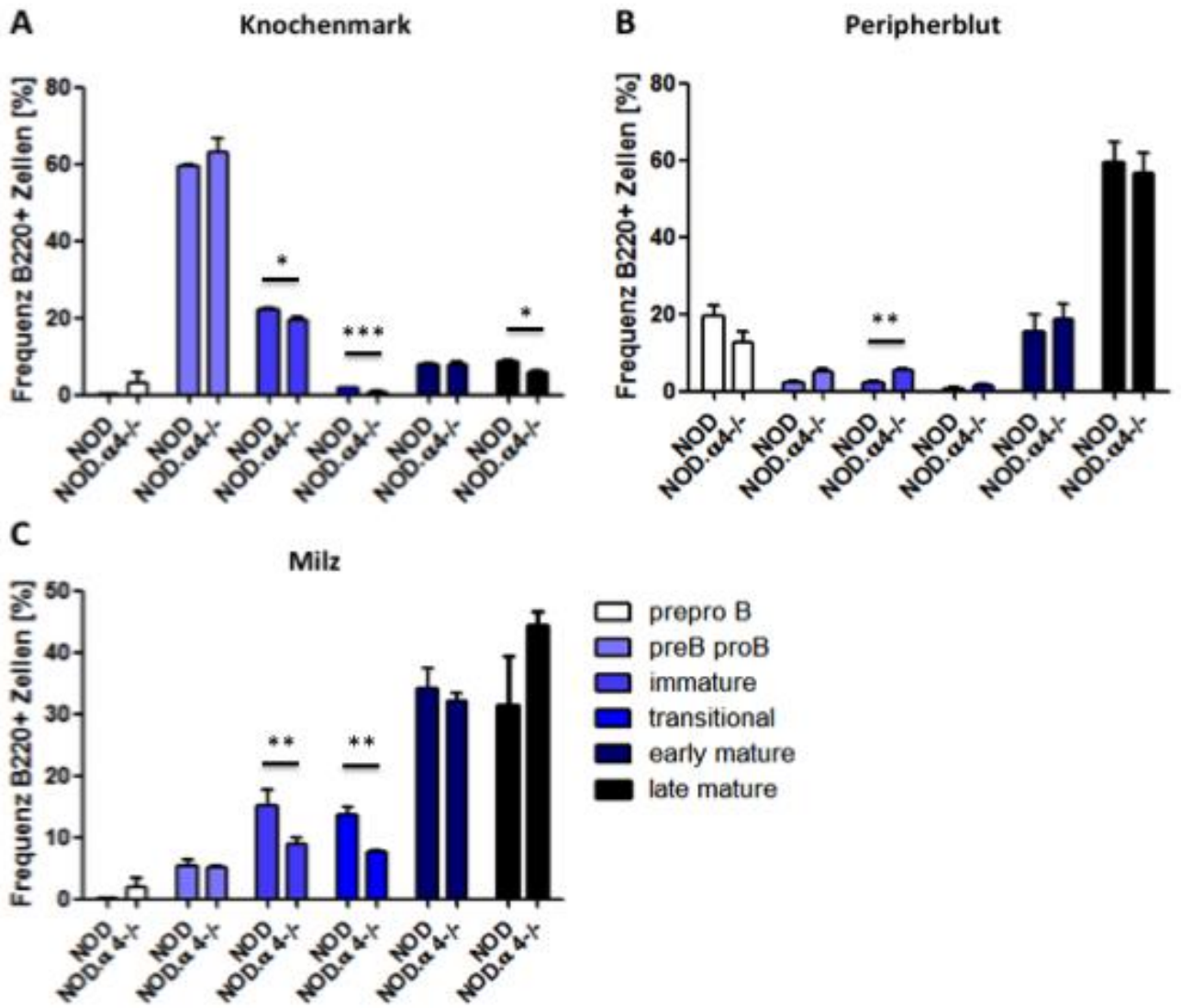

Abbildung 31. B-Zell-Reifung. Frequenz der verschiedenen Entwicklungsstufen an allen B220+ Zellen in $\operatorname{NOD}(n=4)$ und NOD.a4-/- $(n=5)$ Weibchen in verschiedenen Kompartimenten (A: Knochenmark, B: Peripherblut, C: Milz). (MW \pm SEM; Asterisken indizieren statistische Signifikanz mit einem B-Fehler von ${ }^{*} p<0.05,{ }^{* *} p<0.01,{ }^{* * *} p<0.005$.)

\subsubsection{Impfantwort: Primär- und Sekundärimmunisierung}

Zur Untersuchung der Funktionalität der B-Zellen wurden die Mäuse mit humanem rekombinanten Hepatitis B Impfstoff behandelt. Hierzu erfolgte eine intramuskuläre Injektion einmal wöchentlich über drei Wochen mit 10\% der bei Menschen üblichen Impfdosis. Eine Woche nach der dritten Behandlung erfolgte eine Blutentnahme und schließlich die Gewinnung von Plasma zur Bestimmung des Anti-HBs-Titers (s. Abbildung 32). Nach der primären Immunisierung konnte eine vergleichbare spezifische Immunantwort in beiden Kohorten festgestellt werden. 12 Wochen nach der primären Immunisierung erfolgte eine weitere intramuskuläre Injektion derselben Dosis zur Überprüfung der Ausbildung von B-Gedächtniszellen und deren Funktionalität. Je eine Woche vor und nach dieser Injektion erfolgten weitere Blutentnahmen und 
Titermessungen. Hier zeigt sich bei den NOD Mäusen schon eine Woche vor erneuter Immunisierung („Boost“) eine deutliche Erhöhung des Anti-HBs-Titers um mehr als das Dreißigfache des Ausgangswertes $(1126 \pm 430 \mathrm{mlU} / \mathrm{ml})$ während eine Erhöhung des Titers bei den NOD.a4-/- Mäusen (39 $\pm 15 \mathrm{mlU} / \mathrm{ml})$ nicht beobachtet werden kann $(p=0,04)$. Nach Boost steigen die Titer in den NOD Mäusen auf einen Wert von $2680 \pm 666 \mathrm{mlU} / \mathrm{ml}$ und in den NOD.a4-/Mäusen auf $121 \pm 66 \mathrm{mIU} / \mathrm{ml}(p=0,0015)$. NOD.a4-/- haben demnach eine grundsätzlich kompetente, quantitativ jedoch attenuierte humorale Immunfunktion, was die Beobachtung zu den Inselzellantikörpern (s. Abbildung 33) relevant komplementiert.

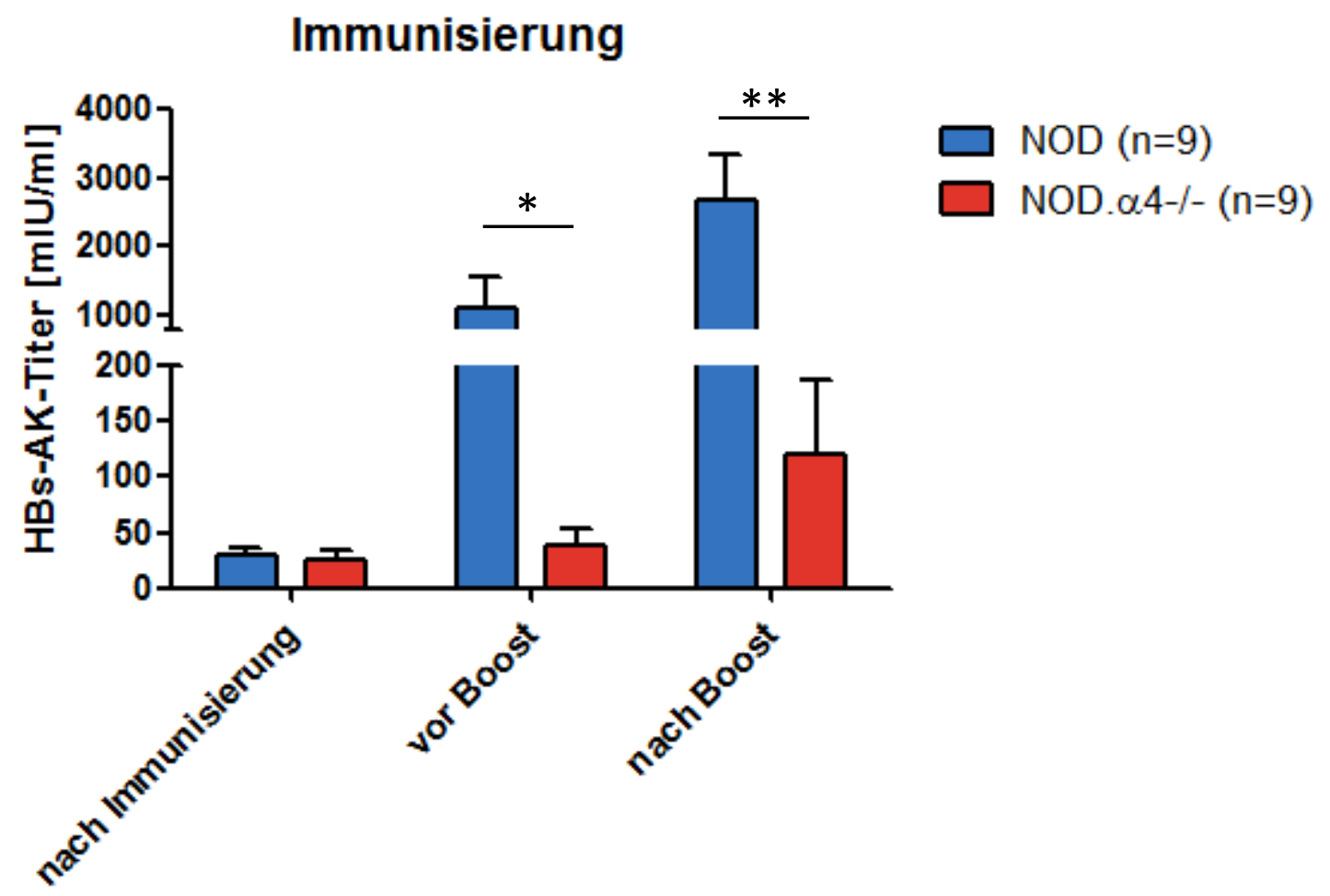

Abbildung 32 Humorale Immunantwort gegenüber einem für Induktion einer B-ZellAntwort optimierten Impfstoff. Weibliche Mäuse, a4-kompetent oder -defizient, wurden mit dem klinisch relevanten rekombinantem HBsAG-Impfstoff EngerixB intramuskulär wöchentlich für 3 Wochen (Primärimmunisierung) sowie noch einmal nach 12 Wochen (Sekundärimmunisierung oder Boost) immunisiert. Anti-HBs Titer wurden unmittelbar nach Ende der Primärimmunisierungsserie, sowie eine Woche vor und eine Woche nach Gabe des EngerixB Boosts bestimmt. ( $\mathrm{n}=9$ Mäuse/Gruppe; MW \pm SEM; Asterisken indizieren statistische Signifikanz mit einem $B$-Fehler von ${ }^{*} p<0.05$ bzw. ${ }^{* *} p<0.01$ ).

\subsubsection{Insulin-Autoantikörper}


NOD Mäuse produzieren Antikörper gegen mehr als ein Dutzend inselzellspezifische Antigene, die allerdings sehr variabel zu detektieren sind. ${ }^{21}$ In dieser Arbeit wurden die Titer von Insulin Autoantikörpern (IAA) untersucht, da diese Methode zum einen für die NOD Maus etabliert ist und zum anderen diese Autoantikörper schon früh detektierbar sind. ${ }^{88}$ Hierzu wurde zwischen 8. und 12. Lebenswoche Plasma von je 7 NOD und NOD.a4-/- Mäusen gewonnen und diese durch einen Sandwich-ELISA untersucht. Hierbei zeigt sich ein IAATiter von $38,74 \pm 4,7 \mathrm{ng} / \mathrm{ml}$ in der NOD Kohorte, $23,4 \pm 3,5 \mathrm{ng} / \mathrm{ml}$ in der NOD.a4-/Kohorte und $15,7 \pm 3,7 \mathrm{ng} / \mathrm{ml}$ in 9 C57BI/6 Mäusen als biologische Negativkontrolle (unspezifischer Hintergrund). Nach Subtraktion des Durchschnitts-Titers der Negativkontrolle ergibt sich ein spezifischer IAA-Titer von $21,3 \pm 4,7 \mathrm{ng} / \mathrm{ml}$ für die NOD Kohorte und von $5,4 \pm 3,5 \mathrm{ng} / \mathrm{ml}$ in der NOD.a4-/- Kohorte ( $p=0,02 ;$ Abb. 33).

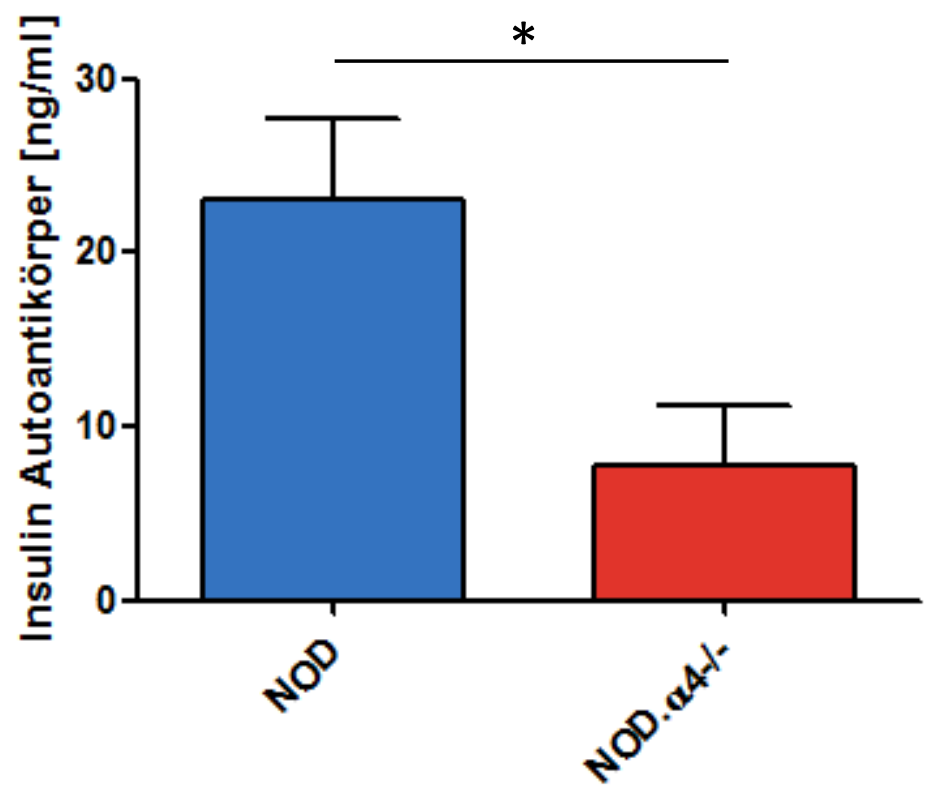

Abbildung 33. Insulin-Autoantikörper. Zur Bestimmung der Insulin-Antikörpertiter wurden Blutentnahmen zur Plasmagewinnung von unbehandelten a4-kompetenten oder -defizienten NOD Mäusen durchgeführt. Dargestellt sind die IAA-Titer $(\mathrm{ng} / \mathrm{ml})$ in weiblichen 8-12 Wochen alten NOD und NOD.a4-/- Mäusen nach Subtraktion des Mittelwerts der C57BI/6Negativkontrolle (MW \pm SEM, jeweils $n=7, p=0,022)$.

\subsection{Sekundärprävention}


In Kapitel 3.1. konnte gezeigt werden, dass $\alpha 4$-inkompetente NOD.a4-/- Mäuse vor Diabetes geschützt sind. Inwiefern ein kompletter Verlust des a4 Integrins auf Leukozyten zu einem späteren Zeitpunkt, an dem schon eine beginnende Insulitis vorhanden ist, den Progress der Erkrankung unterbinden kann, sollte durch Transplantation prädiabetischer Empfänger mit NOD oder NODa4-/Knochenmark überprüft werden.

Bekanntermaßen besitzen a4-negative Stammzellen einen Knochenmarkshomingdefekt und eine entsprechend kompromittierte Repopulierungskapazität. 53;54 In einem Pilotversuch konnte beobachtet werden, dass eine Bestrahlung mit 9.5 Gy und eine anschließende Injektion von $2 \times 10^{6}$ NOD.a4-/- Knochenmarkzellen zu einer endogenen Rekonstitution des NOD Knochenmarks und der Entstehung einer gemischten hämatopoetischen Chimäre führte (nicht gezeigt). Um dies zu vermeiden, wurde die Bestrahlungsdosis auf 10.5 Gy erhöht und im Falle der Transplantation von a4inkompetenten Knochenmarkzellen eine Zellzahl von $10 \times 10^{6}$ gewählt. Insgesamt wurden 29 NOD Mäuse im Alter von 8-12 Wochen, einem Zeitpunkt an dem von einer beginnenden Insulitis bei allen Empfängern auszugehen ist (Oulghazi et al. Cells 2020), mit einer Bestrahlungsdosis von 10.5 Gy behandelt. Daraufhin erhielten 23 dieser Mäuse $2 \times 10^{6}$ a4-kompetente Knochenmarkzellen und 6 Mäuse $10 \times 10^{6} \alpha 4$-inkompetente Knochenmarkzellen. Die Knochenmarkzellen stammten in beiden Fällen von 3 Spendern, um die Spendervariabilität zu minimieren.

Abbildung 34 zeigt die Diabetes-Prävalenz der 29 Empfänger über einen Beobachtungszeitraum von 32 Wochen nach Knochenmarktransplantation. Während die 23 Empfänger von NOD-Knochenmark in vergleichbarem Maße (91\% nach 40 Lebenswochen bei leicht verzögerter Kinetik) Diabetes entwickelten, erkrankte keiner der Empfänger von NOD.a4-/- Knochenmark innerhalb des Beobachtungszeitraums $(p<0,0001)$. 


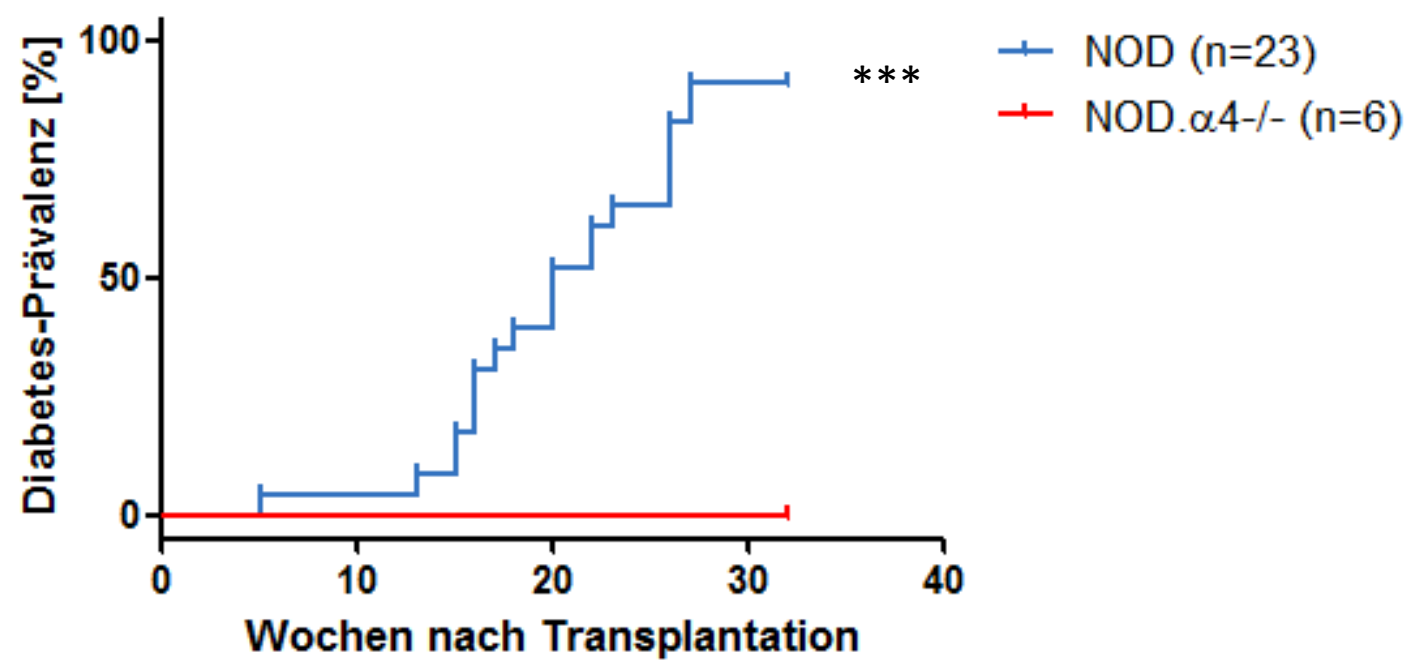

Abbildung 34 Sekundärprävention durch Knochenmark-Transplantation. Da die a4Defizienz NOD Weibchen vor Diabetes schützt, sollte durch die Sekundärprävention untersucht werden, ob prädiabetische 8-12 Wochen alte NOD Weibchen durch eine KnochenmarkTransplantation mit a4-defizienten hämatopoetischen Stammzellen (HSCs) kurativ behandelt werden können. Dargestellt ist die Diabetes-Prävalenz von 29 8-12 Wochen alten NODEmpfängern, die nach 10.5 Gy Bestrahlung entweder $2 \times 10^{6}$ NOD-Knochenmarkzellen oder $10 \times 10^{6}$ NOD.a4-/--Knochenmarkzellen erhalten haben. Der Beobachtungszeitraum nach Transplantation betrug 32 Wochen $(p<0,0001)$.

\section{Diskussion}

In dieser Arbeit konnte die Rolle des a4-Integrins in der Pathophysiologie des Autoimmundiabetes erstmals anhand einer NOD.a4-/- Maus untersucht werden. Unsere Daten demonstrieren auf deutlichste Weise die dominante Rolle des a4Integrins in der Entstehung des Autoimmundiabetes. So hat keine der 19 untersuchten NOD.a4-/- Mäuse im Laufe der ersten 40 Lebenswochen eine Hyperglykämie oder eine Insulitis gezeigt, bei einer zu erwartenden Inzidenz von etwa $80 \%$. Grundsätzlich hatten die publizierten Daten zur antikörpervermittelten a4-Blockade eine präventive Wirkung der a4-Ablation erwarten lassen, wenn auch die Stärke des Effekts den von Antikörpern weit übersteigt: Kommajosyula et al. konnten durch eine ab dem 7. Lebenstag beginnende vierwöchige Gabe von anti-a4 (PS/2) eine Reduktion der DiabetesInzidenz von $71 \%$ auf $33 \%$ erreichen, während eine Kombination sieben verschiedener anti-CAM Antikörper (anti- $\alpha 4$, anti- $\alpha 4 \beta 7$ anti- $\beta 2$, anti- $\beta 7$ und ihrer Liganden anti-MAdCAM-1, anti-VCAM-1 und anti-ICAM-1) zu einer Reduktion der Inzidenz auf $17 \%$ führte. ${ }^{63}$ Ein späterer Beginn einer anti-a4 oder anti-CAM 
Kombinationstherapie ab dem 70. Lebenstag führte interessanterweise zu einem schlechteren Ansprechen mit einem Inzidenzanstieg auf 50\% und 100\% zwischen Tag 94 und Tag 250. Die alleinige a4-Blockade konnte also mit dem Inzidenzanstieg auf 50\% eine gewisse Wirkung beibehalten. Yang et al. führten histologische Untersuchungen an NOD Mäusen durch, welche ab der 5. Lebenswoche für 7 Wochen mit Antikörpern gegen a4 (R1-2) oder L-Selectin (Mel-14) behandelt wurden. Hier zeigte sich in der mit R1-2 behandelten Kohorte eine vollständige Abwesenheit von Leukozyteninfiltraten der Langerhans-Inseln, während in der mit Mel-14 behandelten Kohorte bloß eine Reduktion der Insulitis-Schwere beobachtet wurde. Die Splenozyten dieser behandelten Mäuse wurden anschließend in vitro dahingehend untersucht, ob sie auf Inselzellantigene reagieren und diese als Autoantigene wahrnehmen. Der gemessene Proliferationsindex der drei behandelten Kohorten (PBS, R1-2, Mel-14) auf die untersuchten Autoantigene (GAD67, GAD65, Peripherin, CPH und HSP65) unterschied sich nicht signifikant, sodass die Autoren dies dahingehend deuteten, dass eine a4-Blockade nicht zu einer abgeschwächten Sensibilisierung gegenüber Autoantigenen führt. ${ }^{61}$ Dies steht in Einklang mit unseren Daten zu der Abwesenheit von Insulitis sowie der quantitativ verminderten, jedoch eindeutig nachweisbaren autoreaktiven CD8+ T-Zellen und Insulin-Autoantikörpern in der NOD.a4-/- Maus. Die hier gezeigten Daten aus dem genetischen Modell der a4-Insuffizienz beantworten jedoch eine Reihe von Fragen, die mit a4-blockierenden Antikörpern nicht beantwortet werden konnten. Unser Mausmodell ist von der Entstehung des ersten Lymphozyten bereits kontinuierlich und effizient a4-insuffizient. Weder stellt sich die Frage nach möglicherweise unzureichender oder nicht kontinuierlicher a4-Insuffizienz, d.h. Fragen der Pharmakokinetik und -dynamik der Antikörper, noch nach etwaigen direkten Effekten der a4-Antikörper auf Lymphozyten, wie direkte Zytotoxizität, Opsonierung, etc. Es ist aus den publizierten Arbeiten nicht erkennbar, dass die Mäuse einen a4-Blockade-Phänotyp mit Leuko/Lymphozytose hatten und nicht etwa eine antikörpervermittelte Leuko/Lymphopenie. 60;61;63 Das Antikörper-Modell bleibt außerdem die Antwort schuldig, ob a4-Defizienz vor Sensibilisierung gegen Autoantigene schützt. Unsere Daten zeigen erstmals, dass das nur bedingt der Fall zu sein scheint: Zwar sind Inselzell-autoreaktive T-Zellen in ihrer Frequenz bei a4-/- Mäusen 
vermindert im Vergleich zu wildtypischen NOD Mäusen, jedoch ist eine gewisse Frequenz auch bei a4-/- Mäusen sicher nachweisbar. Da a4-/- Lymphozyten das (Pankreas-)Gewebe nicht infiltrieren können, möchten wir bezüglich des Ortes des Kontakts zwischen Autoantigen und Lymphozyt das Pankreas als maximal unwahrscheinlich ausschließen. Dass in Ermangelung einer Insulitis und des sich hieraus ergebenden positiven Proliferationssignals die Frequenz, möglicherweise auch die Diversität der anti-Inselzell-T-Zellen vermindert sein soll, ist unmittelbar nachvollziehbar. Inselzell-reaktive Autoantikörper, trotz ihrer nicht abschließend geklärten Rolle für die Diabetogenität, haben wir ebenfalls untersucht, können welche nachweisen, in allerdings erheblich niedrigeren Titern als bei wildtypischen NOD. Während die zelluläre Immunität der a4defizienten Maus bereits breit charakterisiert ist, war die humorale Immunität bisher wenig betrachtet worden. Um zu prüfen, ob sich die attenuierte humorale Antwort der a4-/- Maus auf Autoantigene (oder sogar: auf Inselzellautoantigene) beschränkt, führten wir intramuskuläre Impfversuche durch, die prinzipiell dasselbe Ergebnis erbringen: Antikörperplasmaspiegel der a4-/- Mäuse waren denen der NOD Mäuse nach primärer Immunisierung nicht relevant verschieden. Die Sensibilisierung, auch die Boosterung, gelingt, jedoch auf quantitativ sehr niedrigem Niveau. Dass der Autoimmundiabetes der NOD Maus durch Transfer von Splenozyten (prä)diabetischer Spender auf die MHCisogene, jedoch Lymphozyten-freie NOD.scid sicher und mit kürzester Latenz übertragen werden kann, ist gut dokumentiert. Im Rahmen eines adoptiven Transfers von Splenozyten diabetischer Spender konnte Baron et al. feststellen, dass eine vorige in vitro Behandlung der Zellen mit anti-a4 (LPAM-1) zu einer Reduktion der Diabetes Inzidenz zuvor bestrahlter NOD.scid Mäuse von 100 auf 70\% zur Folge hatte. Eine weitere viermalige Behandlung (an Tag 0, 3, 6, 9 nach Transfer) der Empfänger des adoptiven Transfers führte zu einer Reduktion der Inzidenz auf 10\% nach dem Beobachtungszeitraum von 40 Tagen. ${ }^{60}$ Yang et al. führten eine tägliche anti-a4 (R1-2) Therapie nach adoptivem Transfer durch und konnten hierdurch alle $(n=5)$ Empfänger vor der Diabetes-Entwicklung schützen. ${ }^{62}$ Uniyal et al. konnten 1998 zeigen, dass im Modell des Cyclophoshamid-induzierten Diabetes eine anschließende zweimalige Gabe einer gegen a4 und a5 gerichteten Antikörper Therapie mit einer Verminderung der Insulitis einhergeht. Hierbei wurde jedoch schon 48 
Stunden nach letzter Gabe der histologische Nachweis einer Aggravation der Insulitis festgestellt. ${ }^{64}$ Dies verdeutlicht die 2015 von Magnuson et al. festgestellte Dynamik der Leukozyteninfiltration mit konstantem Zell-Turnover der Langerhans-Inseln und macht dementsprechend eine kontinuierliche, möglichst frühe anti-Integrin Therapie notwendig, um die Funktion der Langerhans-Inseln auf Dauer zu gewährleisten. ${ }^{89}$ In Zusammenschau dieser Daten fällt auf, dass eine kürzere Therapiedauer oder ein späterer Therapiebeginn $\mathrm{zu}$ einer deutlich schlechteren Protektion vor Autoimmundiabetes im Sinne des histologischen Nachweises einer progredienten Insulitis führt. Unsere histologischen Daten zeigen einen durch die embryonale Ablation bewirkten unbegrenzten, vollständigen Schutz der Langerhans-Inseln der NOD.a4-/- Maus. Unser genetisches Modell ermöglichte erstmals die Untersuchung der Rolle von a4-kompetenten T-Zell-Subtypen für die Diabetesentstehung in Anwesenheit aller anderen T-Zell-Subtypen, nämlich indem wir a4-/- Empfänger verwenden konnten. Transfer von diabetogenen a4kompetenten Splenozyten in junge NOD-Empfänger führte, wie beschrieben, mit sehr kurzer Latenz und 100\%iger Penetranz zu einem rasch progredienten Diabetes. Auch die für spontanen Autoimmundiabetes resistente a4-/..NOD Maus entwickelte als Empfängerin diabetogener T-Zellen mit 100\%iger Penentranz Diabetes, jedoch war die Latenz deutlich länger. Wir postulieren, dass die in den wildtypischen (derzeit noch) nicht-diabetischen Empfängern infundierten T-Zellen vom entzündeten Pankreas angelockt werden, während das läsionsfreie Pankreas der a4-/-.NOD Maus erst mit einiger Verzögerung von diabetogenen T-Zellen infiltriert wird. Adoptiver Transfer von diabetogenen CD4+ T-Zellen in wild-typische respektive NOD.a4-/- Mäuse hingegen führte nur in den wildtypischen, nicht aber in NOD.a4-/- Mäusen zur Entstehung eines Diabetes, d.h. die a4-Kompetenz der (endogenen) CD8+ T-Zellen, die von den CD4+ co-rekrutiert werden, ist offenbar kritisch für die Kommunikation mit diabetogenen Helferzellen und die Zerstörung der Inselzellen.

Während die Daten zur a4-vermittelten Protektion vor T1D in der NOD Maus zumindest qualitativ eindeutig waren, zeigte sich bezüglich der von 1986 erstmals beschriebene Sialitis der NOD Maus bisher kein eindeutiges Bild. ${ }^{90}$ Während Brando et al. 2000 eine verminderte Infiltration nach nicht-selektiver a4 $\beta 1$-, $\alpha 4 \beta 7$ - und $\alpha 5 \beta 1$-Blockade durch das Gift EC3 von Echis carinatus 
suchoreki zeigt, konnten Yang et al. keinen Einfluss auf die Sialitis-Inzidenz durch anti-a4 Behandlung beobachten. ${ }^{62 ; 91}$ Eine Gabe von Antikörpern gegen a4 oder L-Selectin schien nach bisherigem Stand des Wissens nur die Schwere der Sialitis zu beeinflussen: Während für 4 Wochen mit PBS behandelte neugeborene NOD Mäuse einen Sialitis-Score von 2 (Range 0-4) aufwiesen, zeigten mit Mel-14 (anti-L-Selectin) oder R1-2 (anti-a4) behandelte NOD Mäuse einen diskret attenuierten Sialitis-Score von 1,2 oder 1,5. Genau wie im Falle der Insulitis, zeigt sich auch in den Leukozyteninfiltraten in Gll. Submandibulares ein heterogenes Bild mit vorwiegend T-Zellen, aber auch BZellen, Makrophagen und dendritischen Zellen. Unsere Daten implizieren eindeutig eine übergeordnete Rolle des a4-Integrins in der Entstehung der Sialitis im NOD Modell. So konnte in keiner der entnommenen Gll. Submandibulares ein Infiltrationsherd gesehen werden, während die gleichaltrigen NOD-Kontrolltiere eine mittlere Anzahl von 19 Infiltrationsherden pro histologischem Schnitt aufweisen. Neben der Betrachtung der Histologie sind allerdings noch weitere Untersuchungen notwendig, um abzuklären, ob die Abwesenheit der Sialitis auch mit einem verminderten spezifischen Autoantikörper-Titer und/oder autoreaktiven T-Zellen einhergeht. Hierzu wäre eine Bestimmung der Autoantikörper ANA, anti-Ro, anti-SSA und/oder ein Proliferationsassay mit Speicheldrüsen-Antigenen sinnvoll. $92 ; 93$

In der letzten Dekade häuften sich Studien zu dem Einfluss der Darmflora auf den Autoimmundiabetes, sowohl bei der NOD Maus als auch beim Menschen. Die Zusammensetzung des Mikrobioms unterliegt einer Homöostase. ${ }^{94}$ Gleichzeitig unterliegt sie aber auch multiplen exogenen Einflüssen, beispielweise der Art der Entbindung, der Ernährung, der Antibiotikaeinnahme, oder dem pH-Wert des Trinkwassers. ${ }^{95}$ Speziell für die NOD-Maus wurde bereits eine Vielzahl von assoziativen Studien von Mikrobiom und Diabetes durchgeführt, die kausal zu interpretieren versucht worden war.68;69;76 Änderungen der Mikrobiota durch Antibiotika werden, auch für die NOD-Maus, reproduzierbar gezeigt, was auch wenig überrascht. Dann allerdings berichten die Gruppen wahlweise protektive und präzipitierende Effekte der Mikrobiota auf die Diabetesentstehung. In der NOD Maus führte eine postnatal bis zur 40 . Lebenswoche durchgeführte Behandlung mit Vancomycin zu einer veränderten Zusammensetzung der Darmflora (vermehrt Escherichia, Lactobacillus und 
Sutterella Genera und verminderte Clostridiales, Lachnospiraceae, Prevotellaceae und Rikenellaceae Familien) und einer damit einhergehenden Abnahme der regulatorischen T-Zellen in der intestinalen lamina propria und letztlich einem Diabetes-Inzidenzanstieg. ${ }^{96}$ Auch eine Antibiotika-Therapie mit Metronidazol, Neomycin und Polymyxin von schwangeren NOD Mäusen führte zu einem Diabetes-Inzidenzanstieg des Nachwuchses mit einhergehender verminderter $\alpha$-Diversität des Mikrobioms. ${ }^{97} \mathrm{Hu}$ et al. beschrieben 2015 andererseits nach dreiwöchiger Gabe von Neomycin/Polymyxin/Streptomycin eine altersabhängige Inzidenzabnahme. ${ }^{98}$ Die Dreifachtherapie führte zu einem signifikant verschobenen Gram+/Gram- Verhältnis des Mikrobioms, welches selbst 6 Monate nach Behandlungsende noch nachweisbar war. In den NPSKohorten konnten weniger Proteobacteriae und deutlich vermehrte Lachnospiraceae als auch Coriobacteriaceae nachgewiesen werden. Während die Inzidenzabnahme bei einer Therapie während der Schwangerschaft am deutlichsten war, war die Wirkung bei einer Therapie 3 Wochen alter NOD Weibchen mit einer Inzidenzabnahme von $80 \%$ auf $55 \%$ geringer ausgeprägt. In Anbetracht der teilweise widersprüchlichen Literatur ist man noch weit davon entfernt, die Rolle des Mikrobioms in der T1D Pathogenese vollständig zu verstehen. Zu den oben genannten Studien zu Antibiotika-Therapien von NOD Mäusen muss erwähnt werden, dass Antibiotika wie Vancomycin und Streptomycin mit unerwünschten Arzneimittelwirkungen wie Nephro-, Neuround Ototoxizität einhergehen. $\mathrm{Da}$ in unserer Studie keine medikamentöse Intervention erfolgte, können hier derartige unerwünschte Einflüsse ausgeschlossen werden. Durch die vom Diabetes geschützte NOD.a4-/- Maus ist es uns möglich gewesen, das Mikrobiom dieser gesunden Maus mit dem NOD-Mikrobiom zu vergleichen. Mäuse wurden unabhängig vom Genotyp gemeinsam gehalten. Aufgrund der speziestypischen Coprophagie wäre eine Angleichung der Mikroflora über alle Genotypen zu erwarten. Wäre eine bestimmte Mikrobiota für die Diabetes-Entstehung ursächlich (und nicht Konsequenz des Diabetes) und bei den diabetischen Mäusen zu finden, sollten alle Mäuse, wiederum unabhängig vom Genotyp, ebenfalls diese Flora und ebenfalls Diabetes haben. Dies ist jedoch nicht, was wir beobachtet haben: Unsere Daten zeigen eine weitgehend übereinstimmende $\alpha$ - und $\beta$-Diversität des Mikrobioms in NOD.a4-/- und prädiabetischer NOD Kohorte (d.h. kein 
Effekt der a4-Kompetenz auf die Mikrobiota), während diabetische NOD Mäuse eine deutlich verminderte $\alpha$ - und $\beta$-Diversität bis hin zum vollständigen Verlust bestimmter Erreger aufweisen (Diabetes verändert Wirtsfaktoren im Darm und daraus sich ergebend die Mikrobiota). Hervorzuheben ist hierbei vor allem die Abnahme oder der vollständige Verlust von Ruminococci, Candidatus Saccharimonas und Prevotellaceae, sowie eine Zunahme von Bacteroides. Erwähnenswert ist hierbei insbesondere die Abnahme von Prevotellaceae in unserer Diabetes-Kohorte, die nach Vancomycin-Gabe durch Candon et al. mit einem Inzidenzanstieg einherging und für die eine kausale Rolle impliziert wurde. Unsere Daten können diese Kausalität sicher ausschließen, vielmehr verstehen wir die veränderte Microbiota als "Signatur" einer diabetischen Stoffwechsellage. Vergleiche unserer Microbiota mit der von diabetischen Mäusen aus anderer Ätiologie werden in Kürze begonnen.

Der hämatopoetische Phänotyp der a4-/- Maus wurde erstmals 2003 von Scott et al. beschrieben. ${ }^{53}$ Hierbei zeigte sich eine Akkumulation von Progenitorzellen in Peripherblut und Milz. Zudem zeichneten sich die auf dem C57BI/6 Hintergrund generierten a4-/- Mäuse durch ein eingeschränktes short-term Engraftment und Knochenmark Homing aus, während das Homing in die Milz unauffällig war. In einer Folgestudie zeigte sich zudem ein kompetitiver Nachteil der a4-/- gegenüber wildtypischen hämatopoetischen Stammzellen in Transplantationsexperimenten. ${ }^{54}$ Abschließend wurden diese Daten von den Autoren so interpretiert, dass das a4-Integrin wichtiger für Situationen des regenerativen Stresses sei als für das Aufrechterhalten der hämatopoetischen Hömoostase. In der untersuchten NOD.a4-/- Maus konnten im steady state keine signifikanten Unterschiede im Immunphänotyp festgestellt werden. Bei genauerer Betrachtung der T-Zell-Subtypen konnte jedoch eine verminderte Frequenz CD8+ Zellen in Peripherblut und Milz zu Gunsten der Frequenz von CD4+ Zellen in selbigen Kompartimenten festgestellt werden. Innerhalb der zytotoxischen und T-Helfer Zellen konnte eine sowohl im Peripherblut als auch der Milz bestehende Verminderung der naiven CD3+ Zellen zu Gunsten der Effektor-Zellen festgestellt werden.

Mit der Generierung erster funktionierender Peptid-MHC-Komplexe wurde es erstmals möglich, antigenspezifische T-Zellen durchflusszytometrisch zu bestimmen. 2011 gelang es Crawford et al., einen spezifischen Insulin-B 
Peptid-MHC-Komplex zu generieren und hiermit autoreaktive CD4+ Zellen in den Pankreata wildtypischer NOD Mäuse zu bestimmen. ${ }^{73}$ Während Crawford et al. diese spezifische Multimer-TCR-Bindung in $0.5 \%$ der CD4+ positiven Zellen beschrieben haben, zeigen unsere Daten nach Abzug der internen Negativkontrolle etwa 1.3\% Insulin B spezifische MHCll-Multimer+/CD4+ Zellen. Hierbei sei zu erwähnen, dass Crawford et al. CD4+ Zellen aus den Pankreata 8 Wochen alter NOD Weibchen untersucht hat, während unsere Peripherblutproben von bereits 20 Wochen alten NOD Weibchen stammen. Die beobachtete Größenordnung ist somit absolut plausibel. In dieser Arbeit gelang es jedoch nicht, einen signifikanten Unterschied hinsichtlich der autoreaktiven MHCII-Multimer+/CD4+ Zellen in unseren Kohorten darzustellen. Dies könnte sowohl am Mangel von Positivkontrollen als auch etablierter Protokolle liegen das Reagens wurde von der Diabetes-Core des NIH der USA zur Erprobung und Protokollentwicklung zur Verfügung gestellt. Während Crawford et al. das experimentelle MHCll Reagenz entwickelt und erstbeschrieben haben, ist das in dieser Arbeit genutzte $\mathrm{MHCl}$ Reagenz qualitätsgesichert und kommerziell erhältlich. Das gegen das Inselzellantigen IGRP gerichtete CD8+ Zellen detektierende $\mathrm{MHCl}$ Reagenz konnte sowohl in Peripherblut als auch in der Milz der NOD Kontrollkohorte konsistent eine Population in der Frequenz von 1-2\% der CD8+ Zellen detektieren. Trotz der beschriebenen Schwierigkeiten in der Detektion Insulin-B spezifischer CD4+ Zellen durch das MHCII Reagenz, konnten mit Hilfe der beiden Reagenzien autoreaktive CD4+ und CD8+ Zellen im Peripherblut detektiert werden. Für beide Zellspezies schien die Frequenz der inselzellspezifischen T-Zellen in den NOD.a4-/- Mäusen vermindert, im Falle der CD8+ Zellen sogar statistisch signifikant vermindert. Dies unterstützt den Befund der abgeschwächten Sensibilisierung von T-Zellen im a4-/- Asthma Modell, welches zuvor durch Banerjee et al. beschrieben wurde. ${ }^{56}$ Zur weiteren Sicherung dieser Befunde wäre es sinnvoll, weitere antigenspezifische T-Zellen in NOD-Kontrollkohorte und der generierten NOD.a4-/- Maus zu untersuchen. So könnte es sein, dass in unserem Modell einige, aber nicht alle inselzellspezifische T-Zellen aufgrund der a4-Inkompetenz entstehen können. ${ }^{77}$ Um funktionell nachzuweisen, ob eine Sensibilisierung der a4-/- Leukozyten gegenüber Inselzellantigene besteht, erfolgte ein in vitro Zytokin-Assay. Hierzu wurden Splenozyten von NOD.a4-/- und NOD Kontrollmäusen mit dem 
inselzellspezifischen IGRP-Peptid inkubiert und anschließend die intrazelluläre IFNy-Sekretion durchflusszytometrisch bestimmt. Die Wahl auf das IGRPPeptid fiel, nachdem wir beobachten konnten, wie dieses verlässlich von CD8+ Zellen erkannt wird (s. Abb. 20). Hierbei konnte sich jedoch kein signifikanter Unterschied bezüglich der intrazellulären IFNY-Sekretion nach Inkubation mit inselzellspezifischem Antigen (IGRP) zeigen. Die Schwächen dieser Methode sind einerseits die Untersuchung nur eines von vielen Inselzellantigenen und zweitens, dass es sich hierbei um die einzige Methode dieser Arbeit handelt, in der Splenozyten 16 Wochen alter männlicher Mäuse verwendet wurden. Die hormonell bedingt verminderte Diabetes-Inzidenz könnte sich auf die Sensibilisierung gegenüber inselzellspezifischen Antigenen auswirken und somit das Ergebnis beeinflussen. ${ }^{36}$ Außerdem gibt es für dieses Experiment keine sichere Positivkontrolle und es können keine Aussagen darüber getroffen werden, ob das Peptid prozessiert und präsentiert wurde. Diese Schwächen könnten durch Untersuchung verschiedener Inselzellantigene wie GAD65 oder ZnT8, als auch der Verwendung von prädiabetischen Weibchen im Alter von 12-20 Wochen minimiert werden. Zudem erscheint eine durch PMA- und Ionomycin-Inkubation hervorgerufene IFNY-Sekretion einer Frequenz von 5-6\% der CD4+ Zellen als im Vergleich zu anderen in vitro Studien vermindert. ${ }^{99}$ Dies kann am Modell der NOD Maus oder einer zu schwachen Dosis der Stimulanzien sprechen und sollte vor einer weiteren Untersuchung genauer hinterfragt werden. Zusammenfassend sprechen diese Daten für eine verminderte Sensibilisierung der NOD.a4-/- Maus gegenüber Inselzellantigenen. Es sind jedoch Untersuchungen mit primär weiblichen prädiabetischen Mäusen und weiteren inselzellspezifischen Antigenen notwendig, um den genauen Status der Sensibilisierung gegenüber sezernierten und zytosolischen Inselzellantigenen zu bestimmen. Zudem sollten weitere Untersuchungen geplant werden, um den T-Zell Phänotyp der NOD.a4-/- Maus mit dem einhergehenden erhöhten CD4/CD8 Verhältnis, als auch der auffälligen Verschiebung hin zu einem erhöhten Effektor/Naive T-Zell Phänotyp zu untersuchen. Hierbei wäre es interessant zu klären, ob und wenn ja, warum ein Ausbleiben von Leukozyteninfiltrationen und Entzündung als auch diabetischer Stoffwechsellage zu einem erhöhten Effektor/Naive T-Zell 
Phänotyp führt. Die bisherigen Daten des a4-/- Genotyps in anderen Mausmodellen haben diesen Befund nicht beschrieben.

Der Autoimmundiabetes der NOD Maus ist eine primär T-Zell vermittelte Erkrankung. 1994 konnten Christianson et al. zeigen, dass ein Transfer mit CD3+ Zellen oder aufgereinigten CD4+ Zellen aus den Milzen diabetischer NOD-Spender Diabetes in NOD.scid Mäusen auslösen kann. ${ }^{41}$ Das heißt, die etwaige humorale anti-Inselzellantigen-Reaktivität ist funktionell irrelevant oder zumindest redundant. Im Kontrast dazu führt ein Transfer aufgereinigter CD8+ Zellen in NOD.scid Empfängern nicht zur Erkrankung. Yagi et al. konnten 2 Jahre zuvor schon im Modell der athymischen nude NOD Maus zeigen, dass ein Transfer aufgereinigter CD8+ Zellen weder zur Hyperglykämie noch zur Insulitis führte, während ein Transfer aufgereinigter CD4+ Zellen eine milde Insulitis ohne einen IDDM auslöste. ${ }^{100}$ In beiden Studien wurden monoklonale Antikörper gegen CD4 oder CD8 verabreicht, um einen möglich selektiven Transfer sicherzustellen. Im Falle des sequenziellen Transfers von CD4+ und anschließend CD8+ Transfer führte diese Kombination zur Erkrankung aller Empfänger. Rohane et al. nutzten 1995 erstmals Inselzell-infiltrierende Leukozyten für einen adoptiven Transfer in NOD.scid Mäuse und lösten hiermit etwa nach 25 Tagen einen symptomatischen Diabetes mellitus aus. ${ }^{101}$ Bei KoTransfer von Splenozyten oder CD4+ Zellen aber nicht CD8+ Zellen, führte dies zu einem verspäteten Erkrankungszeitpunkt und weist somit die immunregulatorischen Einflüsse von CD4+ Zellen hin. Mittlerweile sind ein gutes Dutzend inselzellspezifische Antigene bekannt, die in der Lage sind, TZellen der NOD Maus gegenüber inselzellspezifischen Antigenen zu sensibilisieren. ${ }^{21}$ Zudem scheinen CD4+ Zellen meist mehrere und im Falle von GAD65 sogar 15 Epitope zu erkennen. ${ }^{78}$ Eine Gemeinsamkeit all dieser adoptiven Transferexperimente von Splenozyten und auch letztlich der im weiteren Verlauf diskutierten adoptiven Transferexperimente Pankreasinfiltrierender oder prospektiv isolierter Inselzellantigen-spezifischer T-Zellen ist, dass die Empfänger den NOD Mäusen bezüglich der Histokompatibilität isogen sind, die NOD.scid Empfänger auch die Mehrzahl der Diabetes Susceptibility Loci besitzen, sie aber keinerlei Lymphozyten besitzen, also einen schweren kombinierten Immundefekt haben. Die Konsequenzen hieraus sind komplex: Adoptiv transferierte T-Zellen können sich ohne Vorbehandlung der NOD.scid 
Empfänger dramatisch expandieren, da keine Kompetition mit endogenen TZellen besteht und endogene T-Zell-stimulierende sezernierte Faktoren infolge fehlenden Feedbacks spontan, d.h. schon ohne radiologische Lymphodepletion, aufreguliert sind. Auf supportive T-Zell Spezies angewiesene T-Zell Funktionen können in diesem Modell in Ermangelung von Empfänger-T-Zellen nicht ausgebildet werden. Überraschend ist, dass die sehr geringe zytotoxische Aktivität von CD4+ T-Zellen ausreichen soll, ohne Unterstützung von CD8+ TZellen mit rascher Kinetik das Pankreas der NOD.scid Mäuse zu zerstören. In der Tat waren spätere Untersuchungen mit rigoroseren Selektionstechnologien nur bedingt in der Lage, eine Diabetesentstehung allein durch Transfer hochreiner diabetogener CD4+ T-Zellen zu bestätigen (58\% Inzidenz nach CD4+ Splenozyten Transfer und anti-CD8 Therapie). Durch einen CD3+ Transfer nach subletaler Bestrahlung, wie in dieser Arbeit durchgeführt, bewirkt man eine Reduktion endogener a4-/- Leukozyten in der immunologischen Nische. Durch Transfer von T-Zellen diabetischer Spender (und somit gegen verschiedene Inselzellantigene gerichteter, polyklonaler T-Zellen) in eine zuvor durch Bestrahlung freigeräumte immunologische Nische wird die Proliferation der Spender T-Zellen angeregt. Die hier durchgeführten Untersuchungen sind in dieser Art in nicht-genetischen Modellen nicht vorstellbar: Wir können, da die NOD.a4-/- Mäuse ein nachweislich (wenn auch mit gewissen qualitativen und quantitativen Defiziten) funktionelles adaptives Immunsystem besitzen, durch Transfer isolierter T-Zell Spezies diabetischer Spender in NOD.a4-/- Empfänger eruieren, welche T-Zellen kritisch auf a4-Integrin angewiesen sind, um diabetogen zu wirken. Für CD3+ Zellen und CD4+ Zellen haben wir bereits gezeigt, dass NOD.a4-/- Mäuse nach Transfer der ersteren, wenn auch mit signifikant verlängerter Latenz im Vergleich zu NOD-Empfängern, alle einen Diabetes entwickeln, während NOD.a4-/- Empfänger von CD4+ T-Zellen weiter gegenüber T1D gefeit sind, obwohl diese Zellen nach Transfer in nichtdiabetische NOD Mäuse innerhalb kürzester Zeit zu letalem Diabetes führen. Im Gegenteil zu NOD.scid und athymischen NOD Maus besitzt die NOD.a4-/Maus ein funktionelles Immunsystem. Dies erklärt wahrscheinlich den verspäteten mittleren Erkrankungszeitpunkt an Tag 30 nach CD3+ Transfer während dies bei den NOD-Kontrollempfänger schon an Tag 18 eintritt. Im Vergleich zu den bisher genutzten Modellen stellt dies eine neue Möglichkeit 
dar, den Einfluss eines bis auf den a4-/- Phänotyp gleichen Immunmilieus auf die Potenz von diabetogenen CD4+ Zellen zu untersuchen. In Kontrast zu den aufgeführten Erstarbeiten bezüglich fraktionierter T-Zell Transfers in der NOD Maus zur Untersuchung der Beteiligung von verschiedenen T-Zell Subtypen zeigen unsere Ergebnisse, dass der alleinige Transfer diabetischer CD4+ Zellen in die NOD.a4-/- Maus nicht ausreichend ist, um Diabetes auszulösen. Dies könnte damit zu tun haben, dass das endogene Immunsystem der NOD.a4-/- Maus einen regulatorischen Effekt auf die transferierten CD4+ Zellen ausübt. Studien von von Herrath et al. unterstützen diese Hypothese durch ihre Beobachtungen bezüglich einer initialen regulatorischen Balance in der NOD Maus, welche erst im späteren Verlauf der Insulitis und Sialitis in einer Imbalance und letztendlich fulminanten Erkrankungsbeginn hineinmündet. ${ }^{12}$ In unseren NOD.a4-/- Mäusen dasselbe Experiment auch für CD8+ T-Zellen durchzuführen, ist trotz der negativen Ergebnisse in T-Zell-freien Empfängern von sehr großem Interesse, auch aus klinischer Warte. Es wurde nämlich klinische Evidenz vorgelegt, dass ein Transfer von antigenspezifischen (hier: CMV pp65-spezifischen) CD8+ T-Zellen in extrem lymphopene und ziemlich sicher selber für antigenspezifische T-Zellen negative Patienten mit maximaler Zuverlässigkeit zu einer antigenspezifischen Expansion und Kontrolle der Viruskrankheit führte. ${ }^{102}$ Analog wäre nicht auszuschließen, dass $\alpha 4-/-C D 4+$ in der Lage sein könnten, den CD8+ T-Zellen T-Zell-Hilfe zu leisten. Diese Experimente dauern derzeit an. In unserer Studie mangelt es derzeit noch an histologischen Auswertungen vor allem der gesunden NOD.a4-/- Empfänger, um zu beantworten, ob es nach Transfer diabetogener CD4+ Zellen zu einer subklinischen Insulitis kommt. Durch ihre a4-Expression können SpenderLymphozyten in unserem Modell auch noch Wochen nach dem Transfer erkannt und durchflusszytometrisch analysiert werden. An dieser Stelle wäre interessant zu erfahren, ob und inwiefern sich die Spender-Lymphozyten nach dem Transfer in vivo verändern und welchen Einfluss Spender- und EmpfängerLymphozyten aufeinander haben. Schließlich unterstreichen die in dieser Arbeit erfolgten T-Zell Transfers das diabetogene Potenzial von CD3+ Zellen aus diabetischen NOD Spendern und deuten auf immunregulatorische Funktionen des endogenen NOD.a4-/- Immunsystems hin. 
Nachdem die Ergebnisse aus dem CD3+ T-Zell Transfer einen deutlich verzögerten Erkrankungsbeginn in den Empfängerkohorten zeigten, sollte eine Methode etabliert werden, die es erlaubt, den verspäteten Erkrankungsbeginn bildmorphologisch zu untersuchen und darzustellen. Dies sollte durch Biolumineszenz Imaging in Kooperation mit Prof. Ullrich aus der Pädiatrie der Uniklinik Frankfurt verwirklicht werden. Nach Optimierung der Transfektion und Transduktion von primären T-Zellen der NOD Spender, erfolgte ein ex vivo Imaging von Pankreata, Speicheldrüsen und Milzen der Empfänger zur Darstellung der Spender-Lymphozyten in diesen Organen. Die ersten Ergebnisse unterstreichen den a4-/- Phänotyp in der Milz im Sinne einer erhöhten Radiance durch Homing-Vorteil von a4-kompetenten SpenderLymphozyten in der NOD.a4-/- Milz. Die ersten Daten zu den Pankreata und Speicheldrüsen zeigen einen prominenten Fokus in der Speicheldrüse eines wildtypischen Empfängers, entsprechend der aufgestellten Hypothese nach Beobachtung unserer CD3+ Transfers. Nebenbefundlich zeigte sich nach Transfer transduzierter diabetischer CD3+ T-Zellen eine transiente Hyperglykämie aller Empfänger mit Blutzucker-Werten von 150-250 mg/dl. Zu diesem Zeitpunkt fand die erste ex vivo BLI statt. In den kommenden Tagen stellte sich in beiden Kohorten wieder eine Normoglykämie ein, sodass die zweite Aufnahme bei zwei zu diesem Zeitpunkt normoglykämen Mäusen stattfand. Um auszuschließen, dass der Grund hierfür nicht in der in vitro Expansion und Transduktion der CD3+ Zellen liegt („exhausted T cells“), sollte vor einer BLI einer größeren Kohorte ein erneuter adoptiver Transfer von tranduzierten T-Zellen mehrerer diabetischer Spender durchgeführt werden, um das diabetogene Potenzial nach in vitro Behandlung sicherzustellen. Abschließend ist festzuhalten, dass es in dieser Arbeit gelungen ist, ein Protokoll zur Transfektion und Transduktion primärer NOD T-Zellen und anschließendem adoptivem T-Zell Transfer sowie Biolumineszenz-Imaging zu etablieren, um die Kinetik der Entstehung von Leukozyteninfiltraten zu untersuchen.

Scott et al. konnten 2003 anhand der C57BL/6.a4-/- Maus zeigen, dass diese nach cre-Rekombinase-induzierter Ablation eine etwa 10-fach erhöhte Anzahl an Progenitorzellen im Peripherblut aufweisen als wildtypische C57BL/6 Mäuse. ${ }^{53}$ Bönig et al. konnten 2008 vergleichbare Wirkungen bei mit 
Natalizumab behandelten MS-Patienten feststellen. ${ }^{87}$ Diese hatten bereits einen Tag nach erster Injektion des a4-Antikörpers eine etwa 6-fach über das Normale erhöhte Anzahl an Progenitorzellen im Blut. Eine erhöhte Anzahl an Progenitorzellen und/oder HSCs ist also eine typische Folge der a4-Blockade. Bei der initialen Untersuchung des humoralen Immunsystems der NOD.a4-/Maus zeigt sich ausschließlich im Knochenmark eine reduzierte Frequenz an BZell Vorläufer. Diese wurden anhand der verminderten Expression von B220 analog dem Protokoll von Montecino-Rodriguez identifiziert. ${ }^{84}$ Zur Bestimmung, welche der B-Zell Vorläufer genau reduziert vorliegen, erfolgte eine multiparametrische durchflusszytometrische Analyse der B-ZellReifungsstadien. Hierbei zeigte sich im Einklang mit den Vorbefunden eine verminderte Frequenz der unreifen, transitionalen aber auch des späten Reifestadiums der B-Zellen im Knochenmark im Sinne eines diskreten Retentionsdefekts. Im Peripherblut zeigte sich eine signifikante Erhöhung der Frequenz unreifer B-Zellen und in der Milz eine verminderte Frequenz der unreifen und transitionalen B-Zellen. Ähnlich wie durch Scott et al. beschrieben, zeigt die NOD.a4-/- Maus eine erhöhte Anzahl an Progenitorzellen im Peripherblut (Daten nicht gezeigt). Der Mangel des a4-Integrins auf der Oberfläche der B-Zellen führt also zu einer defizienten Retention im Knochenmark mit exzessiven Vorläuferzellzahlen im Peripherblut mit einhergehender Verschiebung der im Wildtyp beschriebenen Verteilung der Reifestufen. Eine verfrühte Migration von Vorläufer-B-Zellen könnte der Grund der verminderten Entwicklung in reife B-Zellen sein. Außerdem wäre denkbar, dass durch den a4-Mangel der Leukozyten durchaus auch a4-abhängige outside-in Signale fehlen, um eine geordnete und quantitativ normale B-ZellReifung zu gewährleisten. Zudem ist ein Cosignaling von a4 und CXCR4 beschrieben. ${ }^{103 ; 104}$ Eine a4-Blockade könnte hierbei das CXCR4 Signaling beeinflussen, welches vor allem für B-Zell-Vorstufen von essenzieller Bedeutung ist. ${ }^{83}$

Neben der durchflusszytometrischen Phänotypisierung erfolgte eine Immunisierungsstudie mit einem für Menschen zugelassenen Hepatitis B Impfstoff. Der Vorteil dieses Reagenz ist vielseitig: Es ist ein Peptid, das für eine gute Immunreaktionsinduktion optimiert und garantiert für den murinen Organismus fremd ist. Zudem gibt es ein hochspezifisches, sensitives und 
quantitatives Messgerät für diese Immunreaktion. In dieser Studie zeigte sich eine quantitativ vergleichbare primäre Immunisierung (s. Abb. 32) nach dreimaliger Behandlung. Jedoch zeigte sich nach 3 Monaten ein um das 20fache signifikant verminderter Impftiter in der NOD.a4-/- Maus und nach sekundärer Immunisierung ein deutlich weniger ausgeprägter Anstieg des Impftiters im Sinne einer Booster-Reaktion. Zusammenfassend zeigt sich eine vergleichbare primäre Immunisierung und ein sekundärer Immunisierungsdefekt. Banerjee et al., welche die bisher einzigen immunologischen Untersuchungen in der a4-/- Maus erhoben haben, konnten nach Transplantation von a4-/- Knochenmark in Rag2-/- Mäuse verminderte $\lg M$ und $\lg E$ Spiegel bei normalwertigem $\lg G$, sowie ein abgeschwächtes Homing in den Thymus und ins darmassoziierte Lymphgewebe feststellen. ${ }^{55 ; 56}$ Während die Autoren annahmen, dass a4 für die initiale humorale Immunantwort relevanter als für die Ausbildung einer langfristigen Immunisierung sei, sprechen unsere Daten eine andere Sprache. Durch die dreimalige Messung und einen Beobachtungszeitraum von über 3 Monaten sowie die genaue Messfähigkeit des ARCHITECT, können wir mit großer Sicherheit sagen, dass die a4-/- Maus einen quantitativen sekundären Immunisierungsdefekt aufweisen. Um schließlich zu untersuchen, ob die vor Diabetes geschützte NOD.a4-/- Maus vergleichbare Autoantikörper-Titer produziert, erfolgte die Messung von Insulin-Autoantikörpern im Plasma der beiden Kohorten. Der hier genutzte Sandwich-ELISA hat einen außerordentlich hohen Reaktivitätshintergrund. Um diesen herausrechnen zu können, wurden Plasmen von diabetesresistenten C57BI/6 Mäusen als Kontrollen mitgeführt. Der mittlere Messwert im Plasma dieser Mäuse wurde als Hintergrund subtrahiert. Hierbei zeigte sich für die NOD.a4-/- Kohorte ein im Vergleich zu NOD Mäusen signifikant verminderter IAA-Titer nahe der Nachweisgrenze. Die beobachtete Differenz in der NOD.a4-/- Kohorte lässt sich, was die absolute Stärke des Signals angeht, mit Daten aus der Literatur nicht bewerten, da in IAA-Studien stets Laborinterne Indices angegeben werden. ${ }^{21 ; 105}$ Somit deuten unsere Daten darauf hin, dass die NOD.a4-/- Maus Antikörper gegen Inselzellantigene, jedoch reduzierte IAA-Titer produziert. Ob dies teilweise auch durch den Phänotyp der in der Immunisierungsstudie beobachteten generellen 
quantitativen Immunisierungsdefekts begründet liegt, kann hier nicht ausgeschlossen werden.

Die kritische Rolle des a4-Integrins, insbesondere des a4-Integrins auf CD3+ TZellen, bei der Entstehung des T1D haben wir in unserem neuartigen Modell definitiv belegt. Bezüglich eines therapeutischen Ansatzes ist diese Information jedoch nicht unmittelbar nutzbar, da die Inzidenz des T1D zu niedrig ist, als dass eine generelle a4-Blockade bei allen Neugeborenen empfohlen werden könnte. Frühestens wäre so eine Therapie bei Identifikation hoch prädiktiver Risikoparameter zu erwägen; beim T1D könnte das beispielsweise eine Familienanamnese, ungünstige HLA-Konstellationen und Auftreten gewisser inselzellspezifischen Antikörper sein. ${ }^{20}$ Noch günstiger wäre es, wenn man den Therapiebeginn bis unmittelbar nach Erstmanifestation verschieben könnte. Um dieses Szenario in unserem Modell abzubilden, hatten wir neben der NOD.TekCrea4 auch noch eine NOD.TamCrea4 Maus generiert. Leider war nach Einkreuzen des TamCre über 10 Generationen auf den NOD Hintergrund TamCre nicht mehr aktivierbar. Als Alternativmodell, weniger elegant und wenig subtil, prüften wir den sekundär-prophylaktischen Effekt der isogenen Knochenmarktransplantation auf die Diabetes-Prävalenz der NOD Maus. Hierzu gibt es Studien, die den Einfluss einer antikörpervermittelten Blockade von a4 in der NOD Maus beschreiben (s. Kapitel 1.3.). Um dies in diesem Mausmodell definitiv zu untersuchen, wurden 8-12 Wochen alte NOD Mäuse letal bestrahlt und anschließend mit wildtypischem oder a4-/- Knochenmarkzellen transplantiert. Wildtypische Empfänger junger NOD-Knochenmärker nichtdiabetischer Spender erkrankten mit typischer Latenz und Frequenz, während Empfänger altersgematchten NOD.a4-/- Knochenmarks, der genetischen Prädisposition der wildtypischen Empfänger zum Trotz, lebenslang vor Diabetes geschützt waren. Während die oben erwähnten Therapien alle einen Einfluss auf die Diabetesinzidenzmit den verschiedenen Dosen und Behandlungsräume zeigten, können wir den dominanten Einfluss der a4-Blockade auf die DiabetesPrävalenz bestätigen und zeigen, dass eine vollständige Blockade zu einem sicheren Sistieren der Erkrankung führt. Diese Studie bekräftigt die Potenz der a4-Blockade als Sekundärprävention und unterstreicht die Wirkung einer antikörperbasierten Therapie im Menschen als mögliche Behandlung bei besonders schwierigen Verläufen. 


\section{Anhang}

\section{Literaturverzeichnis}

(1) Harjutsalo V, Sjoberg L, Tuomilehto J. Time trends in the incidence of type 1 diabetes in Finnish children: a cohort study. Lancet 2008;371:1777-1782.

(2) Moltchanova EV, Schreier N, Lammi N, Karvonen M. Seasonal variation of diagnosis of Type 1 diabetes mellitus in children worldwide. Diabet Med 2009;26:673-678.

(3) Kukko M, Kimpimaki T, Korhonen S et al. Dynamics of diabetes-associated autoantibodies in young children with human leukocyte antigen-conferred risk of type 1 diabetes recruited from the general population. J Clin Endocrinol Metab 2005;90:2712-2717.

(4) Dabelea D, Bell RA, D'Agostino RB, Jr. et al. Incidence of diabetes in youth in the United States. JAMA 2007;297:2716-2724.

(5) Karvonen M, Viik-Kajander M, Moltchanova E, Libman I, LaPorte R, Tuomilehto J. Incidence of childhood type 1 diabetes worldwide. Diabetes Mondiale (DiaMond) Project Group. Diabetes Care 2000;23:1516-1526.

(6) Vandewalle CL, Coeckelberghs MI, De Leeuw IH et al. Epidemiology, clinical aspects, and biology of IDDM patients under age 40 years. Comparison of data from Antwerp with complete ascertainment with data from Belgium with $40 \%$ ascertainment. The Belgian Diabetes Registry. Diabetes Care 1997;20:15561561.

(7) Patterson CC, Dahlquist GG, Gyurus E, Green A, Soltesz G. Incidence trends for childhood type 1 diabetes in Europe during 1989-2003 and predicted new cases 2005-20: a multicentre prospective registration study. Lancet 2009;373:2027-2033.

(8) Maahs DM, West NA, Lawrence JM, Mayer-Davis EJ. Epidemiology of type 1 diabetes. Endocrinol Metab Clin North Am 2010;39:481-497.

(9) Eisenbarth GS. Type I diabetes mellitus. A chronic autoimmune disease. N Engl J Med 1986;314:1360-1368.

(10) Meier JJ, Bhushan A, Butler AE, Rizza RA, Butler PC. Sustained beta cell apoptosis in patients with long-standing type 1 diabetes: indirect evidence for islet regeneration? Diabetologia 2005;48:2221-2228.

(11) Akirav E, Kushner JA, Herold KC. Beta-cell mass and type 1 diabetes: going, going, gone? Diabetes 2008;57:2883-2888.

(12) von HM, Sanda S, Herold K. Type 1 diabetes as a relapsing-remitting disease? Nat Rev Immunol 2007;7:988-994.

(13) Redondo MJ, Fain PR, Eisenbarth GS. Genetics of type 1A diabetes. Recent Prog Horm Res 2001;56:69-89. 
(14) Cooper JD, Smyth DJ, Smiles AM et al. Meta-analysis of genome-wide association study data identifies additional type 1 diabetes risk loci. Nat Genet 2008;40:1399-1401.

(15) Concannon P, Rich SS, Nepom GT. Genetics of type 1A diabetes. N Engl J Med 2009;360:1646-1654.

(16) Pociot F, Akolkar B, Concannon P et al. Genetics of type 1 diabetes: what's next? Diabetes 2010;59:1561-1571.

(17) Pescovitz MD, Greenbaum CJ, Krause-Steinrauf H et al. Rituximab, Blymphocyte depletion, and preservation of beta-cell function. N Engl J Med 2009;361:2143-2152.

(18) Bingley PJ. Clinical applications of diabetes antibody testing. J Clin Endocrinol Metab 2010;95:25-33.

(19) Knip M, Korhonen S, Kulmala P et al. Prediction of type 1 diabetes in the general population. Diabetes Care 2010;33:1206-1212.

(20) Winter WE, Schatz DA. Autoimmune markers in diabetes. Clin Chem 2011;57:168-175.

(21) Pietropaolo M, Towns R, Eisenbarth GS. Humoral autoimmunity in type 1 diabetes: prediction, significance, and detection of distinct disease subtypes. Cold Spring Harb Perspect Med 2012;2.

(22) Wilkin TJ. The accelerator hypothesis: weight gain as the missing link between Type I and Type II diabetes. Diabetologia 2001;44:914-922.

(23) Cooke A. Review series on helminths, immune modulation and the hygiene hypothesis: how might infection modulate the onset of type 1 diabetes? Immunology 2009;126:12-17.

(24) von Herrath MG, Fujinami RS, Whitton JL. Microorganisms and autoimmunity: making the barren field fertile? Nat Rev Microbiol 2003;1:151-157.

(25) Vaarala O, Atkinson MA, Neu J. The "perfect storm" for type 1 diabetes: the complex interplay between intestinal microbiota, gut permeability, and mucosal immunity. Diabetes 2008;57:2555-2562.

(26) Wasserfall C, Nead K, Mathews C, Atkinson MA. The threshold hypothesis: solving the equation of nurture vs nature in type 1 diabetes. Diabetologia 2011;54:2232-2236.

(27) Gale EA. Congenital rubella: citation virus or viral cause of type 1 diabetes? Diabetologia 2008;51:1559-1566.

(28) Jaidane H, Sauter P, Sane F, Goffard A, Gharbi J, Hober D. Enteroviruses and type 1 diabetes: towards a better understanding of the relationship. Rev Med Virol 2010;20:265-280.

(29) Gerstein HC. Cow's milk exposure and type I diabetes mellitus. A critical overview of the clinical literature. Diabetes Care 1994;17:13-19. 
(30) Adler K, Mueller DB, Achenbach P et al. Insulin autoantibodies with high affinity to the bovine milk protein alpha casein. Clin Exp Immunol 2011;164:42-49.

(31) Pozzilli P, Manfrini S, Crino A et al. Low levels of 25-hydroxyvitamin D3 and 1,25-dihydroxyvitamin D3 in patients with newly diagnosed type 1 diabetes. Horm Metab Res 2005;37:680-683.

(32) Bailey R, Cooper JD, Zeitels L et al. Association of the vitamin D metabolism gene CYP27B1 with type 1 diabetes. Diabetes 2007;56:2616-2621.

(33) Bogdanou D, Penna-Martinez M, Filmann N et al. T-lymphocyte and glycemic status after vitamin $D$ treatment in type 1 diabetes: A randomized controlled trial with sequential crossover. Diabetes Metab Res Rev 2017;33.

(34) Dahlquist GG, Patterson C, Soltesz G. Perinatal risk factors for childhood type 1 diabetes in Europe. The EURODIAB Substudy 2 Study Group. Diabetes Care 1999;22:1698-1702.

(35) Makino S, Kunimoto K, Muraoka Y, Mizushima Y, Katagiri K, Tochino Y. Breeding of a non-obese, diabetic strain of mice. Jikken Dobutsu 1980;29:1-13.

(36) Makino S, Kunimoto K, Muraoka Y, Katagiri K. Effect of castration on the appearance of diabetes in NOD mouse. Jikken Dobutsu 1981;30:137-140.

(37) Diana J, Simoni Y, Furio L et al. Crosstalk between neutrophils, B-1a cells and plasmacytoid dendritic cells initiates autoimmune diabetes. Nat Med 2013;19:65-73.

(38) Shoda LK, Young DL, Ramanujan S et al. A comprehensive review of interventions in the NOD mouse and implications for translation. Immunity 2005;23:115-126.

(39) Fujino-Kurihara H, Fujita H, Hakura A, Nonaka K, Tarui S. Morphological aspects on pancreatic islets of non-obese diabetic (NOD) mice. Virchows Arch B Cell Pathol Incl Mol Pathol 1985;49:107-120.

(40) Leiter EH. The NOD Mouse: A Model for Analyzing the Interplay Between Heredity and Environment in Development of Autoimmune Disease. 35[1], 4-14. 1-1-1993. ILAR Journal.

(41) Christianson SW, Shultz LD, Leiter EH. Adoptive transfer of diabetes into immunodeficient NOD-scid/scid mice. Relative contributions of CD4+ and CD8+ T-cells from diabetic versus prediabetic NOD.NON-Thy-1a donors. Diabetes 1993;42:44-55.

(42) Shultz LD, Schweitzer PA, Christianson SW, Schweitzer IB, Tennent B, McKenna $S$ et al. Multiple defects in innate and adaptive immunologic function in NOD/LtSz-scid mice. 154[1], 180-191. 1-1-1995.

(43) Park Y. Functional evaluation of the type 1 diabetes (T1D) susceptibility candidate genes. Diabetes Res Clin Pract 2007;77 Suppl 1:S110-S115.

(44) Krishnamurthy B, Dudek NL, McKenzie MD et al. Responses against islet antigens in NOD mice are prevented by tolerance to proinsulin but not IGRP. $J$ Clin Invest 2006;116:3258-3265. 
(45) Wen L, Ley RE, Volchkov PY et al. Innate immunity and intestinal microbiota in the development of Type 1 diabetes. Nature 2008;455:1109-1113.

(46) Christen U, Bender C, von Herrath MG. Infection as a cause of type 1 diabetes? Curr Opin Rheumatol 2012;24:417-423.

(47) Baker RL, Wagner DH, Jr., Haskins K. CD40 on NOD CD4 T cells contributes to their activation and pathogenicity. J Autoimmun 2008;31:385-392.

(48) Lee LF, Xu B, Michie SA et al. The role of TNF-alpha in the pathogenesis of type 1 diabetes in the nonobese diabetic mouse: analysis of dendritic cell maturation. Proc Natl Acad Sci U S A 2005;102:15995-16000.

(49) Lobb RR, Hemler ME. The pathophysiologic role of alpha 4 integrins in vivo. $J$ Clin Invest 1994;94:1722-1728.

(50) Shishido S, Bonig H, Kim YM. Role of integrin alpha4 in drug resistance of leukemia. Front Oncol 2014;4:99.

(51) Alon R, Kassner PD, Carr MW, Finger EB, Hemler ME, Springer TA. The integrin VLA-4 supports tethering and rolling in flow on VCAM-1. J Cell Biol 1995;128:1243-1253.

(52) Liu S, Kiosses WB, Rose DM et al. A fragment of paxillin binds the alpha 4 integrin cytoplasmic domain (tail) and selectively inhibits alpha 4-mediated cell migration. J Biol Chem 2002;277:20887-20894.

(53) Scott LM, Priestley GV, Papayannopoulou T. Deletion of alpha4 integrins from adult hematopoietic cells reveals roles in homeostasis, regeneration, and homing. Mol Cell Biol 2003;23:9349-9360.

(54) Priestley GV, Scott LM, Ulyanova T, Papayannopoulou T. Lack of alpha4 integrin expression in stem cells restricts competitive function and self-renewal activity. Blood 2006;107:2959-2967.

(55) Banerjee ER, Latchman YE, Jiang Y, Priestley GV, Papayannopoulou T. Distinct changes in adult lymphopoiesis in Rag2-/- mice fully reconstituted by alpha4-deficient adult bone marrow cells. Exp Hematol 2008;36:1004-1013.

(56) Banerjee ER, Jiang Y, Henderson WR, Jr., Scott LM, Papayannopoulou T. Alpha4 and beta2 integrins have nonredundant roles for asthma development, but for optimal allergen sensitization only alpha4 is critical. Exp Hematol 2007;35:605-617.

(57) Banerjee ER, Jiang Y, Henderson WR, Jr., Latchman Y, Papayannopoulou T. Absence of alpha 4 but not beta 2 integrins restrains development of chronic allergic asthma using mouse genetic models. Exp Hematol 2009;37:715-727.

(58) Polman $\mathrm{CH}$, O'Connor PW, Havrdova E et al. A randomized, placebo-controlled trial of natalizumab for relapsing multiple sclerosis. N Engl J Med 2006;354:899910.

(59) Sandborn WJ, Feagan BG, Rutgeerts $P$ et al. Vedolizumab as induction and maintenance therapy for Crohn's disease. N Engl J Med 2013;369:711-721. 
(60) Baron JL, Reich EP, Visintin I, Janeway CA, Jr. The pathogenesis of adoptive murine autoimmune diabetes requires an interaction between alpha 4-integrins and vascular cell adhesion molecule-1. J Clin Invest 1994;93:1700-1708.

(61) Yang XD, Michie SA, Tisch R, Karin N, Steinman L, McDevitt HO. A predominant role of integrin alpha 4 in the spontaneous development of autoimmune diabetes in nonobese diabetic mice. Proc Natl Acad Sci U S A 1994;91:12604-12608.

(62) Yang XD, Michie SA, Tisch R, Karin N, Steinman L, McDevitt HO. Cell adhesion molecules: a selective therapeutic target for alleviation of IDDM. J Autoimmun 1994;7:859-864.

(63) Kommajosyula S, Reddy S, Nitschke K, Kanwar JR, Karanam M, Krissansen GW. Leukocytes infiltrating the pancreatic islets of nonobese diabetic mice are transformed into inactive exiles by combinational anti-cell adhesion therapy . 70[4], 510-517. 1-10-2001. Journal of Leukocyte Biology.

(64) Uniyal S, Boeters L, Chakrabarti S, Singh B, Chan BM. Leukocytes utilize both alpha4 and alpha5 integrins for intraislet infiltration in non-obese diabetic mice. J Autoimmun 1999;12:167-176.

(65) Wagner J, Pfannenstiel V, Waldmann A et al. A Two-Phase Expansion Protocol Combining Interleukin (IL)-15 and IL-21 Improves Natural Killer Cell Proliferation and Cytotoxicity against Rhabdomyosarcoma. Front Immunol 2017;8:676.

(66) Trembleau S, Penna G, Gregori S, Gately MK, Adorini L. Deviation of pancreasinfiltrating cells to Th2 by interleukin-12 antagonist administration inhibits autoimmune diabetes. Eur J Immunol 1997;27:2330-2339.

(67) Li DS, Yuan YH, Tu HJ, Liang QL, Dai LJ. A protocol for islet isolation from mouse pancreas. Nat Protoc 2009;4:1649-1652.

(68) Knip M, Siljander $\mathrm{H}$. The role of the intestinal microbiota in type 1 diabetes mellitus. Nat Rev Endocrinol 2016;12:154-167.

(69) Giongo A, Gano KA, Crabb DB et al. Toward defining the autoimmune microbiome for type 1 diabetes. ISME J 2011;5:82-91.

(70) Callahan BJ, McMurdie PJ, Rosen MJ, Han AW, Johnson AJ, Holmes SP. DADA2: High-resolution sample inference from Illumina amplicon data. Nat Methods 2016;13:581-583.

(71) Price MN, Dehal PS, Arkin AP. FastTree 2--approximately maximum-likelihood trees for large alignments. PLoS One 2010;5:e9490.

(72) Lozupone C, Lladser ME, Knights D, Stombaugh J, Knight R. UniFrac: an effective distance metric for microbial community comparison. ISME J 2011;5:169-172.

(73) Crawford F, Stadinski B, Jin N et al. Specificity and detection of insulin-reactive CD4+ T cells in type 1 diabetes in the nonobese diabetic (NOD) mouse. Proc Natl Acad Sci U S A 2011;108:16729-16734. 
(74) Jasinski JM, Eisenbarth GS. Insulin as a primary autoantigen for type $1 \mathrm{~A}$ diabetes. Clin Dev Immunol 2005;12:181-186.

(75) Abel T, El FE, Waern J et al. Specific gene delivery to liver sinusoidal and artery endothelial cells. Blood 2013;122:2030-2038.

(76) de Goffau MC, Luopajarvi K, Knip M et al. Fecal microbiota composition differs between children with beta-cell autoimmunity and those without. Diabetes 2013;62:1238-1244.

(77) Nakayama M, Abiru N, Moriyama $\mathrm{H}$ et al. Prime role for an insulin epitope in the development of type 1 diabetes in NOD mice. Nature 2005;435:220-223.

(78) Yang J, James EA, Sanda S, Greenbaum C, Kwok WW. CD4+ T cells recognize diverse epitopes within GAD65: implications for repertoire development and diabetes monitoring. Immunology 2013;138:269-279.

(79) Barclay AN, Brown MH. Heterogeneity of interactions mediated by membrane glycoproteins of lymphocytes. Biochem Soc Trans 1997;25:224-228.

(80) Janeway CA, Jr. The T cell receptor as a multicomponent signalling machine: CD4/CD8 coreceptors and CD45 in T cell activation. Annu Rev Immunol 1992;10:645-674.

(81) Massilamany C, Krishnan B, Reddy J. Major Histocompatibility Complex Class II Dextramers: New Tools for the Detection of antigen-Specific, CD4 T Cells in Basic and Clinical Research. Scand J Immunol 2015;82:399-408.

(82) Crawford TQ, Jalbert E, Ndhlovu LC, Barbour JD. Concomitant evaluation of PMA+ionomycin-induced kinase phosphorylation and cytokine production in $\mathrm{T}$ cell subsets by flow cytometry. Cytometry A 2014;85:268-276.

(83) Mandal M, Okoreeh MK, Kennedy DE et al. CXCR4 signaling directs Igk recombination and the molecular mechanisms of late B lymphopoiesis. Nat Immunol 2019;20:1393-1403.

(84) Montecino-Rodriguez E, Leathers H, Dorshkind K. Identification of a B-1 B cellspecified progenitor. Nat Immunol 2006;7:293-301.

(85) Allman D, Lindsley RC, DeMuth W, Rudd K, Shinton SA, Hardy RR. Resolution of three nonproliferative immature splenic $B$ cell subsets reveals multiple selection points during peripheral B cell maturation. J Immunol 2001;167:68346840.

(86) Hardy RR, Carmack CE, Shinton SA, Kemp JD, Hayakawa K. Resolution and characterization of pro-B and pre-pro-B cell stages in normal mouse bone marrow. J Exp Med 1991;173:1213-1225.

(87) Bonig $\mathrm{H}$, Wundes A, Chang KH, Lucas S, Papayannopoulou T. Increased numbers of circulating hematopoietic stem/progenitor cells are chronically maintained in patients treated with the CD49d blocking antibody natalizumab. Blood 2008;111:3439-3441.

(88) Bonifacio E, Atkinson M, Eisenbarth G et al. International Workshop on Lessons From Animal Models for Human Type 1 Diabetes: identification of insulin but not 
glutamic acid decarboxylase or IA-2 as specific autoantigens of humoral autoimmunity in nonobese diabetic mice. Diabetes 2001;50:2451-2458.

(89) Magnuson AM, Thurber GM, Kohler RH, Weissleder R, Mathis D, Benoist C. Population dynamics of islet-infiltrating cells in autoimmune diabetes. Proc Natl Acad Sci U S A 2015;112:1511-1516.

(90) Miyagawa J, Hanafusa T, Miyazaki A et al. Ultrastructural and immunocytochemical aspects of lymphocytic submandibulitis in the non-obese diabetic (NOD) mouse. Virchows Arch B Cell Pathol Incl Mol Pathol 1986;51:215-225.

(91) Brando C, Marcinkiewicz C, Goldman B, McLane MA, Niewiarowski S. EC3, a heterodimeric disintegrin from Echis carinatus, inhibits human and murine alpha4 integrin and attenuates lymphocyte infiltration of Langerhans islets in pancreas and salivary glands in nonobese diabetic mice. Biochem Biophys Res Commun 2000;267:413-417.

(92) Silveira PA, Baxter AG. The NOD mouse as a model of SLE. Autoimmunity 2001;34:53-64.

(93) Skarstein K, Wahren M, Zaura E, Hattori M, Jonsson R. Characterization of T cell receptor repertoire and anti-Ro/SSA autoantibodies in relation to sialadenitis of NOD mice. Autoimmunity 1995;22:9-16.

(94) Zheng P, Li Z, Zhou Z. Gut microbiome in type 1 diabetes: A comprehensive review. Diabetes Metab Res Rev 2018;34:e3043.

(95) Brown K, DeCoffe D, Molcan E, Gibson DL. Diet-induced dysbiosis of the intestinal microbiota and the effects on immunity and disease. Nutrients 2012;4:1095-1119.

(96) Candon S, Perez-Arroyo A, Marquet $C$ et al. Antibiotics in early life alter the gut microbiome and increase disease incidence in a spontaneous mouse model of autoimmune insulin-dependent diabetes. PLoS One 2015;10:e0125448.

(97) Tormo-Badia N, Hakansson A, Vasudevan K, Molin G, Ahrne S, Cilio CM. Antibiotic treatment of pregnant non-obese diabetic mice leads to altered gut microbiota and intestinal immunological changes in the offspring. Scand $J$ Immunol 2014;80:250-260.

(98) Hu Y, Peng J, Tai N et al. Maternal Antibiotic Treatment Protects Offspring from Diabetes Development in Nonobese Diabetic Mice by Generation of Tolerogenic APCs. J Immunol 2015;195:4176-4184.

(99) Jung T, Schauer U, Heusser C, Neumann C, Rieger C. Detection of intracellular cytokines by flow cytometry. J Immunol Methods 1993;159:197-207.

(100) Yagi H, Matsumoto M, Kunimoto K, Kawaguchi J, Makino S, Harada M. Analysis of the roles of CD4+ and CD8+ T cells in autoimmune diabetes of NOD mice using transfer to NOD athymic nude mice. Eur $\mathrm{J}$ Immunol 1992;22:2387-2393.

(101) Rohane PW, Shimada A, Kim DT et al. Islet-infiltrating lymphocytes from prediabetic NOD mice rapidly transfer diabetes to NOD-scid/scid mice. Diabetes 1995;44:550-554. 
(102) Pfirrmann V, Oelsner S, Rettinger E et al. Cytomegalovirus-specific cytokineinduced killer cells: concurrent targeting of leukemia and cytomegalovirus. Cytotherapy 2015;17:1139-1151.

(103) Bonig H, Watts KL, Chang KH, Kiem HP, Papayannopoulou T. Concurrent blockade of alpha4-integrin and CXCR4 in hematopoietic stem/progenitor cell mobilization. Stem Cells 2009;27:836-837.

(104) Hartmann TN, Burger JA, Glodek A, Fujii N, Burger M. CXCR4 chemokine receptor and integrin signaling co-operate in mediating adhesion and chemoresistance in small cell lung cancer (SCLC) cells. Oncogene 2005;24:4462-4471.

(105) Robles DT, Eisenbarth GS, Dailey NJ, Peterson LB, Wicker LS. Insulin autoantibodies are associated with islet inflammation but not always related to diabetes progression in NOD congenic mice. Diabetes 2003;52:882-886. 


\section{Danksagung}

Herrn Prof. Dr. Halvard Bönig möchte ich zu aller erst dafür danken mich so eng und freundschaftlich die letzten vier Jahre beraten und betreut zu haben. Dankbar bin ich zudem für die Bereitstellung dieser interessanten Fragestellung und der wissenschaftlichen Möglichkeiten in seinem Labor am Institut für Transfusionsmedizin und Immunhämatologie der Goethe Universität. Danke, dass ich jederzeit in dein Büro kommen konnte, du immer ein offenes Ohr für mich hattest und mich auch außerhalb der wissenschaftlichen Arbeit unterstützt hast.

Ein besonderer Dank gilt der ganzen Arbeitsgruppe Bönig für die freundliche und angenehme Atmosphäre und die Integration als fester Bestandteil dieser. Unvergessen bleibt die entgegengebrachte Unterstützung in die Einarbeitung neuer Methoden und den fruchtbaren wissenschaftlichen Austausch, vor allem durch Dr. Eliza Wiercinska, Dr. Benjamin Tast, Elisabeth Ehrend, Dr. Peter Milanov, Dr. Soo-Zin Kim-Wanner und Sabine Harenkamp.

Für die Durchsicht dieser Arbeit danke ich Dr. Benjamin Tast und Elisabeth Ehrend.

Außerdem danke ich Prof. Dr. Evelyn Ullrich und Ihrer Arbeitsgruppe für die freundliche Unterstützung in der Umsetzung des Biolumineszenz Imagings sowie Trina A. Knotts, Ph.D., vom Mouse Metabolic Phenotyping Center der UC Davis für die angenehme und lehrreiche Kooperation im Rahmen unserer Mikrobiota-Studie.

Ganz besonders danke ich natürlich meiner Familie für die kontinuierliche Unterstützung, das Verständnis und die Möglichkeiten, die sie mir eröffneten, sowie meinen Freunden die mich jederzeit unterstützten.

Für die finanzielle Unterstützung danke ich dem Avicenna Studienwerk e.V. und dem BMBF. 


\section{Schriftliche Erklärung}

Ich erkläre ehrenwörtlich, dass ich die dem Fachbereich Medizin der Johann Wolfgang Goethe-Universität Frankfurt am Main zur Promotionsprüfung eingereichte Dissertation mit dem Titel

„Die Rolle des a4-Integrins in der Pathophysiologie des Autoimmundiabetes am Modell der spontan diabetischen NOD Maus“

am Institut für Transfusionsmedizin und Immunhämatologie DRK-

Blutspendedienst Baden-Württemberg-Hessen (Direktor: Prof. Dr. Erhard Seifried) unter Betreuung und Anleitung von Prof. Dr. Halvard Bönig mit Unterstützung durch Eliza Wiercinska ohne sonstige Hilfe selbst durchgeführt und bei der Abfassung der Arbeit keine anderen als die in der Dissertation angeführten Hilfsmittel benutzt habe. Darüber hinaus versichere ich, nicht die Hilfe einer kommerziellen Promotionsvermittlung in Anspruch genommen zu haben.

Ich habe bisher an keiner in- oder ausländischen Universität ein Gesuch um Zulassung zur Promotion eingereicht. Die vorliegende Arbeit wurde bisher nicht als Dissertation eingereicht.

Vorliegende Ergebnisse der Arbeit wurden in folgendem Publikationsorgan veröffentlicht:

Salim Oulghazi, Sarah K. Wegner, Gabriele Spohn, Nina Müller, Sabine Harenkamp, Albrecht Stenzinger, Thalia Papayannopoulou, Halvard Bonig (2020) Adaptive immunity and pathogenesis of diabetes: Insights provided by the a4-integrin deficient NOD mouse, Cells (in press)

\section{$\underline{1,2,4, *}$}

(Ort, Datum)

(Unterschrift) 